\title{
Opening new pathways for development: An exploration into community economies
}

By

\section{Renee Rushton}

2011

A thesis submitted to Victoria University of Wellington in partial fulfilment of requirements for the degree of Master of Development Studies

School of Geography, Environment and Earth Sciences Victoria University of Wellington

Supervisor: Andrew McGregor 



\section{Abstract}

This research explores community economies as a way of practicing development differently. The community economy framework has arisen out of post-development critiques which highlight how some development practices have discursively and practically created linear understandings of economic development. In contrast, the community economy framework involves highlighting the many economic practices and community assets that currently sustain people and suggests that multiple possible pathways to improved wellbeing can be imagined from these local beginnings. The approach seeks to prioritise neither local nor foreign practices, but encourages critical public discussion around which activities could be built on to improve community wellbeing. This research draws on my experiences engaging with the communities of San Miguel and Yachakay in Bolivia between March and June 2010, and contributes to the dialogue on the community economy approach as a way to practice development.

I have explored how this process of negotiating research in the field affects research outcomes. Throughout the process of exploring community economies I faced a number of challenges in negotiating the research in the field. This thesis is grounded in feminist and indigenous methodological approaches that recommend the researcher seek ways to transfer power and benefits to the researched in locally relevant ways. Yet very few works address the process of negotiation required to achieve this. My experience shows that by uncovering this often glossed over process, insights can be gained into the complex ways the researched assert power in research contexts, and thus assert power over research outcomes.

This research explores the viability of researching community economies within a Masters framework. My approach in San Miguel involved collecting data though semi-structured interviews, informal conversations and a reflective research journal. However my research in San Miguel was cut short. In the new location, Yachakay, I added a Participatory Action Research approach to my methodological tool kit. Other attempts to build community economies have involved significant budgets, experience and community engagement periods. While my approaches to building community economies in Bolivia were restricted by the relatively short Masters thesis timeframe, limited funding and my novice researcher status, the experience was not completely fruitless. I believe that benefits were gained both by researched and researcher through this exploration of community economies. 


\section{Acknowledgments}

Undertaking this thesis has been an incredible journey for me. I have battled through many emotional highs and lows through this difficult process. I'd like to take this opportunity to offer a massive thank you to everyone who has helped me stick at it. I would have given up long ago without your encouragement, support and a solid reality check every now and then.

I am thankful to everyone in Bolivia who has made this research possible. I am immensely grateful to my friends and co-researchers, Delia and Alberto from whom I learnt the joy of being friends with the people you do research with. I am thankful to the community members of San Miguel and Yachakay who humoured me by allowing me to carry out this research with them.

To my supervisor, Andrew McGregor, whose critical feedback, encouragement and emotional support has been fundamental in guiding me through this process.

To Victoria University of Wellington, New Zealand Agency for International Development and my Dad for the financial support that has allowed me carry out this research.

To the amazing crew on campus who have kept me stimulated, frequently in exuberant discussions about theory (yes theory!) over one too many glasses of wine. A huge thank you to Morgan, Marianne, Karly, Laura B, Laura S, Annemarie and Marcela who have taken on tutorial work for me. I aim to make it up to you!

Special thanks to friends and family who have helped me with proofing and editing: Marianne, Hannah, Kiri, Laura B, Monica, Mum, Nathan and Vanessa.

Thank you to all the friends and family who have supported me in non-academic ways. The Constable, Wilson and Owen Street flats, you've been fantastic! Thank you for the many shared meals, copious amounts of coffee, emergency yoga sessions and general reminders that life exists beyond the University. 


\section{Table of contents}

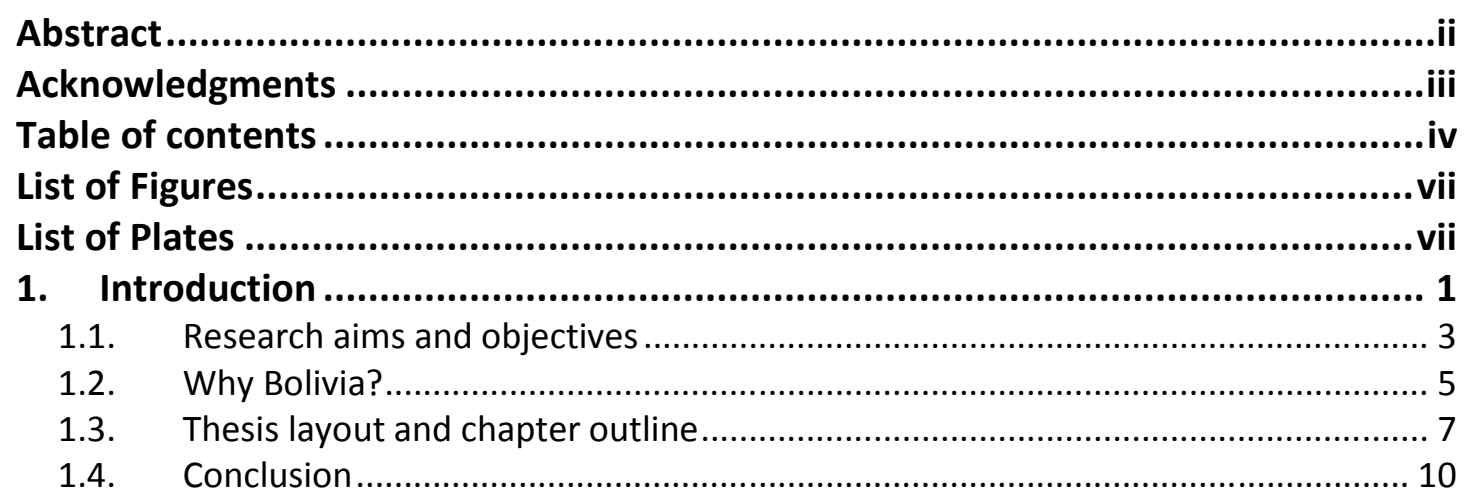

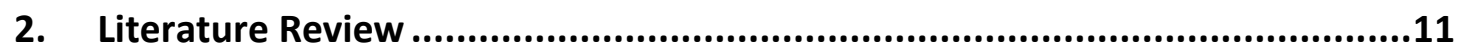

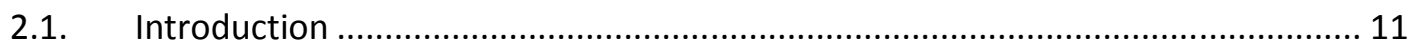

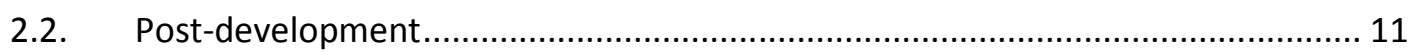

2.2.1. Post-structuralism and discourse analysis ............................................... 12

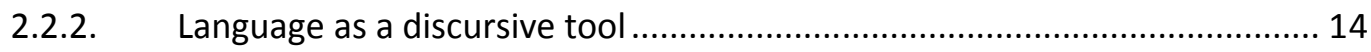

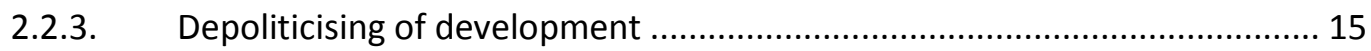

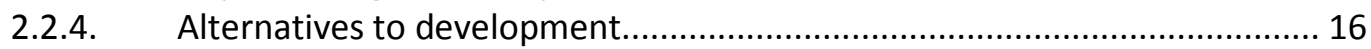

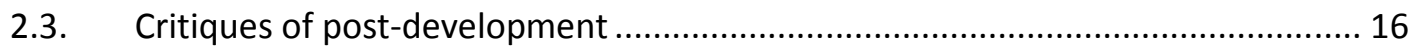

2.3.1. Development $=$ homogenous behemoth? .................................................. 16

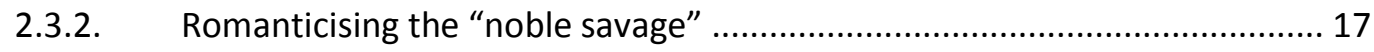

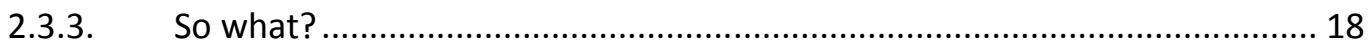

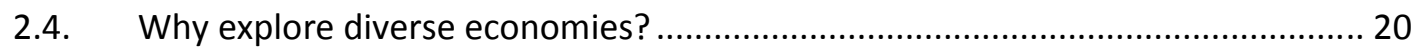

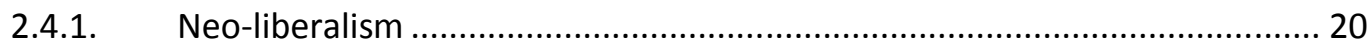

2.4.2. Critiques of neo-liberalism and macro economics...................................... 21

2.4.3. The hegemonic discourse of neo-liberal economics...................................... 23

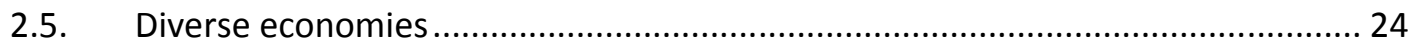

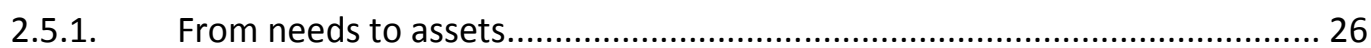

2.5.2. From diverse economies and local assets to community economies........... 27

2.5.3. Critiques of the community economy approach........................................ 28

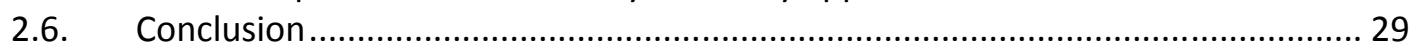

3. Theory, ontology and epistemology: My lenses.......................................31

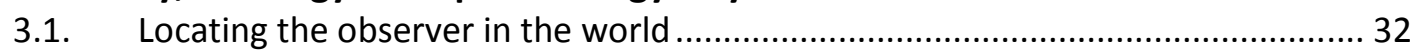

3.2. Research phase one: Whose research is it anyway? .......................................... 33

3.3. Phase two: A reflection on personal safety prompts a location change ................. 37

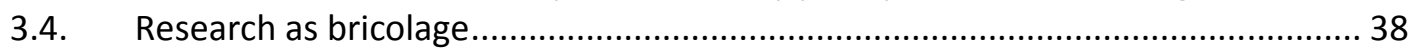

4. Methodology 1: San Miguel ....................................................................40

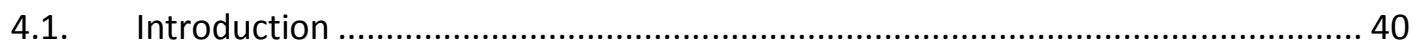

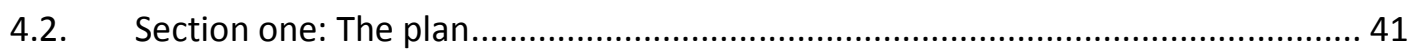

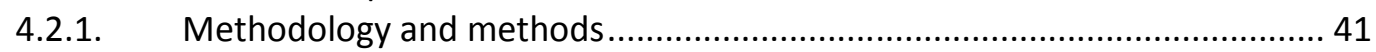

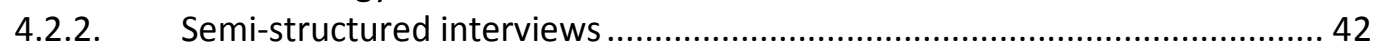

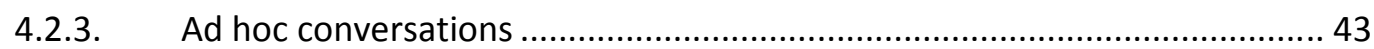

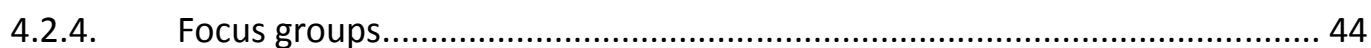

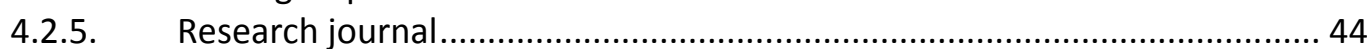

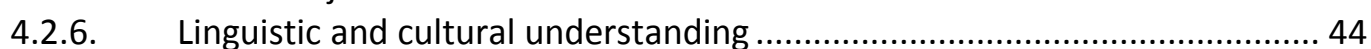

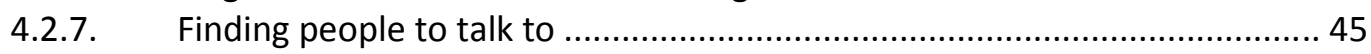

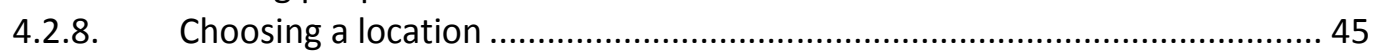

4.3. Section two: re-negotiated methodology ........................................................ 46 
4.3.1. Making contacts and finding a community to work with.............................. 46

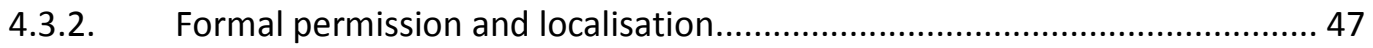

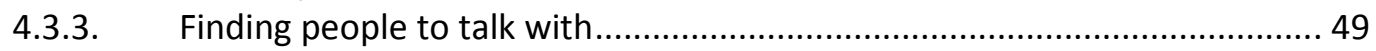

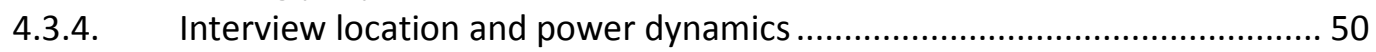

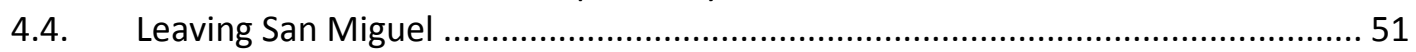

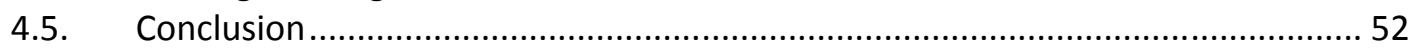

5. Methodology 2: Yachakay..............................................................55

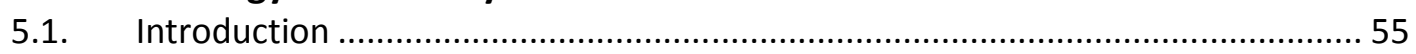

5.2. Section one: The new plan ......................................................................... 55

5.2.1. New Methodology: Participatory Action Research from a post-structuralist

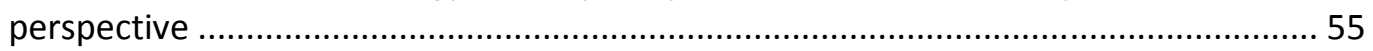

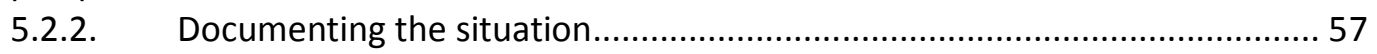

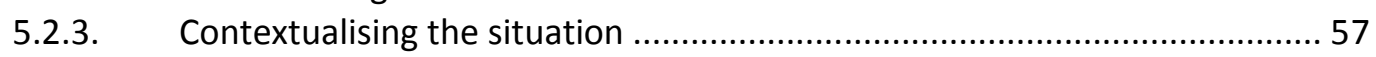

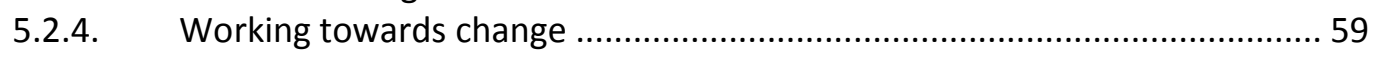

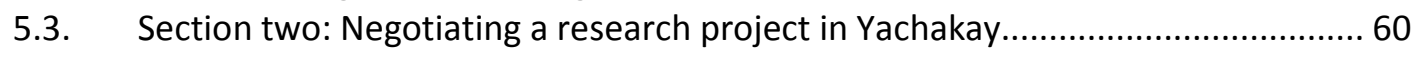

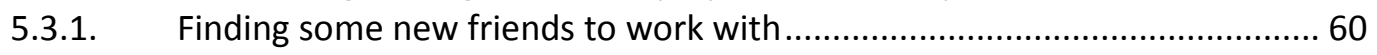

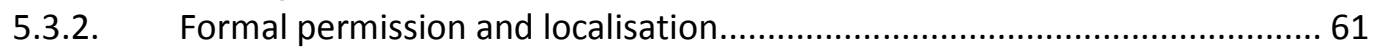

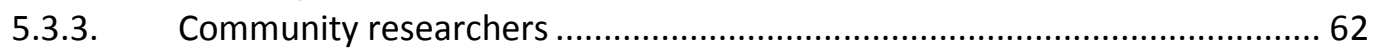

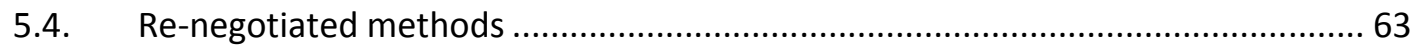

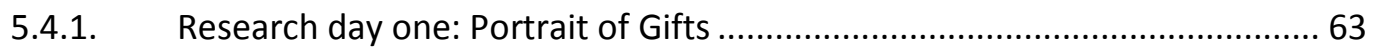

5.4.2. Research day two: Community mapping and brainstorming....................... 65

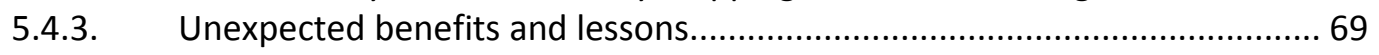

5.4.4. Research days three and four: Semi-structured interviews........................... 70

5.5. How do research contexts shape the production of research and why should we

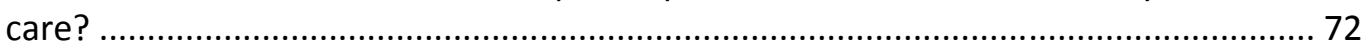

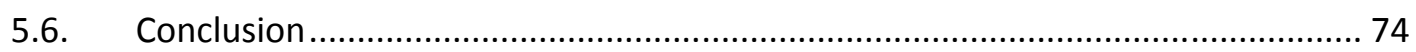

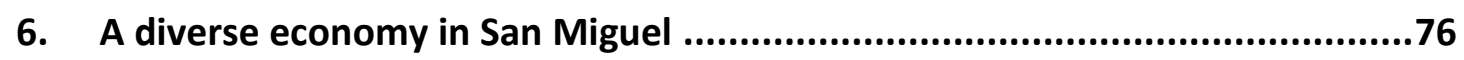

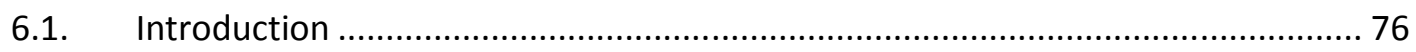

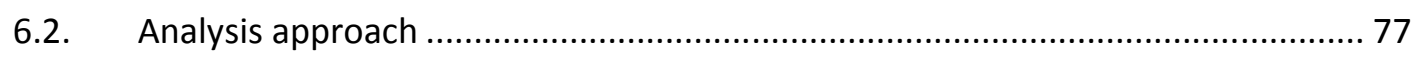

6.2.1. Three practices: Transactions, labour and enterprise.................................. 78

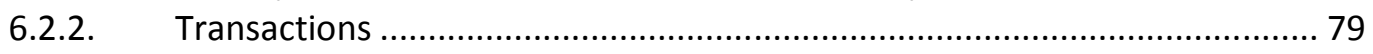

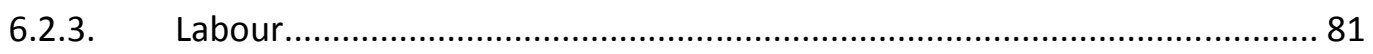

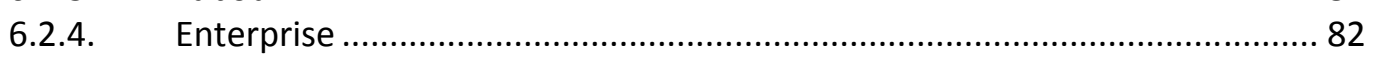

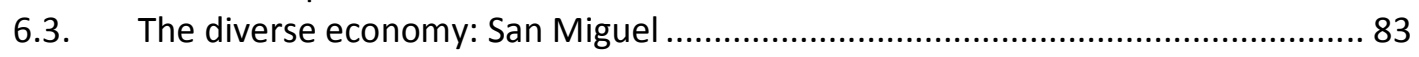

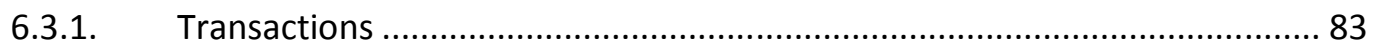

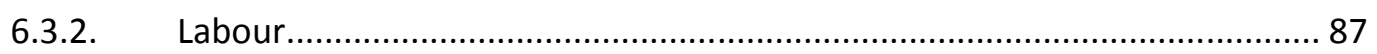

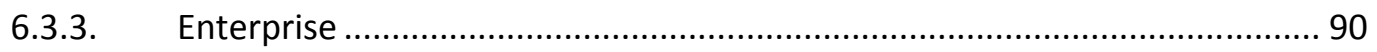

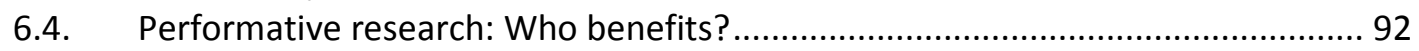

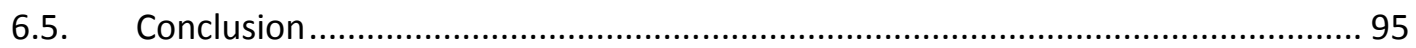

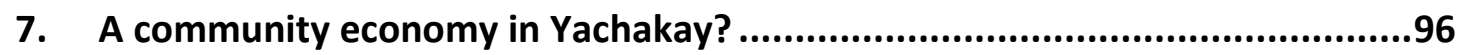

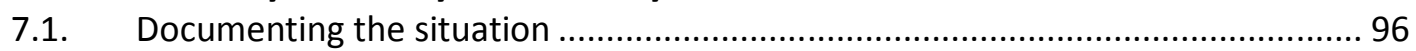

7.1.1. Delia and Alberto: Some stories about life in Yachakay and Bolivia............. 97

7.1.2. Intertwining my researcher's narrative................................................. 100

7.1.3. Connecting with other Yachakay community members ............................ 101

7.2. Contextualising the situation: Assets and economies ..................................... 102

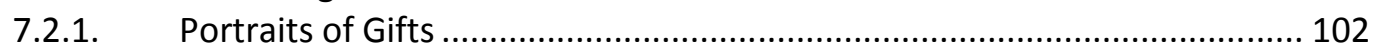

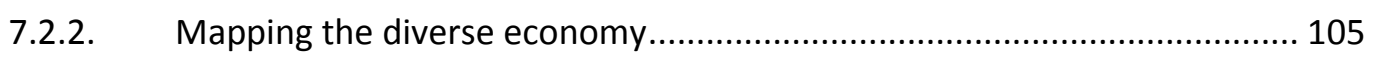

7.3. Working towards change: Sharing dreams and priorities................................. 107

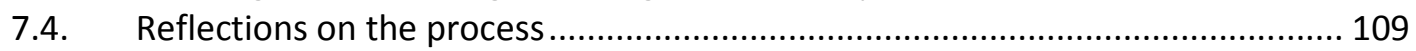

7.4.1. Community economies: An alternative way to practice development?..... 109

7.4.2. Community economies: A Masters level pursuit? ..................................... 111 


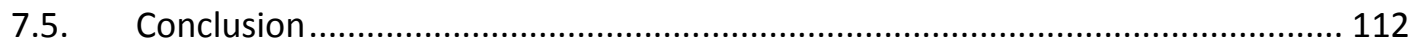

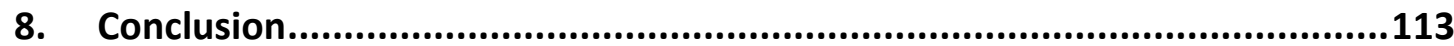

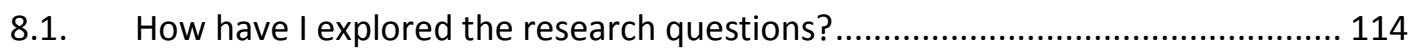

8.2. How has this research responded to the research questions?........................... 116

8.2.1. Research question one: What can be learnt about the community economy approach through exploring community economies with two indigenous communities in Bolivia? ......................................................................... 116

8.2.2. Research question two: How do research contexts shape the production of

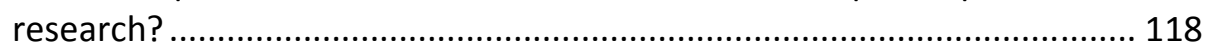

8.2.3. Research question three: What are the limitations and potentials of applying a community economy approach within a Master of Development

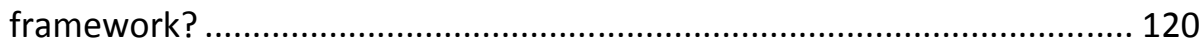

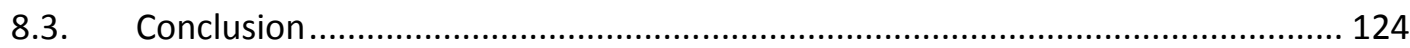

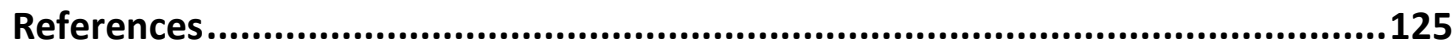

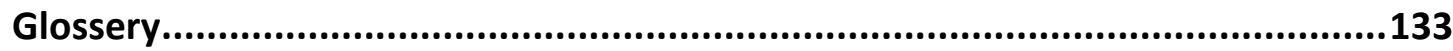

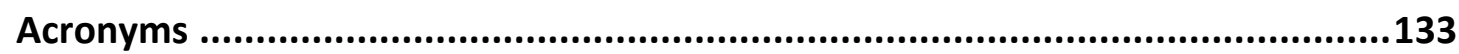

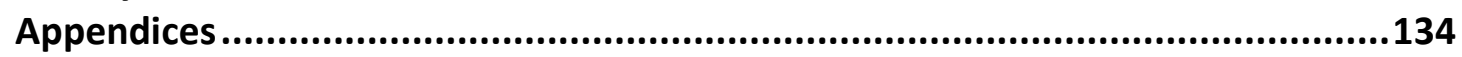

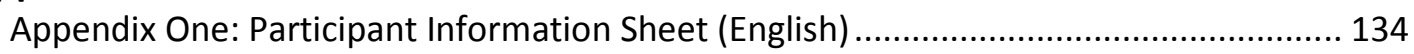

Appendix Two: Participant Information Sheet (Spanish) ................................................ 135

Appendix Three: Consent form (English) ................................................................... 136

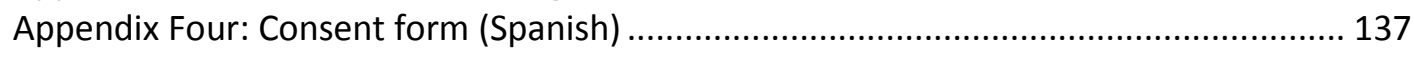

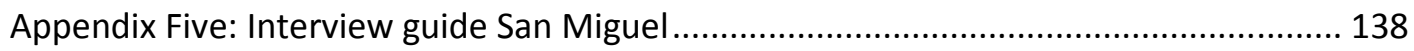

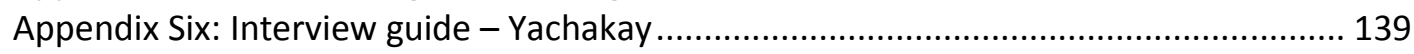

Appendix Seven: Portrait of gifts questionnaire (Spanish) .......................................... 140

Appendix Eight: List of community members involved in the research ........................... 145

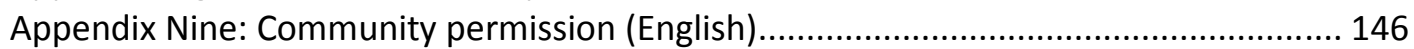

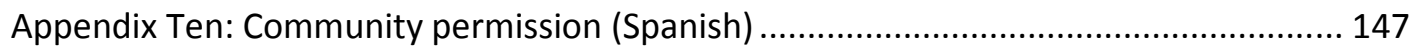




\section{List of Figures}

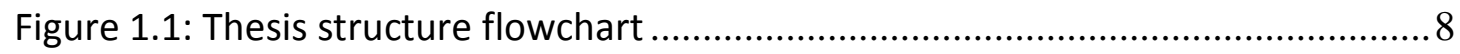

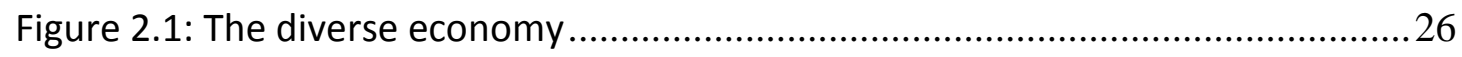

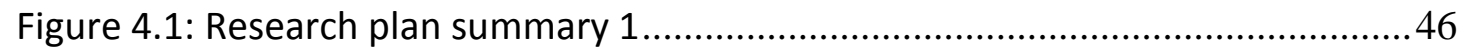

Figure 5.1: Research plan summary Yachakay..................................................... 71

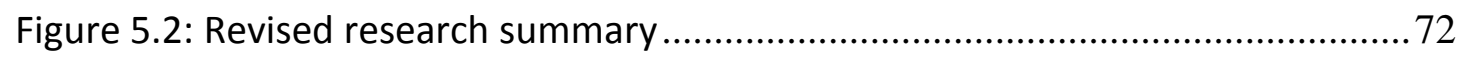

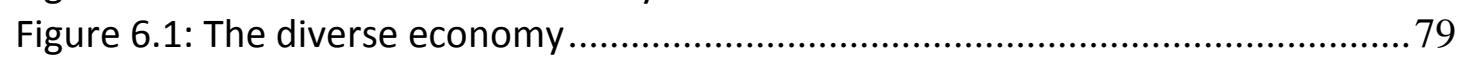

Figure 6.2: The diverse economy in San Miguel ...................................................... 84

Figure 7.1: Skills and abilities of community members in Yachakay ........................103

Figure 7.2: Some passions, dreams and aspirations of community members in

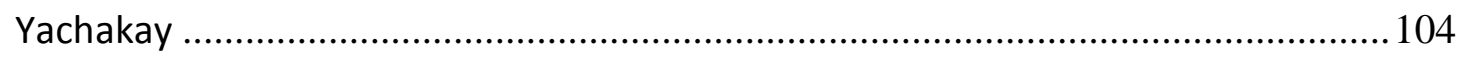

Figure 7.3: Community priorities for a community project................................... 108

\section{List of Plates}

Plate 5.1: Alberto, Delia and Alaín .....................................................................61

Plate 5.2: Yachakay community members and I with the map.................................66

Plate 5.3: Transferring the map to paper. .................................................................66

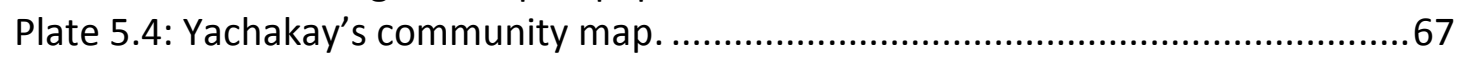

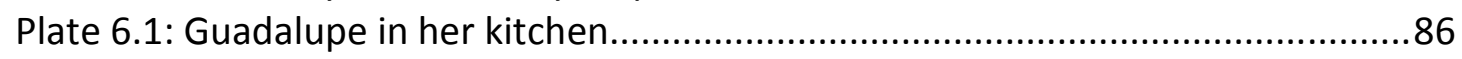

Plate 6.2: Luisa baking bread for a neighbour in exchange for a jornal. ....................89

Plate 6.3: Maize drying outside Guadalupe's home..............................................90

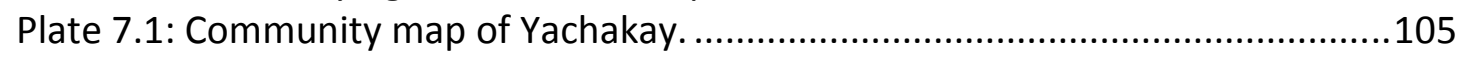




\section{Introduction}

This Masters thesis explores community economies as a means of practising community development. I explore the process of pursuing this approach with two communities in Bolivia, with a particular focus on how the research contexts shaped the research outcomes. I aim to comment on the merits of carrying out research into community economies within a Masters level framework.

Enrolling in the Masters thesis in Development Studies was the cumulative result of a number of years of wanting to help those less fortunate and volunteering for organisations such as Oxfam and Amnesty International in New Zealand and Australia as well as smaller Non Government Organisations (NGOs) in the global south. I could have been considered a naive do-gooder as I meant well, and put that well-meaning intention into action, however I did not have a strong understanding of what 'good development' might look like, let alone what it might entail. Through the process of volunteering in the global south (Nepal and Peru) I became increasingly aware of the critical (local) attitudes to foreign 'do-gooders', the sort of attitudes I have since read about in The Post-Development Reader (Rahnema \& Bawtree, 1997). The Post-Development Reader is composed of a collection of texts which critique development, highlighting the harm, even violence that processes of development have unintentionally caused to people, their cultures and their homes.

This process of awakening to the oft ignored politics of development continued as I interacted with friends and research colleagues in Bolivia. Conversations with three friends that took place at various times during my stay in Bolivia provide an apt introduction to my research topic.

The first anecdote arose out of a conversation with my Spanish teacher. We often spoke about my research and my career aspirations so that I could build relevant vocabulary. This was uneventful until I expressed an interest in working for a development NGO. My teacher was horrified. She asked me why I wanted to work for corrupt organisations which absorbed millions of dollars of foreign money that was supposed to be spent on effecting positive change. Even after reading the harsh critiques of post-development, I was taken aback, I had not realised that development NGOs had such a ubiquitously bad name in Bolivia. 
The second story also critiques development NGOs. A friend spoke to me in exasperation and frustration over his experience with NGOs in his rural Bolivian community. He narrated his experience where well intentioned NGO efforts wasted millions of dollars. An expensive, diesel powered, highly technical water pump and an oversized tractor materialised in the community. However with neither money for diesel nor maintenance, nor technicians with the knowhow to fix these complex machines, both have broken down and sit idly rusting. These are just two examples, although there were many more. My friend lamented the way NGOs and government organisations marched into the community, full of arrogance and self importance about their technologically superior knowledge. He iterated the importance of being humble and getting to know a locality and its people.

The third story came out of a conversation with a different Spanish teacher. I was explaining how within my research I wanted to try and promote positive change in the community I was working with. Challenging me, my teacher asked, "But what's wrong with the community as it is? Why does it need to change? Why do you want to change it?" Despite my best intentions I felt like I was being perceived as a part of this arrogant and sometimes corrupt development machine.

These conversations echo the critiques of post-development literature and point to my motivation for wanting to find a way to practice development differently. For some people in Bolivia, the practice of development is seen to benefit the foreign practitioners rather than those in need. It has resulted in inappropriate technology being boldly introduced in communities (albeit in good will). And perhaps most significantly, its implications are that economically poor people are not okay the way they are, that they need to shed their cultural norms and understandings and adopt foreign ways of life. Although I had seriously considered these factors and sought to explore a way of practicing development that benefitted the communities and celebrated their way of life, these conversations were a reminder of my foreign positionality and of the legacy of harmful development that I was all too easily perceived to be perpetuating.

This thesis represents an attempt to critically engage with these issues. It is an exploration into a way to practice development differently. Community economy projects are "locally grounded and focused" (Gibson-Graham, 2005b, p. 120). What differentiates this approach from previous grass roots development initiatives is that it 
takes seriously the idea that people have different understandings of wellbeing and of ideal ways to go about achieving this. Therefore, no capitalist, indigenous, or any economic practices are prioritised, but all are highlighted for critical consideration. As such, Gibson-Graham state "both economic interdependence and ethics are to be defined, decided and 'deemed' by the 'community' being constituted through the process of shared decision making. Circularity notwithstanding, it is not possible to pre-specify the form of community, nor indeed the ethical process of becoming one" (2005b, p. 121). I have attempted to put post development theories into practice and have seen the community economy framework developed by J. K. Gibson-Graham as a potential way to achieve this.

\subsection{Research aims and objectives}

The community economy approach, developed by economic geographers J. K. GibsonGraham, provides a response to post-development critiques that mainstream development projects have discursively and practically created linear development trajectories. Rather than seeing economic development as involving a single pathway that 'developing' peoples must follow to become more like 'developed' peoples, the community economy approach involves opening up multiple possible pathways to economic development. This is done by uncovering the diverse economic practices that already maintain community wellbeing and facilitating a process of critical discussion among community members as to which activities could be strengthened or extended. While keeping the limitations of this research in mind, I draw on my experience to contribute to the dialogue on the community economy approach as a way to practice development.

I am particularly interested in how research contexts - both place based and institutional affect research outcomes. In order to explore the place based research contexts, I engaged with two economically less well off communities in Bolivia, San Miguel and Yachakay ${ }^{1}$ to explore community economies. I spent ten days with the rural community of San Miguel $\left(15^{\text {th }}-25^{\text {th }}\right.$ April 2010) and seven weeks with the peri-urban community of Yachakay $\left(12^{\text {th }}\right.$ May $-28^{\text {th }}$ June 2010). I drew on feminist and indigenous epistemological and methodological insights which recommend that researchers seek ways to make research appropriate, relevant and beneficial to the people with whom it is carried out. Throughout the process of carrying out this research I became aware that while sensitivity to local

\footnotetext{
${ }^{1}$ These place names are pseudonyms.
} 
contexts is recommended, there are very few studies which include a discussion on what this involves, nor how it affects research outcomes. This thesis explores the process of negotiating an ethical research project, with particular attention paid to the ways in which the Bolivian community contexts affected my research outcomes.

To explore institutional contexts I draw on my experiences of carrying out community economy research within a Masters level framework. Existing community economy projects such as that of Cameron and Gibson's (2005) span several years, have large budgets and employ teams of academics, council employees and community researchers. At Victoria University of Wellington, a Masters thesis in Development Studies should be completed within one year, with extensions not exceeding six months (Research Policy Group, 2011). Furthermore, professors within the programme advise students to spend a maximum of three or four months undertaking the overseas field research component. Is this enough time to carry out ethical research into community economies? How do these time constraints shape what is feasible (and ethical) to pursue in regards to community economies? Drawing on my experiences of carrying out research into community economies in San Miguel and Yachakay, this thesis explores the limitations and potentials for carrying out research into community economies within a Masters level framework.

Based on the above discussion, my central research aim and research questions are as follows:

My main research aim: To explore the potential contribution that can be made at Masters level to strengthening community economies in distant places.

\section{My research questions are:}

1. What can be learnt about the community economy approach through exploring community economies with two indigenous communities in Bolivia?

2. How do research contexts shape the production of research?

3. What are the limitations and potentials of applying a community economy approach within a Master of Development framework? 


\subsection{Why Bolivia?}

Initially I wanted to carry out research in Bolivia because I had spent six weeks travelling in the country in 2008 and had admired the people, their culture and the spectacular landscapes. However, alongside the cultural riches, it was hard to ignore the poverty many Bolivians faced in their daily lives. The Human Development Index (HDI) $)^{2}$ situates Bolivia $86^{\text {th }}$ in the world and $17^{\text {th }}$ out of 21 countries in the Latin American and Caribbean region in 2010 in terms of health, education and economic wealth (United Nations Development Programme, 2010). Bolivia is considered economically poor according to international financial institutions, and the indigenous population is even less well off (Bomberry, 2008). However, as is the case in many localities around the world, the country has a wide variety of economic systems, including traditional systems based on reciprocity and co-operative systems. They have a large informal economy and participate in the export oriented market economy (e.g. Bebbington, 1993; McDaniel, 2003). This made Bolivia an ideal place to search out the diverse economic practices that sustain localities. I was curious as to what place based understandings of wellbeing exist and how these are enacted in the diverse economic activities that currently sustain wellbeing.

A further reason why it was relevant to carry out research into community economies in the geographical context of Bolivia, was because of their particularly strong community level administrations. Bolivia's population includes a $59 \%$ majority of indigenous peoples. Aymara and Quechua peoples make up 55\% of the total population, although there are 36 linguistically distinct indigenous peoples of Bolivia. Ideally, the indigenous community level unit of the ayllu, functions according to democratic principles in regards to all important community decisions (Andolina, Radcliffe, \& Laurie, 2005). Traditionally strong indigenous communities were further empowered by the implementation of the Law of Popular Participation (LPP). The LPP granted formal recognition to local indigenous entities and devolved $20 \%$ of the national budget to be allocated by these newly recognised local level administrations (Kohl, 2002). I reasoned that this could potentially be advantageous for community economy research because communities were already carrying out political processes of decision making as to how this communal resource was to be allocated to best benefit the community. On the other hand it could prove complicated if I came across uneven or exploitative power relations within existing structures.

\footnotetext{
${ }^{2}$ The HDI is a composite index measuring countries' wealth, education and health. It is compiled by the United Nations Development Programme.
} 
Furthermore, a consideration of the unique historical, economic, cultural and political attributes of Bolivia led me to conclude that it could be an appropriate place to investigate community economies. Recent political unrest in response to neoliberal reforms indicates a population that is deeply dissatisfied with these policies. Jeffrey Sachs created Bolivia's Structural Adjustment Program (SAP) in 1985 for Bolivia's National Revolutionary Movement (MNR) government (Kohl, 2002). Bolivia has since been considered the "darling of multilateral agencies" (Lopez Levy, 2001, p. 2) for its implementation of economic reforms of "fiscal reform, trade liberalization, internal price decontrol, and the decentralization or privatization of public enterprises (Sachs, 1987 in Kohl, 2002, pp. 454-455).

Yet the Water War of 2000 and the Gas War of 2003 indicate an extremely dissatisfied population regarding these neoliberal reforms. The Water War arose out of the privatisation of a municipal water project in the Cochabamba region. Proposed price increases in water rates rendered water inaccessible for poor neighbourhoods and farmers reliant on it for irrigation. Protesters organised themselves and forced out the transnational corporation responsible (Postero, 2005). The Gas Wars of 2003 exploded in response to the Sánchez de Lozada administration's proposal to build a gas pipe enabling the sale of gas to USA and Mexico. Widespread protests demanded the renationalisation of the hydrocarbon sector, which had previously been privatised under the Law of Capitalization. The administration of Gonzalo Sánchez de Lozada reacted by cracking down on protesters, resulting in a death toll of 80 , with hundreds more injured. Bolivian's were shocked at the brutality. As violence escalated Sánchez de Lozada lost the support of his allies and was forced to resign (Postero, 2005).

Dissatisfaction with neoliberal processes can also be seen in the election of Evo Morales as President of Bolivia in 2005. Evo Morales' political ideology is argued to be an indication that Bolivian's are not content with a choice between the political categories of left or right:

\footnotetext{
"In this new configuration, the MAS slogan "MAS is neither right nor left we are MAS" is more than a clever call for unity. It asks various constituencies across a broad progressive spectrum to consider a politic that in its excess ruptures prior political formations. In government restructuring, there is a clear sense that there is a move toward an indigenous episteme that is still in formation. Aymara intellectuals bring an alternative vision to the idea of the state. This alternative ideology breaks with traditional leftist ideology that has a long history in Bolivia and has at times reproduced
} 
the same structural patterns of oppression and subordination that it promised to eradicate." (Bomberry, 2008, p. 1794)

The widespread dissatisfaction with neoliberal processes, in addition to growing dissatisfaction with traditional political categories of right and left, prompted me to consider that political openings for alternative ways to practice development might exist among some Bolivians.

\subsection{Thesis layout and chapter outline}

This thesis does not flow like a traditional thesis. The following paragraphs will explain the layout and chapter content. A central focus of this thesis is on methodological themes. For this reason I have included an epistemology chapter in addition to two methodology chapters. The methodology chapters include a critical consideration and analysis of how research contexts affect research outcomes (research question two) and the potentials and limitations of carrying out community economy research within a Masters framework (research question three). While keeping the limitations discussed in the methodology chapters in mind, the analysis chapters (six and seven) respond to research question one, exploring what can be learnt about the community economy approach through my research in San Miguel and Yachakay. This flows into a discussion on the potentials and limitations of each approach within a Masters framework (question three).

Secondly, my particular experiences of carrying out fieldwork resulted in a focus on two case studies, research carried out in San Miguel and research carried out in Yachakay. These case studies can be traced in the chapters of this work as shown in Figure 1.1 below. The research carried out in San Miguel can be traced through the first half of Chapter three, Chapter four and Chapter six. The research carried out in Yachakay can be traced through the second half of Chapter three, Chapter five and Chapter seven. Chapter eight draws on both case studies to respond to my central research aim and research questions. 
Figure 1.1: Thesis structure flowchart

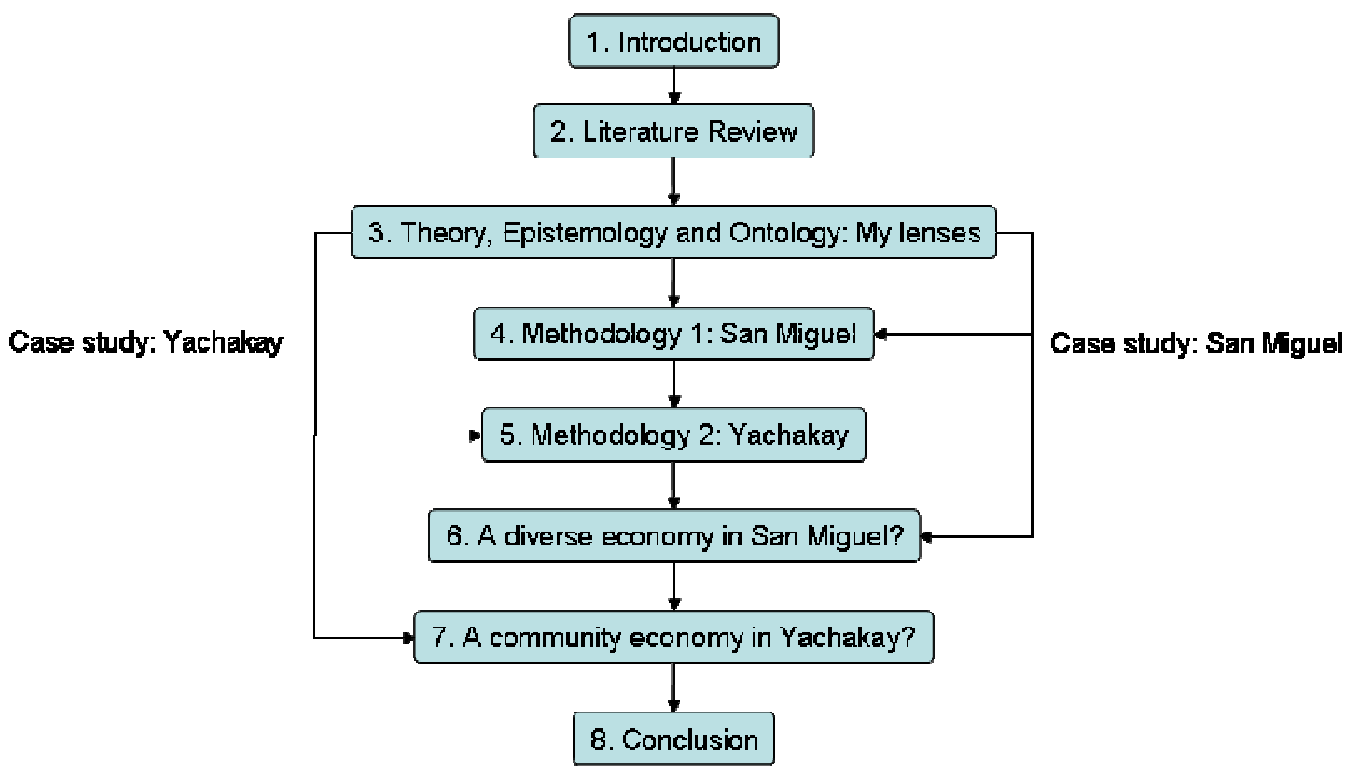

The following paragraphs will introduce the content of each chapter in more depth. Chapter two is a literature review which introduces the post-development arguments which provided theoretical openings for the community economy approach. The arguments and conclusions of post-development are broken down by its critics, but most significantly, it is noted that no viable alternative to development is proffered by post-development writers (Pieterse, 2000; Schuurman, 2000). Over the last ten years a number of academics have begun to emerge who have sought to address the arguments and critiques of post-development. The community economy work of J. K. Gibson-Graham and Jenny Cameron (Cameron \& Gibson, 2005; Gibson-Graham, 2005a, 2006, 2008) fit within this group. This chapter situates community economy literature within the theoretical framework of post-development, introduces key community economy literature and identifies the 'gap' in the literature which this research will respond to.

Chapter three discusses my theoretical, ontological and epistemological lenses and begins to address research questions two and three. Post-structural, feminist and indigenous lenses prompted me to reflect on the exploitative history of social research and to attempt to structure the research in such a way that ensured that I did no harm, but further that the people I collaborated with actually benefitted from it. I discuss how my research resembled a bricolage (Denzin \& Lincoln, 2005) where methodological lenses were pieced together as relevant at different stages in the research process. I set out largely influenced by the post- 
structural and asset based lenses of Gibson-Graham's (2005a) work along with indigenous methodology and epistemology. The change of location part way through my research resulted in a critical reflection of my interpretive lenses. For my second research location, I added participatory action research (PAR) from a post-structuralist perspective to my tool kit. This chapter frames my epistemological perspectives as they evolved throughout the process of carrying out this research.

The bricolage (Denzin \& Lincoln, 2005) is an appropriate metaphor for this thesis as it captures the idea of a messy process involving multiple elements but eventually coalescing into a complete picture. My methodology chapters (four and five) aim to achieve two goals. The first is to discuss the methodology and methods chosen and why. The second is to discuss the messy process of formulating a plan, then negotiating this plan into the research setting. I have sought to explore how this process of negotiation and the difficulties that often accompany this, impact on research insights. These chapters are both an explanation of the methodology and an analysis of the process of carrying out research.

Chapter six explores research questions one and three and draws on the data collected during my ten day stay in San Miguel. Drawing on this data, I have put together a picture of some of the practices within the diverse economy of San Miguel. Drawing on the concept of performative research, I discuss how the act of highlighting the diverse range of economic activity that sustains community wellbeing, is in itself a valuable political act. Reflecting on my approach to exploring community economies in San Miguel, I question the concept of performative research reflecting on who benefits and how.

Chapter seven draws on the data collected from my research with Yachakay to explore research questions one and three. I present findings from the PAR process of documenting the situation, contextualising the situation and working towards change (Cameron \& Gibson, 2005). I then draw on these findings to respond to research questions one and three.

My final chapter responds to my overarching research aim and research questions. The chapter brings together the findings and analysis from the two communities to highlight my overarching conclusions. 


\subsection{Conclusion}

This chapter has introduced my research topic of exploring the process of carrying out research into community economies in distant places, within a Masters framework. It has introduced my rationale for exploring a different way to practice development and has justified my reasons for carrying out this research in Bolivia. I have also outlined the chapters of this thesis. In summary, this thesis is an attempt to contribute to critical thinking regarding a different focus for development, a focus that is grounded in local realities and is open to hopeful futures. The following chapter will introduce the literature which frames the aim and central research questions within this thesis. 


\section{Literature Review}

\subsection{Introduction}

This chapter introduces the literature surrounding my research topic. I will introduce the broader theoretical body of post-development, from which community economy research has emerged. First, I will discuss the post-development arguments which led to an initial rejection of 'development' by some theorists. I cover some of the responses to postdevelopment, including what is perhaps the most significant argument against postdevelopment - that it does not offer a viable alternative to the practice of development. Following these discussions, I will introduce Gibson-Graham, a partnership of economic geographers made up of the late Julie Graham and Kathy Gibson and their work on community economies. They are one team to emerge out of a larger group of diverse academics and practitioners seeking to learn from the lessons of post-development and its critics, and thus, to practice development differently. This chapter situates community economy literature within its broader theoretical framework of post-development, introduces the key community economy texts and locates the particular 'gap' which this research seeks to respond to.

The particular 'gap' which this work addresses is how Masters level research can contribute to community economy research in distant places. While this chapter justifies the impetus for carrying out research into community economies, the literature framing research questions two and three is introduced in Chapters two, three and four. Research questions two and three pertain to place based methodological and institutional constraints and opportunities, therefore it is appropriate that the literature for these questions is introduced in the epistemology and methodology chapters.

\subsection{Post-development}

\footnotetext{
"The last 40 years can be called the age of development. This epoch is coming to an end. The time is ripe to write its obituary ... The idea of development stands like a ruin in the intellectual landscape. Delusion and disappointment, failures and crimes have been the
} 
steady companions of development and they tell a common story: it did not work."

(Sachs, 1992, p. 1)

"From the unburied corpse of development, every kind of pest has started to spread. The time has come to unveil the secret of development and see it in all its conceptual starkness." (Esteva, 1992, p. 6)

Melodramatic statements such as these pervade the early post-development literature and characterise the mood of many post-development authors. Post-development is not a unified theory but a collection of ideas that culminate in unforgiving critiques of what many writers describe as the post-World War II (WWII) development project ${ }^{3}$. Collections of texts such as Rahnema and Bawtree's (1997) The Post-Development Reader, bring together a wide range of perspectives, from economists to anarchists and even Dadacha, an 'illiterate' sage. These authors address development from the perspective of those affected, seeking to examine who benefits and who is disadvantaged by 'progress' or 'productivity'. The critiques in this volume and other post-development publications (e.g. Escobar, 1995; Sachs, 1992) assert that development was a post WWII project that has failed in its stated aims of improving socioeconomic wellbeing in the global south. Furthermore, it is argued that the development project has not merely failed, but it has been a Eurocentric project that has left a trail of destruction in its path, with neither diverse cultural values nor the environment being spared in the name of progress. Rather than searching for ways to improve on its failings, it is suggested that the development project is rejected and alternative mechanisms sought out (e.g. Escobar, 1995; Rahnema \& Bawtree, 1997; Sachs, 1992; Santos, 2004; Tucker, 1999).

\subsubsection{Post-structuralism and discourse analysis}

Rather than strictly examining the success or failure of development as a socio-economic endeavour which attempts to alleviate poverty and maximise happiness, post-development theorists have approached the questions of development from a different direction, by studying it as a historically produced discourse (e.g. Crush, 1995; Escobar, 1995; Esteva, 1992; Ferguson, 1990; Rahnema \& Bawtree, 1997; Sachs, 1992). Many post-development writers apply the post-structuralist technique of discourse analysis, a theoretical tool that differentiates their critiques from earlier critiques of development. Escobar (1995, p. 5)

\footnotetext{
${ }^{3}$ Although Cowan and Shenton (1996) trace the formation of the 'development project' to early in the $19^{\text {th }}$ century where old ideas of progress were replaced by the development doctrine.
} 
draws on Foucault's (e.g. 1972, 1973) $)^{4}$ understanding of the "dynamics of discourse and power in the representation of social reality" noting how this method enables one to see how "discourse produces permissible modes of being and thinking, while disqualifying and even making others impossible." Along these lines Sachs $(1992$, p. 1) notes that "development is more than just a socio-economic endeavour, it is a perception which models reality." Post-development theorists attempt to deconstruct the discourse of development by aiming to uncover the "power relations and knowledges that shape contemporary development norms" and by analysing "texts to highlight and destabilise the truth claims and power relationships contained within" (McGregor, 2009, p. 1689). Although not a unified theory, most post-development writers address development as a discourse. They examine the power dynamics surrounding the creation and legitimisation of knowledge about the global south by development institutions and the ways in which alternative knowledges are silenced.

Post-development writers also take inspiration from the theoretical traditions of postmodernism, post-colonialism, and feminism in that they examine the truth claims of "modernism" and note the inseparability of the creation of Western knowledge and the implementation of Western power (e.g. Crush, 1995; Ferguson, 1990; Kothari, 2002). As McKinnon (2007, p. 773) states "Postcolonialism has made it possible to analyze the ways in which development discourses - from a paradigm of "progress" and "underdevelopment" to contemporary discourses of participatory development - engender neo-colonial logics." Attention is drawn to the geopolitical context in the Cold War era where international development strategies were formed by the USA and the USSR for the purpose of gaining the allegiance of recently decolonised countries (e.g. Rahnema \& Bawtree, 1997; Sachs, 1992). Thus the truth claims made by the USA or the USSR regarding the inferiority of ways of life in the global south (and their need for modernisation) are contextualised within their geopolitical and ideological contexts. This throws light on the political motivations underlying these representations.

The formation of international organisations in the post WWII period such as the United Nations, the World Bank, the International Monetary Fund (IMF) and the World Trade Organisation (WTO) hailed the formation of powerful global discourses. Post-development

\footnotetext{
${ }^{4}$ Although Brigg (2002) argues that the in-depth use of the tools of Foucault by post-development writers such as Sachs (1992)and Escobar (1995) leaves room for improvement.
} 
theorists argue that through the formation and practices of these powerful organisations, linear visions that placed Western norms as the ideal were actively imposed on other countries (e.g. Escobar, 1995; Esteva, 1992; Nandy, 1997; Rahnema \& Bawtree, 1997; Ramonet, 1997; Sachs, 1992; Shiva, 1997). Through the global human rights framework, Structural Adjustment Programs, the Millennium Development Goals, or other policy mechanisms, Western ideals for economic, social and cultural ways of life, are imposed on the global south. The directive of quashing other worldviews can be seen in statements such as this one from the United Nations:

"There is a sense in which rapid economic progress is impossible without painful adjustments. Ancient philosophies have to be scrapped; old social institutions have to disintegrate; bonds of cast, creed and race have to burst; and large numbers of persons who cannot keep up with progress have to have their expectations of a comfortable life frustrated. Very few communities are willing to pay the full price of economic progress." (United Nations, Department of Social and Economic Affairs [1951], 15, quoted in Escobar, 1995, p. 4)

Post-development writers argue that statements like this one make clear the discursive violence of development institutions which have worked to legitimise Western norms, while actively silencing other forms of knowledge and ways of life.

\subsubsection{Language as a discursive tool}

Post-development writers emphasize the ways in which "words make worlds" (Cornwall, 2007 , p. 471). Drawing on post-structural epistemologies, the ways in which language is used to represent and legitimise particular knowledges and worldviews are analysed (e.g. Cammack, 2002; Cornwall, 2007; Eade, 2007; Rist, 2007; Sachs, 1992). Theorists give the example of President Harry Truman's 1949 inaugural speech, which is hailed as naming and therefore discursively creating a state of underdevelopment for three quarters of the world's people in just one sentence (e.g. Escobar, 1995; Esteva, 1992; Sachs, 1992). Truman stated:

"More than half the people of the world are living in conditions approaching misery. Their food is inadequate, they are victims of disease. Their economic life is primitive and stagnant. Their poverty is a handicap and a threat both to them and to more prosperous areas. For the first time in history humanity possesses the knowledge and the skill to relieve the suffering of these people ... I believe that we should make available to peaceloving peoples the benefits of our store of technical knowledge in order to help them 
realize their aspirations for a better life ... What we envisage is a program of development based on the concepts of democratic fair dealing ... Greater production is the key to prosperity and peace. And the key to greater production is a wider and more vigorous application of modern scientific and technical knowledge." (Truman [1949] 1964 cited in Escobar, 1995, p. 3)

The use of dichotomies such as First World/Third World and the constant reification of the 'needs' of the global south not only imply the superiority of the global north, but work to legitimise development interventions (Escobar, 1995; Gibson-Graham, 2005a; McGregor, 2009). As McGregor (2009, p. 1690) states, “... the terms implicitly assume the desirability and cultural superiority of developed spaces, which are generally associated with Western social, political and economic systems, or the 'American dream', and assume that developing spaces are somehow inferior, defined by what they lack, not what they have, and in need of transformation." Language used by development institutions reveals the ways in which people in the Global South are stereotyped in specific ways for the purposes of legitimising further development interventions.

\subsubsection{Depoliticising of development}

Post-development theorists note how the ideal of 'development' has become depoliticised, it is held up as a universal good that everyone should have access to. It is argued that the discourse surrounding 'development' is constructed in a way that allows no room for the possibility that people might not want to become 'developed,' or that might allow for different understandings of what 'development' is. Rahnema and Bawtree (1997, p. ix) state that the concept of development had grown into "such a sacred cow that it appeared totally irresponsible to question its relevance." Post-development theorists acknowledge that there has been a rich history of critique within the development field, however, "If 'development' is ... challenged, it is still almost always challenged in the name of 'real development.' Like 'goodness' itself, 'development' in our time is a value so firmly entrenched that it seems almost impossible to question it, or to refer to any standard beyond its own" (Ferguson, 1990, p. xiv). So, while many post-development writers reflect on the critiques within development, they consider these critiques to be attempts to find a better way to do development, thus leaving the idea that development is necessary or desirable unquestioned. 


\subsubsection{Alternatives to development}

In opposition to the perceived hegemony of development, post-development theorists suggest that ways for moving forward might be found by embracing other cultures as other systems of knowledge, as other ways of life (Escobar, 1995). In a similar vein others suggest thinking locally (Esteva \& Prakesh, 1997), or call for a home perspective (Sachs, 1997). For example, they suggest that grand theories should not be sought, but rather, alternatives to development might be found in local place based practices, collective action and political mobilisation (e.g. Escobar, 1995). Post-development theorists thus reject the international practice of development in favour of local, place based initiatives that are planned, directed and carried out by local people for the benefit of local people.

\subsection{Critiques of post-development}

The irate tone and strong rejection of development by post-development writers has provided a much needed wake-up call to the underlying violence present in the 'knowledge' about people in the 'developing' world, that is created and legitimised in development projects. However, critics have found many flaws in post-development arguments and this has allowed a more robust understanding of the contributions of post-development to development theory and practice. Many of the critiques revolve around reductive or simplistic use of concepts and terms such as 'development', 'the West' and 'local cultures.' Some theorists argue that the lack of practical solutions for moving forward is the most significant flaw in post-development theories. The following paragraphs will briefly cover some of these critiques.

\subsubsection{Development $=$ homogenous behemoth?}

Critics highlight that post-development writers have cast development as a "homogenous behemoth" which treats even opposing development theories as "irrelevant or ... [as] unknowing contributors to a greater post-colonial system of exploitation" (McGregor, 2009, p. 1695). Peet (1997, p. 79) reminds us that discourse analysis is about understanding the social constructions of meaning, paying attention to the positions people speak from and the power relations surrounding these positions. Post-development theorists critique the creation of knowledge about 'developing' peoples, and the uneven power relations surrounding this knowledge creation. Yet meaning that is created within opposing theories 
of development is not given the same critical treatment. Rather it is lumped into one overbearing discourse of development (e.g. Corbridge, 1998; Curry, 2003; Kiely, 1999; Peet, 1997; Pieterse, 2000; Storey, 2000). As McGregor (2009, p. 1695) notes "It makes little sense, for example, to portray neo-Marxist dependency theories as being particularly beneficial to the developed North; similarly dismissing the gamut of practices and ideas that accompanied the alternative grassroots empowerment theories of the 1980s onwards as doing little more than furthering neoliberal agendas seems unfair (see Cooke 2004; Kothari 2005)." Little is gained from treating the theory and practice of development as a single homogenous behemoth.

Furthermore Storey (2000, p. 42) refers to post-development theorists' "hegemony of negativity" noting how the achievements of development, such as significant increases in life expectancy, are not acknowledged (see also Corbridge, 1998; Peet, 1997; Rapley, 2008). Pieterse (2000) draws attention to the way post-development literature has considered examples from Africa, Latin America and India in their consideration that development has failed, yet the rise of East Asia is ignored. While post-development theorists would argue that any benefits achieved through development are offset by the harm caused to culture and environment, Storey doubts whether this can be empirically proven, and argues that the important point to note is that gains are achievable. The rashness of claims that development has completely failed in its stated aims is tempered by an acknowledgement of the achievements of development.

\subsubsection{Romanticising the "noble savage"}

"[Post-development writers have] ...tendencies to deny that poverty originally existed in the Third World, to romanticize alternatives to development, to assume a position of reverse snobbery in which indigenous knowledge systems are automatically superior to Western science." (Peet, 1997, p. 82)

Reviewers have noted that post-development writers have treated local cultures uncritically, romanticising the 'noble savage', and championing local cultures regardless of violence or inequality (Corbridge, 1998; Peet, 1997; Pieterse, 1998, 2000; Schuurman, 2000; Storey, 2000). Diversity within communities and amongst social movements in the global south is ignored. Post-development writers prioritise local values, but questions must be raised as to which local values are to be prioritised? Which social movements are to be endorsed? As 
Storey (2000, p. 43) notes in reference to social movements: "not all sagas are sagas of resistance and liberation." Furthermore, Schuurman (2000)and Storey (2000) note how many people and social movements in the global south are doing their best to attain the benefits of modernism, rather than reject them. Consequently post-development writers are rebuked for prioritising local cultures as always superior to modern alternatives because this undermines the efforts of those in the global south who are genuinely attempting to access the benefits of mainstream development (Curry, 2003; McGregor, 2009; Storey, 2000). Even though it is improbable that Western levels of material development could be sustained for all in the context of a finite ecosystem, this does not mean that these standards are not desired by many in the global south (Storey, 2000).

Furthermore, post-development theorists are taken to task for consistently portraying people in the global south as the passive victims of development projects (Bebbington, 2000; Kiely, 1999; McGregor, 2007, 2009; Nustad, 2001; Pieterse, 2000; Storey, 2000) ${ }^{5}$. Critics have argued that people and communities do exercise considerable agency and actively influence development processes to suit local needs and epistemologies (e.g. Curry, 2003; McGregor, 2009; Nustad, 2001). For example, McGregor argues that "societies and cultures are far more resilient and active than how they are portrayed in much post-development literature" (2009, p. 1695). While care needs to be taken not to overstate agency, or to assume equality of abilities to exert agency within communities, the uncritical depiction of people and communities as helpless victims is inaccurate and disempowering.

\subsubsection{So what?}

A significant challenge to post-development has been that it does not offer practical solutions. As Crush (1995) notes, the suggestion that development ought to be rejected is problematic because it assumes that one could delimit the concept and practice of development. This would be necessary in order to know what exactly needed to be rejected and how that might be achieved. This critique also applies to those in search of alternatives to development. It is difficult to search for alternatives to, or to think beyond an ill defined, extremely broad concept like development which today can cover everything from "globalisation, international trade, biotechnology and universal human rights to farmer field

\footnotetext{
${ }^{5}$ Although Escobar (1995) does attempt to address the problem of uni-directionality of power by paying attention to resistance movements where people are not viewed as passive victims, but active agents of change.
} 
schools, health clinics, microfinance and safe sex" (McGregor, 2009, p. 1695). Along with the practical difficulties of disengaging with development, moral qualms are also raised.

Although it may not be possible to speak for others in an unproblematic way, saying nothing is also problematic because it is tantamount to agreeing with the status quo (Pieterse, 2000). Schuurman (2000) and Kiely (1999) point out that the seemingly laudable position of multiculturalism easily slides into cultural relativism or indifference where "we tolerate each other but have nothing to say to each other any more" (Schuurman, 2000, p. 15). If the key problem is the uneven power surrounding the discourse of development, the way 'development' is communicated and imposed as the solution to economically poor peoples' (and economically well off peoples') problems, a rejection of development does not logically follow as the only possible solution. Other options could be imagined which allow different ideals of 'development,' to be pursued.

So if the idea of doing nothing is unappealing, what then, is to be done? How can we learn from the critiques put forward by post-development writers, as well as the critiques of postdevelopment? Ziai (2007) summarises this predicament:

"What are the politically problematic aspects of post-development theory and how can they be addressed and overcome? How can the positive elements of vernacular societies' (direct democracy, communal solidarity, harmonious and humble relationship to nature) be told from the negative ones (patriarchal and oppressive traditions) - and according to what standards? How can the prevalent ideal of consumer society be criticised without preaching modesty to the poor from a position of affluence? How can the desire of many people for material improvements in their standard of living be taken seriously without supporting the notion that a good life is dependent on consumer goods? How can the state centred model of development be attacked without implicitly supporting the agenda of neo-liberalism that wants to leave the poor to their fate? How can a fundamental critique of modern society be formulated without proscribing the subsistence community as the new model to be implemented? How can the imperialist universalism, that all societies have to be transformed according to the image of the ideal society be critized while defending the modest universalism that every society (every culture? Every social group? Every individual?) should have a right to define their own ideal way of life? How can the Eurocentrism of development be criticized while avoiding the dangers of relativism on the one hand and anti-modern fundamentalism on the other hand?" (Ziai, 2007, p. 11) 
Out of the juxtaposition of post-development and its critiques a range of significantly more hopeful approaches and perspectives to development have begun to arise. These hopeful approaches form one of my starting points in this thesis. While the diversity in the approaches is fairly wide-ranging (see McGregor, 2009), I have chosen to explore the diverse economies and community economies work of J. K. Gibson Graham and Jenny Cameron (e.g. Cameron \& Gibson, 2005; Gibson-Graham, 2005a, 2006, 2008). I was initially inspired by their work because it appears to approach the criticisms raised by post-development writers as a challenge, rather than an indication that the whole project should be rejected:

\footnotetext{
"The postdevelopment agenda is not, as we see it, anti-development. The challenge of postdevelopment is not to give up on development, nor to see all development-past, present and future, in wealthy and poor countries - as tainted, failed, retrograde; as though there were something necessarily problematic and destructive about deliberate attempts to increase social wellbeing through economic intervention; as though there were a space of purity beyond or outside development that we could access through renunciation. The challenge is to imagine and practice development differently."
} (Gibson-Graham, 2005a, p. 6)

As I read more of their work I was increasingly satisfied with the broad range of postdevelopment critiques that were addressed through their diverse economies approach to practicing development.

This chapter has argued the need for a different way to practice development. The next section will make an argument for the community economy approach as an alternative way to practice development.

\subsection{Why explore diverse economies?}

\subsubsection{Neo-liberalism}

Many post-development critiques have focused on the way the mainstream development industry has practiced development as economic development. Writers have highlighted how the emergence of a discourse of development economics has come to pervade "the entire practice of development" (Escobar, 1995, p. 18). In the last three decades this economic discourse has taken the form of neo-liberalism. Neo-liberalism is an economic 
system that favours a minimal state and a free market. It "combines a commitment to the extension of markets and logics of competitiveness with a profound antipathy to all kinds of Keynesian and/or collectivist strategies. The constitution and extension of competitive forces is married with aggressive forms of state downsizing, austerity financing, and public service 'reform'”' (Peck \& Tickell, 2002, p. 381). Neo-liberalism was originally a utopian intellectual movement (Peck \& Tickell, 2002) with roots in the classical liberal political economy of Adam Smith, but revived in its modern form through the works of Frederick Hayek (1944), Milton Friedman (1962) and Francis Fukuyama (1992) (Kohl \& Farthing, 2006). Neo-liberalism as an ideology became an uncompromising political force through the administrations of Ronald Reagan and Margaret Thatcher in the 1980s, before gaining traction in international financial institutions such as the World Bank and the IMF (Harvey, 2005; Kohl \& Farthing, 2006; Peck \& Tickell, 2002).

By the early 1980s countries dependent on international aid were forced to comply with neo-liberal policy recommendations as international financial institutions aggressively pursued conditionality mechanisms named Structural Adjustment Programmes (SAPs). Already indebted countries that could not make their repayments were granted debt rescheduling on the condition that they "implement institutional reforms, such as cuts in welfare expenditures, more flexible labour market laws, and privatisation" (Harvey, 2005, p. 29). However, in the case of Bolivia and many other nations, state spending was reduced in areas such as social services, but continued in repressive areas: "When Bolivian civil society contested the tax and gas economic strategies of the government and proposed alternative strategies and beneficiaries, the neoliberal state responded with violence and human rights violations" (Postero, 2005, p. 77). As Gibson-Graham note with reference to their research location in the Philippines, "The message that comes through loud and clear from the national government, the International Monetary Fund and the World bank is that localities are only going to survive if they can insert themselves into the global arena, competing with others to get a slice of the pie" (Gibson-Graham, 2005a, p. 9).

\subsubsection{Critiques of neo-liberalism and macro economics}

There are many critiques of neo-liberalism, many of which echo the broader critiques of modernism and development. Some theorists critique the continued rhetoric that a free market will result in the "trickle down effect" of the wealth generated through a neoliberalised market economy to the economically less well off. The consolidation of 
resources among a small group of wealthy elites and the compounding of inequality between this small wealthy group and an increasing poor majority are noted to have occurred under neoliberal economic policies (e.g. Peet, 1999). Another common critique is that neo-liberalism leads to the unrestricted exploitation of the earth's finite resources (e.g. Sachs, 1992). In the following section I will focus on those critiques that direct the argument towards a justification for pursuing diverse economies.

A key problem with the discourse of development economics is that it has resulted in the development 'success' of a country being measured in narrow terms of economic growth through Gross National Product (GNP) and Gross Domestic Product (GDP). Latouche (1997) notes how it is accepted to pour scorn on the use of per capita GNP as a measure of development due to its inability to measure more than the economic aspects of social life, and its arbitrary calculations. Despite this, the level and growth of GNP is still widely used to gauge countries' levels of development alongside other indicators by the IMF, the World Bank and the economists of development NGOs (Latouche, 1997). While care needs to be taken not to flatten out diversity across development institutions, to assume that all are measuring success only in terms of level and growth of GDP, the continued reliance on and widespread use of the measure is surprising given its limitations.

Others have highlighted the inappropriateness of economic growth as a measure of development success. As Peet (1999, p. 8) notes, "Many critics conclude that GNP and GDP measure economic modernization in the prejudiced sense of how closely a country replicates the characteristics of the West, rather than development in a whole range of indigenous senses." For many, the principles that ground the capitalist economy, such as individual accumulation of possessions, are not compatible with their own ideals. Bolivia is a case in point. Bomberry (2008, pp. 1790-1791) argues that:

\footnotetext{
"The greatest tests that Bolivia is facing in the next several years include the displacement of social structures that have subordinated indigenous peoples, the creation of a coherent narrative of the new nation that deflects and corrects the official histories of the Republic, a fundamental change in the parameters of citizenship and belonging, and an elaboration of an indigenous epistemology from which to launch a new conception of the state."
} 
Hope is held in the government of Evo Morales and the MAS party (Movamiento a Socialismo, Movement Towards Socialism) which combined a platform of indigenous issues in addition to class issues. While care needs to be taken not to romanticise or homogenise local cultures or demonise development, the rhetoric that neoliberal capitalism is the only viable system is ethnocentric, as is the perpetuation of this system without democratic discussions as to the preferences of local people.

Expanding on the theme of the limitations of GNP and GDP to measure development 'success', Peet (1999) notes how only goods and services exchanged in the formal market economy are included, resulting in the exclusion of commodities consumed in the home, or exchanged "informally" that make up a significant part of the economic activity in a large number of developing countries. Research completed by Schneider (2005) found that the shadow economy ${ }^{6}$ made up 40\% of the GDP of developing countries between 1999-2000. Furthermore, Bolivia's shadow economy made $60.4 \%$ of GDP in the 1994/1995 period, and this had grown to $67 \%$ in the $1999 / 2000$ period. While this informal market activity is captured in measures of the GDP, there is a significant amount of informal market activity that is not included in GDP (e.g. such transactions which involve payment in kind - not a frequent occurrence in Bolivia). This indicates that a large amount of economic activity is taking place, working to maintain people's wellbeing, which is not taken into consideration by formal measures of development 'success' such as GNP or GDP. What Gibson-Graham (2006) draw attention to is that not only are 'other' non-capitalist activities not included in measures of development success, they are also excluded from the imaginary of future possible ways of practicing development.

\subsubsection{The hegemonic discourse of neo-liberal economics}

The post-structural theoretical lens allows an examination of the ways in which the neoliberal capitalist economy has become a strong discourse, where challenging it is dismissed as nonsensical. This can be seen in statements such as this one by John Williamson, a World Bank economist, when he argues that the Washington Consensus:

\footnotetext{
"seems to me to be in some sense the economic equivalent of [pro-human rights and anti-racist issues] (hopefully) no longer political issues ... [T] he sooner it wins general acceptance ... the better for all concerned ... [T] he superior economic performance of
}

\footnotetext{
${ }^{6}$ Schneider (2005) used the definition of the shadow economy as products and services produced by unregistered organisations, but exchanged in the formal market.
} 
countries that establish and maintain outward-oriented market economies subject to macroeconomic discipline is essentially a positive question. The proof may not be quite as conclusive as the proof that the Earth is flat, but it is sufficiently well established as to give sensible people better things to do with their time than to challenge its veracity." (Williamson 1993: 1330 in Kohl \& Farthing, 2006, p. 23)

This statement reinforces the dominant neo-liberal economic discourses by both asserting its superiority (while admitting that the evidence is not conclusive), and dismissing alternative discourses as fools errands. Furthermore, Peck and Tickell (2002) highlight how neoliberal discourses have a self-actualising quality because they misrepresent the social world in the way they colour it in its own image. They state that "Discourses of neoliberalism are "strong discourses" in part by virtue of this self-actualising nature and in part because of their self-evident alignment with the primary contours of contemporary politicaleconomic power" (p. 382). This 'strong discourse' has become very hard to challenge as it is both represented and perpetuated as already pervasive and anyone who attempts to challenge it is discredited as not 'sensible.'

\subsection{Diverse economies}

One strategy for moving forward can be seen in the work of J. K. Gibson-Graham and Jenny Cameron (Cameron \& Gibson, 2005; Gibson-Graham, 2005a, 2006, 2008) who have developed a theory that recognises the economy as made up of a diverse range of economic practices. Gibson-Graham (2006) note that in any location there are already many alternative discourses of economy in existence, but they are prevented from succeeding due to the hegemonic discourse of capitalocentrism. This is important because "Most development agencies do not consider these less formal economic practices as a viable avenue for improving people's well-being compared with the formal market capitalist system. By ignoring these economic practices in their planning, they overlook a whole range of resources, networks and activities that could stimulate local economic development" (Cahill, 2008, p. 300).

Gibson-Graham have sought to develop a theory of the 'diverse economy' that aims to incorporate these other forms of economy in an open model. It is not a theory of economy 'as it really is', (like the strong theory of capitalism) but a way of thinking 
that is exploratory and intentionally open to "creative expressions of the new, the unthought, the unexpected" (2006, p. 60). This approach reflects their post-structural positionality, where they develop 'weak theory' (Gibson-Graham, 2008) which approaches theorizing not from the perspective that the world has a structural logic, but that social outcomes are contingent. I will go into more detail regarding the poststructural epistemology in Chapter three.

Gibson-Graham's (2006) diverse economy model works to tease out the differences within and outside of the hegemonic capitalist economy. They have sorted this diverse range of economic activity into three main practices: transactions, labour and enterprise. Referring to Figure 2.1 below and reading vertically down the columns, transactions, labour and enterprise are then divided out into their capitalist, non-capitalist and alternative capitalist counterparts. Alternative market transactions such as barter, non-wage labour such as housework, or alternative enterprises such as those with an environmental ethic are emphasised and counted as economic activity. So too are exploitive labour forms such as slavery and inequitable transactions such as theft. The reasoning behind this is to emphasise that there are all kinds of economic activity taking place at all times. It is too simplistic to view capitalist activity as 'bad' and indigenous activity as 'good'. Along with this diverse economy model comes a suggestion to treat different economic activities and forms critically because this "allows for reflection on what the community is nourished by (rather than what it lacks) and for public discussion of which of these practices could be strengthened or extended" (Gibson-Graham, 2006, p. 178). A new way of viewing the economic landscape is then opened up as capitalist entries are joined by the multiplicity of alternative capitalist and non-capitalist practices.

Carnegie (2008) has drawn on this model of the diverse economy to understand the complexities of the local economy in Oelua, Rote a region in Eastern Indonesia. Drawing on Gibson-Graham's work, she applies an anti-essentialist Marxist understanding of class processes to highlight the diverse ways in which surplus labour is appropriated and distributed to promote social and economic wellbeing. Delineating the many place based, coexisting economic practices, she argues that building a community economy could compliment mainstream development initiatives in Oelua. In finding a different way to practice development, my research will investigate diverse economic activities as potential resources to stimulate local economic development. 
Figure 2.1: The diverse economy

\begin{tabular}{|c|c|c|}
\hline Transactions & Labour & Organisational Form \\
\hline Market & Wage & Capitalist \\
\hline “Free" & Salaried & Family firm \\
\hline Naturally protected & Unionized & Private unincorporated firm \\
\hline Artificially protected & Nonunionized & Public company \\
\hline Monopolized & Part time & Multinational \\
\hline Regulated & Temporary & \\
\hline Niche & $\begin{array}{l}\text { Seasonal } \\
\text { Familial }\end{array}$ & \\
\hline Alternative Market & Alternative Paid & Alternative Capitalist \\
\hline Sale of public goods & Co-operative & Socially responsible firm \\
\hline Ethical "fair trade" markets & Self-employed & State enterprise \\
\hline Local trading systems & Indentured & Green firm \\
\hline Alternative currencies & Reciprocal labour & Nonprofit \\
\hline $\begin{array}{l}\text { Underground market } \\
\text { Co-op exchange }\end{array}$ & $\begin{array}{l}\text { Work for welfare } \\
\text { In kind }\end{array}$ & $\begin{array}{l}\text { Producer and consumer co- } \\
\text { operatives }\end{array}$ \\
\hline $\begin{array}{l}\text { Alternative credit } \\
\text { Barter } \\
\text { Informal market }\end{array}$ & & \\
\hline Non-market & Unpaid & Non-capitalist \\
\hline Household flows & Volunteer & Communal \\
\hline Gift giving & Housework & Independent \\
\hline Indigenous exchange & Family care & Feudal/peasant \\
\hline State allocations & Neighbourhood work & Slave \\
\hline State appropriations & Self provisioning labour & \\
\hline Gleaning & Slave labour & \\
\hline Hunting, fishing, gathering & & \\
\hline Theft & & \\
\hline Poaching & & \\
\hline
\end{tabular}

(Adapted from Gibson-Graham, 2006, pp. 61-65)

\subsubsection{From needs to assets}

One of the key critiques of post-development theorists is the perpetual focus on the needs of people in the global south. Even participatory methods which have been praised for their inclusion of local voices still focus on communities' needs, disempowering communities by "devaluing what exists in place in favour of what is to be built according to universal specifications" (Gibson-Graham, 2006, p. 169). As emphasised by Cahill (2008, p. 294), development interventions such as microfinance or sustainable livelihoods initiatives run the risk of discouraging "the potential for participants to use their own agency by overemphasising an existing lack of resources locally and inadvertently feeding a sense of dependency on formal development interventions initiated by external agencies." In response to this, Gibson-Graham have sought tools to re-read the landscape, attempting to build alternative pathways grounded in what communities have rather than what they lack. 
In the Jagna Municipality in the Philippines, Gibson-Graham (2005a) worked with the local government and community to highlight the community's assets and diverse economic practices. Gibson-Graham began with an existing regional development plan put together by local teams trained in participatory rural appraisal methods. This plan was essentially seen as a detailed 'needs' map. Gibson-Graham (2005a, p. 11) sought to shift the conversation from needs to assets by highlighting to the community "instances where community capacity was exercised and assets were mobilised." A map was drawn up which listed assets under the subheadings: businesses and physical infrastructure, local associations and institutions, and people and practices. This asset map facilitated a perspective of the Jagna Municipality as already resourced and full of people capable of solving their own problems. Furthermore, the map listed a set of resources which could be drawn on in imagining and enacting alternative economic futures.

\subsubsection{From diverse economies and local assets to community economies}

Gibson-Graham seek to go beyond representing the economy as diverse and put forward their idea of the community economy not as a blueprint, but as an empty space from which different economies might be built:

\footnotetext{
"Unlike the structurally configured economy with its regularities and lawful relationships, the community economy is an acknowledged space of social interdependency and self-formation. Anything but a blueprint, it is an unmapped and uncertain terrain that calls forth exploratory conversation and political/ethical acts of decision. The "emptiness" of the community economy, which awaits filling up by collective actions in place, is what distinguishes the project of building community economies from the related and more familiar project of economic development."
} (Gibson-Graham, 2006, p. 166)

Thus in forming a community economy, a space is opened for a critical conversation about the types of economies communities want to build on.

Studies have begun to emerge which seek to build community economies following the above model. Gibson-Graham (2005a) partnered with several NGOs working with Overseas Contract Workers (OCWs), who were exploring ways to reinforce local economies in order to eventually end the need for out-migration. The NGOs organised savings groups and provided 
entrepreneurial and business training for OCWs, making it possible for OCWs to commence enterprises in the Philippines. Gibson-Graham worked with these NGOs and OCWs suggesting that they extend "the scope of certain community practices in the direction of constructing locally based enterprises that marshal and distribute surplus in ways that will strengthen and expand the capacity of the existing community economy" (Gibson-Graham, 2005a, p. 17). One example extended was the possibility of a co-operatively owned trucking enterprise, where the capital from a porter's credit co-operative could be used to extend work into another transportation service that would further benefit the community. GibsonGraham (2005a, p. 19) argue that while there are similarities and differences with past development interventions, "The main point of departure is that the Jagna Community Partnering Project is starting in the community, building on what is there and producing the steps of the process as it goes - not applying a model taken from the shelf of an aid agency, government bureaucracy, or university."

\subsubsection{Critiques of the community economy approach}

Echoing critiques of post-development more generally, a common critique of GibsonGraham's work is that it fails to acknowledge the complexities in terms of power relations and resultant inequalities and the potential for exploitation within community economies (Aguilar, 2005; Curry, 2005; Kelly, 2005; Lawson, 2005). Curry (2005) points out that although Gibson-Graham note the possibility that non-market economies have the potential to entrench exploitative relationships, they are less critical than they should be. He notes how exploitive relations are common within non-market economies. However as shown by Gibson-Graham and Cameron (2003) perceiving the economy as diverse highlights the fact that all aspects of the economy can be both exploitative or beneficial to social wellbeing. They note that, "Within this diverse economy on both sides of the market/non-market, paid/unpaid, capitalist/non-capitalist divides there are opportunities for economically exploitative and emotionally oppressive conditions as well as fair and emotionally creative ones" (2003, p. 153). Furthermore, they argue that positive social values should be encouraged and strengthened in all economic activity. Because community economies are essentially empty spaces to be filled through democratic consideration of the economic makeup of communities, indigenous or local economies are not romanticised, and neither is capitalism demonised. 
Kelly (2005) notes how the uneven power dynamics surrounding decision making processes within communities are insufficiently addressed in Gibson-Graham's (2005a) community economy approach. He states that "it is not clear how 'community agreement' on issues is secured and what structures of power operate in community decision-making processes" (2005, p. 41). Similarly Aguilar (2005, p. 27) questions "Who decides what is ethical? By what criteria is a course of action to be deemed ethical?" In response to this, Gibson-Graham (2005b) argue that it is not for them (nor a university framework, nor an economic system) to decide what is ethical. Rather, the responsibility of deciding what is ethical is positioned with the emerging 'community' to negotiate through a shared decision making process.

Laurie (2005), Lawson (2005) and Kelly (2005) note a lack of attention to processes of scale and power in Gibson-Graham's (2005a) community economy framework. Laurie calls for attention to the connections between community economies and national and international scale institutions. Lawson requests more on the place-based conjuncture of social, cultural and political processes that enable community economies. Perhaps most sceptically, Kelly (2005, p. 41) argues that "A context of highly inequitable wealth distribution, the power of private wealth to overcome the public good and the situation of the Philippines in the global economy are fundamental circumstances that present limits to community economies." Gibson-Graham (2005b) answer these critiques by noting a theoretical point of difference. Rather than seeing the current position of the Jagna community economy in relation to external structures such as the global economy as limits to possibility, they are theorised as conditions to possibility. They are viewed as problems, challenges, barriers and difficulties to be struggled with - rather than insurmountable restrictions to the possible.

\subsection{Conclusion}

This chapter has introduced community economies as situated within the broader theoretical tradition of post-develoment. I have taken the arguments of post-development to indicate the need for a different way to practice development. Post-development theorists examined the use of language to show how development institutions have represented and put into practice their ideology of development with such unquestioned confidence that other ways of life have been discursively and practically marginalised. Gibson-Graham's community economy approach acknowledges and prioritises place based understandings of wellbeing. 
Critics of post-development have highlighted that recipients of development projects do have agency and the power to interact with the discourses of development. However it is an unbalanced playing field. If development is about increasing wellbeing, then it should not start with the discursive violence that subtly or explicitly discredits peoples' ways of life in favour of foreign alternatives. Gibson-Graham (2006) and the community economy framework place democracy and thus politics back into development. This is not a simple equation of foreign = bad and local = good, but an insistence that what is good for the community should not be pre-determined, but considered as an ongoing process that needs to be democratically negotiated by those involved.

As noted above, while the approach has connections and departures from previous community development initiatives, the key point of difference is that the process is started "in the community, building on what is there and producing the steps of the process as it goes - not applying a model taken from the shelf of an aid agency, government bureaucracy, or university" (Gibson-Graham, 2005a, p. 19).

Therefore, based on the above literature review this thesis will attempt to explore the potential contribution that can be made at Masters level to strengthening community economies in distant places. 


\title{
3. Theory, ontology and epistemology: My lenses
}

\author{
"All research is interpretive; it is guided by the researcher's set of beliefs and feelings \\ about the world and how it should be understood and studied ... Each interpretive \\ paradigm makes particular demands on the researcher, including the questions the \\ researcher asks and the interpretations he or she brings to them" (Denzin \& Lincoln, \\ 2005, p. 22).
}

This chapter will introduce my epistemological and methodological lenses and in the process I will begin to address research question two, which asks: How do research contexts shape the production of research? Since returning from Bolivia and reflecting on the process of carrying out research, I have increasingly become aware of the significance of interpretive lenses to research outcomes. This was made particularly apparent in my research because I changed location half way through my time in Bolivia. The change of location prompted a period of reflection and iterative thinking that lead to an altering of some of my interpretive lenses. I set out largely influenced by the post-structural language and asset based community development approaches of Gibson-Graham's (2005a) work, as well as indigenous research recommendations. However, the change in location prompted me to 'go back to the books' to strengthen and revise my research project. Although still influenced by the original ideologies, I was subsequently influenced by Cameron and Gibson's (2005) PAR informed by a post-structuralist approach.

It was a great relief to read that this is a normal part of qualitative research, "If the researcher needs to invent, or piece together new tools or techniques, he or she will do so. Choices regarding which interpretive practices to employ are not necessarily made in advance" (Denzin \& Lincoln, 2005, p. 4). Although I have created a "bricolage" (Denzin \& Lincoln, 2005) of different theoretical influences, I have tried to make the overarching principle guiding its construction a principle of ethicality. That is, I chose theoretical frameworks and subsequent research was undertaken primarily by reference to what I felt was morally right rather than only with regards to convenience or efficiency. This was a choice that no doubt contributed to the "messy process" (Wilkinson, 2008) of my research as I struggled to reconcile the recommendations and restrictions of academia, of the Bolivian people involved with my research, as well as my own critical judgements and emotions. The remainder of this section frames this thesis (or bricolage) within the ideological, 
epistemological and ontological underpinnings, roughly in the order I was inspired by each of them. Although all approaches influence the entire thesis, some approaches were clearly more important at different points in the process than others.

\subsection{Locating the observer in the world}

This thesis is informed by post-modern and post-structural ontological and epistemological assumptions. In conducting my research I held that "Any gaze is always filtered through the lenses of language, gender, social class, race, and ethnicity. There are no objective observations, only observations socially situated in the worlds of - and between - the observer and the observed" (Denzin \& Lincoln, 2005, p. 21). Throughout the process of designing, carrying out and writing up this research, I have tried to be as conscious and overt as possible about how my personal positionality has influenced the research. There is no doubt that my "gaze" was filtered by my socially situated lenses of being a young English speaking woman (with intermediate level Spanish) from New Zealand. These factors shaped my research at all stages. This was made poignantly clear to me through differing interactions I had with a diverse array of research collaborators, whose socially situating lenses affected how they viewed me. However as highlighted by Kincheloe and McLaren (2005), I was aware that ways of knowing are shaped by the researchers specific social location, yet these ways of knowing are not necessarily completely knowable. As this chapter highlights, my ways of knowing certainly evolved through the research process.

This post-structural understanding of the socially situated nature of research refutes the neo-positivist assertion of the possibility and desirability of a neutral, detached researcher. Rather post-structuralism asserts that "[t]he openness and culturally constructed nature of the social world, peppered with contradictions and complexities, needs to be embraced not dismissed" (England, 1994, p. 81). Along these lines, I noted that different aspects of who I am were made visible in relation to different people involved in the research, and I perceived that different people reacted to me in different ways depending on their own socially situating lenses. The most obvious way this was apparent was in the level of similarities and differences between my positionality and that of the different collaborators and the extent to which our worlds overlapped. I noticed that the greater the overlap of worlds, and/or the greater the exposure to each others' worlds, the more comfortable the interactions were and the easier the flow of communication. I will go into further detail 
throughout the thesis regarding how it is "socially situated in the worlds of - and between the observer and the observed" (Denzin \& Lincoln, 2005, p. 21), noting points as they become relevant.

As an extension of my understanding that a researcher can never be impartial, I took into consideration how my emotion's informed my research insights throughout the process. Jagger (1989) highlights how within positivist research, emotion is seen as an interfering or contaminating factor that should be erased by practicing stricter science. Yet this in itself is a position regarding the correct emotional attitude or approach to research. She argues that "rather than repressing emotion in epistemology it is necessary to rethink the relation between knowledge and emotion and construct conceptual models that demonstrate the mutually constitutive rather than oppositional relation between reason and emotion. Far from precluding the possibility of reliable knowledge, emotion as well as value must be shown as necessary to such knowledge" (Jagger, 1989, p. 156). Throughout the process of carrying out this thesis I have paid attention to the ways my emotions focused my attention selectively, directing, shaping and partially defining my observations just as my observations would direct, shape and partially define my emotions (p. 154). I also tried to be sensitive to community member's emotions in an attempt to pick up on when people were, or were not, comfortable with the research process.

\subsection{Research phase one: Whose research is it anyway?}

Much attention has been paid to the negative affects of neo-positivist research (e.g. England, 1994; Gegeo, 1998; Shiva, 1997; Smith, 1999). My concern to explore ways to practice development which discursively and practically empowers local communities flows into my concern to epistemologically frame the research in the same way. At the outset, the two main theoretical influences that shaped my methodology were post-structural approaches regarding the performativity of research and work on indigenous epistemologies. Essentially these two frameworks placed the focus of the research on creating positive outcomes for the chosen community. I was aware that the main purpose of writing a Masters thesis is the process of learning about doing research (Walsh, 2005), which meant that I would likely be the key benefiter of the research. However structuring the research so that there would be positive outcomes for the communities as well was a key priority for me. 
I have drawn on Gibson-Grahams' (2008) theory that research has a performative effect on reality. In contrast to the idea that research objectively presents the world as it appears, this position maintains that research actively constitutes the world. The positivist school of science has taught us to be "discerning, detached and critical" in order to gain ultimate understanding of a "phenomenal world" (Gibson-Graham, 2008, p. 618). The requirement is to search for grand orders or "strong theory" (Gibson-Graham, 2008). With regard to neoliberalism, research data has been ordered into "strong theory" by both opponents and proponents. Yet by treating neo-liberalism as a "strong theory" researchers enact that particular reality while at the same time obscuring other realities. Peck and Tickell (2002, p. 383) shed further light on this when they write that:

“...while conservative commentators emphasize the (ostensibly ubiquitous) benign effects of globalization, critics focus instead on the (just as pervasive) malign effects of neoliberalism. Yet their common flaw is that they have tended to naturalize and exogenize their object of study - be this in the form of an all-powerful globalization process or the all encompassing politics of neoliberalism."

Writing about strong theories of neoliberal globalisation, Gibson-Graham (2008, p. 620) state that "their performative effect is to interfere with, to make non-credible (Santos, 2004), to deny legitimacy to the diverse economies that are already here, and to close down the open futures that are waiting to be performatively enacted." With this approach to research, economic alternatives or new economic ideas are often labelled as a façade of capitalism or as always already co-opted, and are thus not given sufficient opportunity to survive "in all their complexity and incoherence" before being discarded as insufficient (Gibson-Graham, 2008 , p. 618). Therefore my research did not seek to gain an ultimate understanding of the phenomenal world, but acknowledged that by highlighting the diverse economies, this would, albeit in a small way, have a performative effect on reality.

In choosing to focus on community economies, I was conscious of the fact that my research would have a constitutive effect on reality and would affect what exists in the world. The epistemological aspect of this, that is my understanding of what constitutes knowledge and knowledge creation, is that it becomes a conscious choice, how to view, understand and present the world, "One must, in other words, take responsibility for one's approach and its consequences" (Bentz \& Shapiro, 1998, p. 5). Therefore, I have made a conscious effort to 
view, understand and present the world in a way that promotes community wellbeing and resiliency.

\section{Indigenous research counsel}

Indigenous peoples make up approximately $60 \%$ of Bolivia's population. While I did not set out with the aim of working specifically with indigenous people, I knew there was a high chance that I would end up working with an indigenous community. I felt my concern for finding ways to practice development that draw on local place based diverse economic practices could potentially be received receptively by indigenous people. I reasoned that views such as that of Bolivian indigenous intellectual Felix Patzi who argues that "transformation should start from the indigenous people's own philosophy and their own economic and political practices" (2004 in Rojas, 2007, p. 584), might also exist in the wider indigenous population. Furthermore indigenous Bolivian peoples have a rich history of economic traditions, many of which are still practiced today. In his 2002 presidential campaign, Felipe Quispe proposed the indigenous economic system of reciprocity, Ayni, as the way the indigenous people could regain power (Bomberry, 2008). I anticipated that their history of unique economic traditions in combination with modern and hybrid economies could have great potential to alleviate poverty and improve the wellbeing of people who live difficult lives.

As a non-indigenous researcher, I was hyper-consciousness of my positionality. After studying the literature on indigenous research, I had serious doubts regarding the appropriateness and legitimacy of doing research with an indigenous community. Although an enthusiastic "do-gooder" (Hodge \& Lester, 2006, p. 43), I was uncomfortably aware of the utter exhaustion some indigenous people have with the "conspicuous innocence" (Louis, 2007 , p. 131) of western research in addition to the legacy of research as "inextricably linked to European imperialism and colonialism" (Smith, 1999, p. 1). This awareness was very challenging for me throughout the process of my research and hence strongly informed my ideological approach. It was (and is) very important to me that I did not join the legacy of well intentioned, but essentially extractive researchers. To this end I have sought guidance from indigenous epistemology and methodology writers.

Many writers have highlighted the strong association of research with colonialism and European imperialism (e.g. Bishop, 1997; Denzin \& Lincoln, 2005; Hodge \& Lester, 2006; 
Louis, 2007; Smith, 1999). Despite this, there are still indigenous theorists advocating that non-indigenous researchers continue to do research with indigenous people (Crazy Bull, 1997; Hodge \& Lester, 2006; Louis, 2007). However, this advocacy comes with strong recommendations and restrictions regarding how and when it is appropriate to proceed. Louis states that "The most important elements are that research in Indigenous communities be conducted respectfully, from an Indigenous point of view and that the research has meaning that contributes to the community" (2007, p. 131). Linda Tuhiwai Smith maintains that the following questions should guide researchers working with indigenous peoples: "Whose research is it? Who owns it? Whose interests does it serve? Who will benefit from it? Who has designed its questions and framed its scope? Who will carry it out? Who will write it up? How will its results be disseminated?" (1999, p. 10).

The legitimacy of research and development practice with indigenous people that does not include indigenous ways of knowing and indigenous epistemologies within the research design, is questioned by indigenous writers (e.g. Gegeo, 1998; Hodge \& Lester, 2006; Louis, 2007). Indeed Bomberry (2008, p. 1791) states that "To continue an anticolonial project in the Americas, one must enunciate and employ an indigenous epistemology, which requires a profound engagement with the cultural matrices of place." Gegeo (1998) and Louis (2007) argue that this does not indicate a rejection of foreign knowledge, but an insistence that indigenous communities maintain control over the cultural reproduction of this knowledge and furthermore that indigenous epistemologies or systems of knowledge creation and cultural reproduction are prioritised. I felt that my research questions and approach were compatible with this understanding as I sought to highlight community strengths, the diverse range of economic activity that maintained community wellbeing and to create a space for community based discussion. I hoped to present a positive perspective of the community as having multiple potential paths for improving wellbeing, while respecting the role of indigenous cultural reproduction of this perspective.

I have attempted to fulfil these requirements in my research. However, throughout the process of carrying out this research I have discovered that some of the recommendations and requirements are demanding and time consuming (for myself and community members). The practicalities of the community contexts prevented me from achieving some indigenous methodological objectives, yet my relationship with the second community of Yachakay remains strong. This has led me to question whether conducting research respectfully with 
indigenous communities can be reduced to a formulaic approach. Rather it involves listening carefully to the requests and preferences of the community, which, in the case of both communities I carried out research with, did not necessarily involve conducting research from an 'indigenous' perspective. I will go into further detail in my methodology chapters as to how this unfolded and how I reconciled it.

The ideas that I have outlined in this section underpinned my approach at my first research location. I sought to make a connection with a community and conduct research that was framed by indigenous methodological underpinnings that were consequently grounded in local understandings of ethical behaviour. I was intent on forming respectful relationships with community members and serious about altering the focus and methodology if the community preferred another approach. While endeavouring to be realistic about scale, I was committed to carrying out research that would be useful to the community. I reasoned that this could potentially be achieved by highlighting the diverse economy. By drawing attention to the wide range of economic activity that sustains wellbeing, this might contribute to such activity being seen as more viable than it had seemed in the past.

\subsection{Phase two: A reflection on personal safety prompts a location change}

An incident, which is discussed in Chapter four, occurred in my first research location San Miguel which prompted a reflection on my personal safety and resulted in a change of research location. This change of location allowed for a period of reflection during which I took time to review my research focus which led to a reconsideration of my research methodology. Although I was initially inspired by Gibson-Graham's (2005a) work in the Philippines I was perplexed at how they appeared to be both endorsing and critiquing participatory approaches. My focus was caught on their critique of past uses of participatory approaches because of their focus on the needs of communities and the use of the language of 'being in need', which undermined community strengths. It wasn't until I came across Cameron and Gibson's (2005) paper Participatory Action Research in a Poststructuralist Vein, (half way through my fieldwork) that I realised that PAR could be modified to fit a poststructuralist perspective. They draw on Reason and Bradbury (2001) who highlight the commonalities between the two approaches. PAR prioritises local and indigenous knowledges, which is similar to a post-structuralist questioning of overarching theories in favour of multiple knowledges. Both PAR and post-structuralist approaches treat knowledge 
making as political in nature. PAR holds that it is of key importance that ordinary peoples' lives are shaped using everyday knowledges, just as post-structuralists note that language constructs the world.

Cameron and Gibson then go on to describe where post-structuralism departs from PAR, and hence where they have adapted PAR to fit their post-structuralist framework. Firstly, they critique the PAR position that people have a "deep and pre-existing identity that is repressed or alienated by structures, like capitalism and patriarchy" (2005, p. 317) and that through being involved in PAR these subjugated people will be able to envision a freer world and take action to bring about this world. Rather the post-structuralist position is that,

\footnotetext{
"the subject is understood as always in the process of becoming, of being shaped in a multitude of ways by various discourses and practices ... In terms of PAR, this means a shift away from knowledge about the social structures and power relationships that limit and constrain subjugated groups to knowledge about the multiple and often competing narratives, practices and actions that produce certain types of subjects." (Cameron \& Gibson, 2005, p. 317)
}

Secondly, they challenge PAR's inherent prioritisation of local knowledge. They note the possibility of multiple (often competing) local knowledges within communities and individuals, and suggest that not all of these may be transformative. They appeal to the poststructuralist tactic of actively selecting particular realities which are seen as potentially positively transformational. So within my second research location, Yachakay, my epistemological lenses expanded to include PAR from a post-structuralist perspective.

\subsection{Research as bricolage}

As noted earlier, I have come to understand my research as a "bricolage." I, the interpretive bricoleur, have constructed a bricolage, a pieced together "set of representations that is fitted to the specifics of a complex situation ... that changes and takes new forms as the bricoleur adds different tools, methods, and techniques of representation and interpretation to the puzzle" (Denzin \& Lincoln, 2005, p. 4). However, like de Ishtar (2005, p. 365) my research did not consist of "well-oiled and highly controlled processes which the literature too often suggests is possible to achieve." I have subsequently perceived "a degree of 'sanitization' in the presentation of methodological difficulty and its consequences" (Mollinga, 2008, p. 1); and "of editing out the messiness of one's fieldwork" (Wilkinson, 2008, 
p. 48) in the literature. Although I was aware that qualitative research has the potential to change multiple times throughout the process, I was not prepared for the difficulties of carrying out a research project with complex epistemological requirements within a multifaceted research context. With this in mind, I have sought to investigate the potentials and limitations of carrying out community economy research within a Masters framework (research question three).

While some authors grant that epistemological lenses are not completely knowable at any one time (Rose, 1997), and are often evolving throughout the research process (Denzin \& Lincoln, 2005), I have found that this process is not frequently discussed. Nor indeed is the complex place based process of moulding my 'ways of knowing' to suit local contexts. Therefore, this research aims to explore how research contexts affect research outcomes (research question two). Research questions two and three will be investigated more fully in the following two chapters. 


\section{Methodology 1: San Miguel}

\subsection{Introduction}

This chapter is divided into two sections. The first half will detail my planned methodology in my first research location, San Miguel. I will discuss the two main methodological paths which I was open to research collaborators choosing between. First, as discussed in Chapter three, I was committed to an indigenous methodology in which the research was more fully directed by the indigenous community. The second option, which still drew heavily on indigenous methodology recommendations, was grounded in post-structural and feminist methodological recommendations. The methodological lenses directed me to the use of methods that valued the opinions, experiences and ideas of collaborators, so I chose to use semi-structured interviews, focus groups, ad-hoc conversations and a research journal. These methods worked well to investigate my research questions as I could explore diverse economies and community assets through individual semi-structured interviews. I planned to discuss the results of these interviews in subsequent focus groups.

The second half of this chapter focuses on research question two and three. I will investigate how the research context of San Miguel affected my research outcomes. In addition, I will explore the potentials and limitations of carrying out research into community economies within a Masters framework. I will discuss the process of carrying out this research, with a particular focus on those aspects that diverged from my planned methodology due to contextual factors. The context negotiated methodology included a preference of my community contact person for the second methodological approach and to omit the use of focus groups due to inconvenience for community members. The most significant change, however, was my decision to seek a second research location after a ten day initial stay in San Miguel. The decision was made in response to an incident that left me feeling disempowered as a researcher and uncertain regarding my personal safety. I aim to make explicit this process of negotiation, because in examining this iterative process of forming research aims and methodology, a rich picture of the often hidden processes that shape research are exposed. 


\subsection{Section one: The plan}

\subsubsection{Methodology and methods}

The post-structural and indigenous perspective on research outlined in the previous chapter informs my methodology and methods. As I was not seeking to create or inform a 'strong theory' of the world it was not necessary to draw on research techniques that could generate data which could be generalised in order to reach an 'objective' position on my research questions. My feminist, post-structural (de Ishtar, 2005; England, 1994), and indigenous methodological (Evans, Hole, Berg, Hutchinson, \& Sookraj, 2009; Hodge \& Lester, 2006; Louis, 2007; Smith, 1999) lenses also informed my understanding that the researcher can never be objective or impartial. Given this position, it was important to reflect on how my positionality affected the research and to choose research methods that allowed me to explore people's subjective thoughts, values and beliefs and to find an illustrative sample of people to talk to, rather than attempting to locate a representative one (Valentine, 2005).

Attempting to align with indigenous methodology (see chapter three), once I had made a contact who could introduce me to a community, I planned to talk with them regarding structuring the research's aims and methods. Through this process I aimed to make the research respectful, incorporate indigenous epistemology (Hodge \& Lester, 2006) and ensure its appropriateness, relevance and usefulness for the people involved (Louis, 2007). If the community did not want to structure the aims and methods, I was prepared to explore the research questions listed at the end of Chapter one. I felt this would still be compatible with indigenous methodology as “For indigenous people, decolonising research isn't about the total rejection of Western theory, research, or knowledge. It's about changing focus, 'centering our concerns and worldviews and coming to know and understand theory and research from our own perspectives and for our own purposes'" (Smith 1999 in Louis, 2007, p. 132).

I planned to collect data through the use of semi-structured interviews, informal conversations, focus groups and personal reflections in my research journal. I chose these four methods because they were the most appropriate to explore my research questions and because I thought they would triangulate well together. However in line with my postmodern and post-structural theoretical lenses, "the use of multiple methods, or triangulation, reflects an attempt to secure an in-depth understanding of the phenomenon 
in question. Objective reality can never be captured ... Triangulation is not a tool or strategy of validation, but an alternative to validation" (Flick in Denzin \& Lincoln, 2005, p. 5).

I aimed to carry out approximately 20 semi-structured interviews, one or two focus groups and as many informal conversations as I could. I thought that this was an achievable goal in a three month (20 $0^{\text {th }}$ March to $30^{\text {th }}$ June 2010 ) research period and would provide sufficient data to respond to my research questions.

\subsubsection{Semi-structured interviews}

The semi-structured interview is advantageous in that it "is sensitive and people-oriented, allowing interviewees to construct their own accounts of their experiences by describing and explaining their lives in their own words" (Valentine, 2005, p. 111). Semi-structured interviews thus provided an excellent method for gaining an in-depth understanding of people's subjective experiences, understandings and ideas regarding my research questions. I felt that a relaxed interview setting would allow me to explore with the interviewees the diverse activities they participated in throughout their days in order to meet their needs, in addition to their perceived assets in terms of personal skills and networks as well as physical assets. I also hoped that these conversations might lead into discussions about alternative economic futures. In short, I felt that the semi-structured interview was a suitable way to explore a potential community economy.

Drawing from feminist and PAR insights, I refused to see the people I interviewed as "mines of information" rather than people (England, 1994, p. 82), nor of myself as "a mysterious, impartial outsider, an observer freed of personality and bias" (p. 81). Greenwood and Levin note that although it should be common knowledge that studying people is different to studying rocks, molecules and other physical objects, it is amazing "that so many conventional social scientists still place [emphasis] on the claim that being "scientific" requires researchers to sever all relations with the observed" $(2005$, p. 53). Indeed, Fontana and Frey (2000) note that in addition to ethical motivations, this stance is also supported by methodological reasoning. Qualitative researchers argue that they get "a greater spectrum of responses and greater insight" (2000, p. 658) into participants' lives because participants can "control the sequencing and the language of the interview and [the approach] also allows them the freedom of open-ended responses ..." (p. 659). Therefore, I planned a 
question sheet with open ended questions (see appendix five), but was open to re-wording and reordering questions with the flow of interview conversations.

As recommended by Dunn $(2005$, p. 83$)$ I planned my interview design to be "dynamic throughout the research." I aimed to modify the interview schedule to suit the person I was talking to and as I gained further insight into the overall research questions. Maximising comparability in interview responses was not an appropriate goal for my research because I would not be attempting to compare data between interviews in order to find a single objective truth, but rather to get a detailed understanding of people's lives.

I took heed of warnings that an interview guide approach requires a skilled interviewer to keep the flow of the conversation going and to be able to spontaneously word questions clearly and concisely (Dunn, 2005; Kitchin \& Tate, 2000). Due to Spanish being my second language, I constructed the questions in advance to avoid a panic situation where I couldn't remember the words to express what I wanted to ask. Using an interview schedule would allow me the confidence to reword questions as appropriate, because I knew I could use it as a fall-back option (Dunn, 2005) if I stumbled with my Spanish.

I planned to conduct the interviews face-to-face to maximise opportunity to understand meaning through facial expression, body language and tone of voice. As noted by de Ishtar (2005, p. 362) "Language is much more than verbal." She quotes Ted Singelis who notes that messages are communicated through the combined experience of visual, olefactory, tactile and auditory means, and that when working in a second language reliance on these nonverbal means of communication is heightened (Singelis in de Ishtar, 2005). These extra signifiers were considered necessary given Spanish is my second language, but also as methods of enriching the data.

\subsubsection{Ad hoc conversations}

The unstructured nature of ad hoc conversations have the potential to surface completely different problems, or a different way of looking at the problems than what occurs in more structured interview settings. I hoped the relaxed structure would allow "respondents to talk about a topic within their own 'frame of reference' ..." thus affording "... a greater understanding of the interviewees' point of view" (Kitchin \& Tate, 2000, p. 215). I felt this 
method would contribute valuable data which would enrich my exploration of my research questions.

\subsubsection{Focus groups}

Focus groups can compliment interviews because they "replicate people's natural social interaction ... [and] participants may find the focus group environment comfortable and enjoyable, which is likely to impact on their contribution to the discussion" (Hennink, 2007, pp. 6-7). Furthermore, a wide range of opinions, ideas and experiences can be heard at once, and the discussion element allows people to build on the ideas of others (Hennink, 2007). I planned to use focus groups as a way to feedback to the community some of the findings from the interviews regarding which economic activities sustained the community and the range of assets in terms of skills, networks and physical assets. I anticipated opening the space for a group discussion around these findings. I planned to gauge discursive empowerment by noting the attitudes and responses to the discussion around the community's assets. If the people were interested, I hoped to hold a second focus group which would discuss community assets and those economic activities which were perceived to maintain community wellbeing. I did not end up using focus groups in this community so I won't go into further details as to the methodological plan. I will discuss in section two of this chapter, below, why I was advised against undertaking this method in the context of San Miguel.

\subsubsection{Research journal}

Finally, I planned to use a research journal as a record to keep track of what I did and when, as well as recording thoughts, feelings and insights throughout the research process. I have used this research journal to enrich my findings and analysis in relation to my research questions.

\subsubsection{Linguistic and cultural understanding}

In terms of linguistic and cultural preparation I travelled through South America for seven months in 2008. This included six weeks in Bolivia, and three weeks in Sucre where my base was the same home-stay I returned to for this research. This period of travel introduced me to the Spanish language, but also on a small scale to some of the dynamics of Bolivian culture. I continued studying Spanish prior to leaving New Zealand at university and through 
private lessons. Although I was not fluent, I had strong conversational skills by the time I arrived in Bolivia to carry out this research. These skills continued to improve with the Spanish lessons I took in Sucre and the higher level of immersion in a Spanish speaking locale.

However, understanding linguistic and cultural nuances was further complicated by the likelihood that I would be working with an indigenous community. Many indigenous communities are bi-lingual (Spanish and Quechua or other indigenous language), however I knew very little about the indigenous cultures and did not speak their languages. Like Veeck (2001), I was aware that critics argue that outsiders will never be culturally and linguistically fluent, but that is no reason not to conduct research nor to stop continually attempting to improve one's cultural and linguistic fluency. In this situation I decided to learn while doing, while being clear that my understanding of the cultural nuances of Bolivian Spanish was not perfect and of Quechua I knew very little.

\subsubsection{Finding people to talk to}

In order to locate a contact to introduce me to a community to work with I planned to draw on the contacts I had made the first time I was in Sucre and from there rely on "luck" and "the kindness of strangers" (Price, 2001, p. 144). However I do not refer to luck in the sense of idly waiting for the ideal research location to fall into my lap, rather in accordance with Price (2001, p. 144) I took the approach that, "... luck usually comes from building contacts and relationships in the places where we do our research, by talking with people about our work and involving them in it, and by finding ways to give back to the people who help us." This is sometimes referred to as "snowballing." The researcher starts with one contact who can then connect the researcher with another person who can then put the researcher in contact with further people, resulting in a snowballing effect (Valentine, 2005).

\subsubsection{Choosing a location}

My intention was to explore a way to practice development that fostered an enabling environment for a community to explore its own potentials and strengths and I felt GibsonGrahams' $(2005 a, 2006)$ theoretical tools might allow me to do this. I was interested in places that might be considered economically less well off because these are the places traditionally targeted by development interventions. By showing that such locations rely on a diverse range of economic activity (not just capitalist), and are already multiply resourced in terms of skills and assets, I hoped to challenge the practice of constructing economically 
poor localities as helpless and in need of foreign solutions. Furthermore, while I was realistic regarding my capacity to create positive change, I was hopeful that these theoretical perspectives and practices might be advantageous to an economically less well off community by suggesting the possibility of multiple pathways for improving wellbeing.

In summary, I aimed to locate a community to work with, allowing time to gain formal permission and to discuss ways that the research might be structured appropriately according to local indigenous protocols. I then planned to either carry out a methodology jointly developed by the community and I, or if the community preferred, to rely on my design by carrying out approximately 20 interviews and one or two follow up focus groups to explore my research questions. I planned to supplement this data with observations and insights gained from informal conversations and my research journal. Figure 4.1 below summarises this research plan.

\begin{tabular}{|l|l|}
\hline \multicolumn{2}{|c|}{ Figure 4.1: Research plan summary 1 } \\
\hline Research activity & Time needed \\
\hline $\begin{array}{l}\text { Find a community to research with, gain formal } \\
\text { permission to do research, discuss ways to make } \\
\text { the research appropriate and useful to the } \\
\text { community. }\end{array}$ & $3-4$ weeks \\
\hline $\begin{array}{l}\text { If appropriate, carry out interviews with around } \\
20 \text { community members }\end{array}$ & $5-6$ weeks \\
\hline Collate data from interviews & 1 week \\
\hline $\begin{array}{l}\text { If appropriate, carry out 1 or 2 focus groups } \\
\text { discussing the data collected from the interviews. }\end{array}$ & 1 per week over 2 weeks \\
\hline Informal conversations & Throughout fieldwork \\
\hline Research journal & Throughout fieldwork \\
\hline
\end{tabular}

\subsection{Section two: re-negotiated methodology}

This section covers the process of negotiation between the research context, theoretical epistemological and methodological lenses, and personal considerations which structured my research in ways that diverged from my original plans.

\subsubsection{Making contacts and finding a community to work with}

The plan to locate a contact to introduce me to a community by building contacts and relationships in the place I wanted to do research (Price, 2001) worked well. Shortly after 
arriving in Sucre at the end of March 2010, I was introduced to Alejandra ${ }^{7}$ who suggested it might be possible to carry out research in her rural community, San Miguel. Alejandra lives part of the year with her family in Sucre and part of the year at her home in the rural community of San Miguel located approximately six hours drive from Sucre. The population of San Miguel is 90 people, and the population of the surrounding sector of nine communities is around 700 people. ${ }^{8}$ The people, who are largely of Quechua indigenous decent, are commonly referred to as campesinos. ${ }^{9}$ They are mostly agriculturalists cultivating maize, potatoes and other vegetables for sale in local and regional markets.

The community of San Miguel struck me as appropriate to do my research with for several reasons. First, I had met a contact who was well known in the community, interested in the research and keen to introduce me to other community members who might be interested in participating. Second, working with a rural indigenous community meant that indigenous economic customs were more likely to still be practiced, as I was discovering that some indigenous economic systems were not commonly practiced in the cities. Third, Alejandra has been carrying out development projects in San Miguel for the last 20 years and her latest work involved coordinating cultural exchanges between San Miguel residents and Canadian youth. Indigenous people in Bolivia are often shy and cautious of foreigners, so I felt that working with a community that was accustomed to foreigners could facilitate ease of communication that I might not easily find elsewhere.

\subsubsection{Formal permission and localisation}

Alejandra and I had many informal conversations regarding gaining formal permission from the community, and how I might structure the research so that it was ethical, relevant and appropriate for the people of San Miguel. She felt that if at all, I should attempt to gain permission from community members on a person to person basis, and was clear in her opinion that I should not change the focus of my research. While I agreed that official consent forms were sometimes more of a protection mechanism for the institution rather than the research participants (Louis, 2007), I held that the ethical principles behind informed consent of some kind were of key importance. From the perspective of the ethics committee at Victoria University of Wellington, formal consent should be acknowledged at

\footnotetext{
${ }^{7}$ Pseudonym.

${ }^{8}$ Data from a personal communication with Lucia (pseudonym), the doctor responsible for the area (Lucia, 2010).

${ }^{9}$ Country people.
} 
the individual level (Research Policy Group, 2007). Research participants should have the research explained to them in addition to how the information they provide will be used. This is so they have an opportunity to give informed consent to participate in the research if they so choose. I wrote up information sheets and consent forms which can be viewed in appendices one to four. As noted in my application to the ethics committee, I used these forms when it was culturally appropriate. When collaborating with illiterate community members it was an inappropriate form of communication and could be seen as intimidating. In these instances I verbally communicated the content of the information form and requested verbal confirmation of consent from community members.

Given my commitment to indigenous methodological understandings of ethical research, I felt that it was important that the whole community was aware of and in support of my presence in their community, and gaining formal community level permission was one way of achieving this. However I also wished to respect the wishes of my host, I did not want to seem ungrateful for her generosity at hosting me and introducing me to other community members. As a result of this I did not push for community level consent or overtly seek to mould the research aims to local indigenous objectives.

Therefore I fell back on my second methodology plan while still attempting to adhere to the broader recommendations of indigenous methodology in all aspects of my research. I thought that I could still attempt to conduct the research respectfully, attempt to ensure the research had meaning that contributed to the community and incorporated indigenous perspectives through the individual interviews and informal conversations. I attempted to show respect by familiarising myself with local indigenous customs such as always accepting food that is offered to me as a guest. I accepted advice from Quechua friends in Sucre that I could attempt to give back to the interviewees on a small scale by bringing small gifts of food and allowing time for them to ask me questions. I hoped that my research questions which focused on community strengths would have meaning that was valuable to the community and would capture the indigenous perspective.

The second methodology plan was also altered due to the circumstances in San Miguel. Alejandra highlighted that it would be impossible to conduct focus groups or any other form of group research. She argued that it was simply too difficult for community members to commit the time and energy necessary to transport themselves (by foot) to one place at one 
time, given their duties and responsibilities to work the land and care for their families. However, I was confident that it would still be of value to explore community economies through individual interviews. I reasoned that I could possibly attempt to give back to the community by feeding back results from the interviews and allowing a space for discussion of these results through second individual meetings/interviews. Alejandra and the community members I spoke to were happy with this arrangement.

\subsubsection{Finding people to talk with}

The six community members from San Miguel that I conducted interviews with during my ten day stay were selected by Alejandra because of their ability to speak Spanish. My ability to communicate with community members provides a clear example of how research is situated between the social worlds of the observed and the observer (Denzin \& Lincoln, 2005). I was unable to verbally communicate with non-Spanish speakers. This framed which community members I could collaborate with. As noted above, I was interested in speaking to adult men and women because I perceived that people of different ages and genders would participate in different economic activities and could have different opinions regarding community assets. Talking to a range of people would allow a rich picture of the diverse economy and the community assets in San Miguel.

I carried out semi-structured interviews with three campesinas ${ }^{10}$ Luisa, Guadalupe and Sara ${ }^{11}$; the local doctor, Lucia; and the two teachers, Eduardo and Sofia ${ }^{12}$ at the local school. The interviews lasted between 45 minutes and two hours. The three campesina ranged in age from early 20 s to late 40 s and were all mothers, agriculturalists on their family plots, and carers/nurturers for their families. These women participated in the indigenous economic systems of reciprocity, community volunteer labour days, the informal market, household flows and other diverse economic activities. I spoke to the teachers, a husband and wife team and the doctor, a family woman. They participated in different economic activity and thus represented a different aspect of the diverse economy. As state employees their labour was regularly remunerated with a formal salary. Furthermore, the teachers and the doctor were relevant to interview because of their experiences with foreign aid and development projects, further elements to be noted in the diverse economy. I will discuss in more detail

\footnotetext{
${ }^{10}$ Rural indigenous women

${ }^{11}$ Pseudonyms

${ }^{12}$ Pseudonym s
} 
the diverse economic activities I discovered in Chapter six. However I felt it was appropriate to talk to all of these community members to gain an in-depth understanding of their subjective experiences, opinions and ideas in their own words, in order to gain rich data with which to explore my research questions.

\subsubsection{Interview location and power dynamics}

The interviews with two of the campesina women were conducted at their houses, because this was convenient for them. I also felt that it would contribute to lessening any perceived power disparities because the interview would be carried out in what I assumed would be a familiar, comfortable environment for them. The teacher's interview was carried out at the school for similar reasons. However the interviews with the doctor and the third campesina woman, Luisa ${ }^{13}$ were held at Alejandra's house as this was the most convenient location for them. Alejandra was present during these interviews (with the consent of the two women). I didn't feel entirely comfortable with this arrangement, because it meant responses would not be confidential, and I was concerned about power dynamics affecting interviewee responses. However, I felt I couldn't ask Alejandra to leave her own house. Power dynamics did not appear to be an issue when I interviewed the doctor Lucia, however I noticed Luisa's responses were affected. Luisa deferred to Alejandra and Alejandra interjected at several points through the interview. Although both Alejandra and Luisa appeared comfortable with this arrangement, I felt the differential power and positionality of Alejandra and Luisa was exacerbated by the location of Alejandra's house and affected the confidence and content of Luisa's responses. Alejandra employed Luisa on a casual basis, was 35 years older than Luisa and had a university education where Luisa had completed primary school.

Elwood and Martin (2000, p. 655) note how "Different sites may serve to define a participant as having valuable knowledge to contribute, or, conversely, can constitute the researcher as holding expert knowledge." Or in this case, the site may have contributed to Alejandra being constituted as having expert knowledge. It is clear that other factors such as personality could have contributed to the power disparity. Comparing Luisa's responses and body language to those of the other two campesina women I interviewed indicates that a different interview location, such as Luisa's home might have resulted in different responses. Such a location would possibly have been more empowering as she could have constituted herself more confidently as having knowledge and expertise about her life and the economic

\footnotetext{
${ }^{13}$ Pseudonym
} 
activities she participated in. This assumes that she would constitute herself this way in her home, but the key point is that the "microgeographies" (Elwood \& Martin, 2000) of the locations of the interviews affected the responses I received, and impacted the epistemological aims of empowering those with whom I carried out research.

\subsection{Leaving San Miguel}

I stayed in San Miguel for an initial period of ten days. I decided to leave and search for a second research location because a colleague of Alejandra's, Juan ${ }^{14}$, who had become heavily involved the research, propositioned me. Although some researchers have taken advantage of "being constructed as an object of desire" (Cupples, 2002, p. 383) to further their research aims (e.g. Cupples, 2002), I felt uncomfortable and disempowered. These feelings of discomfort were compounded by the remote location of the community, Juan's much older age and marital status, and the close living quarters in Alejandra's house, where he was also staying. Furthermore, I felt uneasy being constructed this way given he was a gatekeeper on whom I was partially dependent to introduce me to other community members.

I felt conflicted. On the one hand, I was concerned that I was over-reacting, that this was a normal part of life and that I shouldn't let it get in the way of a good research location. On the other hand, I felt that this was a compromise of my trust, I was in a remote location and I was potentially vulnerable. Furthermore, my epistemological and methodological commitments to attempt to give back to the community, along with feeling pressure from the university to complete the thesis within the one year framework, ${ }^{15}$ meant that I was unsure about leaving. I considered seeking out alternative accommodation, but there weren't any viable alternatives and I thought such a change might be difficult to explain to Alejandra, Juan and the community. In leaving, I had to abandon the collaborative aspects of research I sought because of the difficulty of communicating long distance. However, I will still attempt to send a summary of the research to the teachers and ask them to share it with other community members involved in the process.

\footnotetext{
${ }^{14}$ This is a pseudonym and parts of this story have been skewed to protect this person's identity as discussed with my supervisor.

${ }^{15}$ Victoria University Policy states that students are able to take up to 18 months to complete their thesis, with allowance for a 28 day grace period (Research Policy Group, 2011). However, the School of Development Postgraduate Prospectus 2011 indicates that students should take up to a year to complete their thesis (Victoria University of Wellington, 2011).
} 
On returning to New Zealand and reflecting on this event and others throughout my fieldwork, I realised that I was so concerned with ensuring that my research was ethically sound and not exploitative for the research participants that I neglected to thoroughly consider my own safety. The implication I initially got from the literature on qualitative research was that "as field-workers we need to exercise common sense and responsibility, ... to our subjects first, to the study next, and to ourselves last" (Fontana \& Frey, 2000, p. 663, my emphasis).

On closer inspection of the literature I have come across others who have noted that it is not always the researcher who is in a position of power (e.g. Chacko, 2004; Mandel, 2003; Sharp, 2005; Thapar-Bjorkert \& Henry, 2004). Sharpe $(2005$, p. 307) notes how despite conceptions of the "western fieldworker" as powerful, "one can feel entirely powerless and dependent upon others and their better knowledge of challenging, or simply very different, environments, languages and customs." She goes on to argue that the presentation of research methodology often does not detail the physically or emotionally overwhelming, embodied challenges that frequently occur in the field. So in addition to enriching the final presentation or bricolage (Denzin \& Lincoln, 2005) with more texture and detail, these challenges affect the way we view the field, and are therefore valuable markers of how the research was shaped. In my case, the specific challenge I faced of being propositioned in the field, led me to (eventually) realise that, like Mandel (2003), I had overlooked my own wellbeing in favour of the research. I had not expected to be "constructed as an object of desire" (Cupples, 2002, p. 383). This was a challenge that resulted in feelings of disempowerment as a researcher and eventually to a change in research location.

\subsection{Conclusion}

This chapter has sought to achieve two objectives. Firstly to detail the methodology and methods with which I sought to explore community economies (research question one). Secondly to interrogate the process of carrying out research with particular attention to how the research context affected research outcomes (research question two).

That I went to San Miguel and carried out five semi-structured interviews, numerous informal conversations and a daily research journal in order to collect data to explore my 
research questions is an outcome based summary of my research in San Miguel. However, leading up to these outcomes is a complex web of negotiations and compromises between my theoretical, epistemological and methodological lenses, along with other university time pressures and restrictions; between the preferences and possibilities of the community and for Alejandra, my contact; and my own personal preferences.

In deciding to go to San Miguel I prioritised advice (both local and theoretical) that having a contact to introduce you to other community members was of key importance to practicing ethical research. The decision to go was also partially motivated by the understanding that I had a limited amount of time in Bolivia in which to carry out my research. My own sense of pride to carry out good substantive research was coupled with my commitment to my university and to scholarship funders to produce a research based thesis. I could not commit too much time to searching out the 'perfect community' that ticked all the boxes. Yet the decision to carry out research with community members in San Miguel resulted in compromising indigenous methodology ideals that seek fully collaborative research. It also resulted in adapting my plan to hold focus groups due to the inconvenience it would cause for local people.

Yet on a positive note, the negotiation of the research process then fostered creative thinking: how could I best explore my research questions within the parameters of my epistemological and methodological lenses, community possibilities, and university requirements? I reasoned that I could achieve these objectives to a certain extent through follow up individual interviews. However this plan was also disrupted when I left San Miguel due to an event that left me feeling unsafe and disempowered as a researcher. Although my epistemological and methodological plans indicated that I should adapt my research to suit the context, I was surprised at the extent to which I had to negotiate between different parameters throughout the process of carrying out the research.

Work within feminist and indigenous methodology has contributed to increasing attention being paid to ethics and politics throughout the process of carrying out research (e.g. England, 1994; Underhill-Sem \& Lewis, 2008). In extension, I think that greater attention should be paid to the ways in which the research plan is negotiated, compromised and adapted by multiple parameters throughout the research process. As students we are advised that "Good planning is critical, but even with careful arrangements and organisation, 
successful fieldwork requires flexibility, a capacity to adjust to unexpected situations and competent juggling of diverse identities in varied situations" (Chacko, 2004, p. 53). However like Mollinga (2008) I found that the majority of research presents a 'sanitized' methodology which does not include instances where the researcher was required to be flexible, or to adjust to unexpected situations. If most research involves such flexibility, and if subsequent negotiation results in significant shaping of the research, then more attention should be paid to this when reporting research outcomes. 


\section{Methodology 2: Yachakay}

\subsection{Introduction}

In this chapter, I will explain my revised methodology and methods. I will also discuss how I came to find my second research location, Yachakay. Here, I retained the indigenous methodological approach whereby I was open to collaborating with a community to design research that suited their needs and wants. My alternative plan was modified to include a PAR approach in an attempt to fine tune my methodology and methods to better investigate community economies. This new plan involved carrying out a number of interactive and collaborative research methods designed to uncover the diverse economy and community assets and open spaces for discussion where alternative economic futures might be imagined and enacted.

A further objective of this chapter is to juxtapose my formulated plan with what was eventually negotiated between the timetables and preferences of the community members, the epistemology and methodology of the research and university frameworks and guidelines. This section responds to research question two asking how research contexts affect research outcomes. In particular, I will focus on the complexity of power dynamics within different research contexts. I will conclude the chapter with a discussion on why a more nuanced understanding of power negotiations in different research contexts can contribute to a more respectful approach to the diverse personalities and motivations of research participants.

\subsection{Section one: The new plan}

\subsubsection{New Methodology: Participatory Action Research from a post-structuralist perspective}

Whilst trying to organise a second research location, I read and revised my methodology. On reflection I found the methods I had employed in San Miguel were not robust enough to uncover the diverse economy, or community assets in sufficient depth, breadth or detail. This may have indicated a need to fine tune my interview guide (see appendix five) to draw 
out more elements of the diverse economy and community assets. However, it could also have been related to having a lack of time to build meaningful rapport and trust with community members of San Miguel. I decided I needed to investigate other ways to explore community economies. Because my research questions were grounded in the theory and practice of Gibson-Graham and Cameron (Cameron \& Gibson, 2005; Gibson-Graham, 2005a, 2006,2008 ), it made sense to draw on their methodology and methods. However, as noted in Chapter three, I did not come across Cameron and Gibson's (2005) paper until part way through my research. This work, which followed a PAR process of documenting the situation, contextualising the situation and working towards change, allowed me to investigate my research questions more robustly, while meeting an increased number of epistemological objectives.

Cameron and Gibson's (2005) use of PAR is founded on the principle that social research is political, not only does it represent reality but it constitutes it. In their research in the Latrobe Valley in Australia, they attempted to uncover success stories involving diverse economic practices. While an increasing number of artist and artisan co-operatives and nonprofit enterprises had begun to emerge, these initiatives were rendered invisible by the defining role of the recently restructured State Electricity Commission (SEC) in the area. They note how the local understanding of the Latrobe Valley as 'decimated' does not allow residents a sense of economic possibility. Conscious of the power of language and representation, they sought understandings of the local economy that created a sense of possibility. This involved uncovering and communicating all the alternative economic practices within a community.

I continued to feel concerned about the ethical legitimacy of my research given my positionality as a non-indigenous, non-Bolivian researcher, so this post-structuralist perspective contributed to the possibility for an ethical positioning of me as a nonindigenous, non-Bolivian researcher. This journal entry is indicative of my continued feelings of discomfort:

"I always feel so nervous when presenting my research to people and asking if I can work with them, ask them questions etc. By implication am I saying they are underdeveloped? What are they thinking when I tell them I'm studying development studies?" (Rushton, 2010, 11/5/2010) 
The combination of the post-structural and indigenous epistemological theoretical perspectives helped to reconcile the legitimacy of an outside development practitioner contributing to positive change within a community. The community economy approach is grounded in local knowledge, perspectives, and visions for the future, but draws on poststructural insights to acknowledge that these factors are multiple, in constant formation, and not always transformative. The role of the post-structuralist researcher "involves carefully interrogating the potential effects of different languages and representations, and self-consciously selecting particular representations because of their potential political effects" $(2005$, p. 318). So, a foreign researcher or development practitioner can contribute by offering a perspective that highlights the diverse knowledges, perspectives, and visions for the future, and prompts a critical discussion around which of these are positive and transformative.

\subsubsection{Documenting the situation}

The aim of documenting the current situation is "to make explicit the prevailing local representations and knowledges" (Cameron \& Gibson, 2005, p. 321) of the community. I planned to emulate Cameron and Gibson's (2005) research method of community researcher produced photo essays. The photo essays produced by Cameron and Gibson's (2005) community researchers told a story of their lives in the Latrobe Valley. Community researchers were selected through a process which targeted groups hardest hit by the restructuring of the SEC in the area. One of the community researchers, an unemployed ex SEC worker, constructed a photo essay which told his story. It contained pictures of unused mining equipment, empty parking lots and vandalised bus shelters at old SEC sites in one corner, and in the other corner 'growth industries' of pawn and thrift shops, and vacant stores could be seen. The essay connected to feelings of loss, abandonment and a lack of options for a bright future. The photo essay allowed the community researcher to present his understanding of life in the Latrobe Valley. I planned to draw on this method to gain an understanding of the local knowledges and representations of life in the community.

\subsubsection{Contextualising the situation}

Contextualising the situation involved trying to elicit stories or understandings about alternative economic activity or community assets that could have the potential to be transformative. Because I aimed to work with an economically less well off community, I assumed I would find prevailing local knowledges or understandings of a poor community 
with limited options for getting ahead. In my role as a post-structuralist researcher, I aimed to search out the diverse economic activities that sustained this community. Through representations of the diverse economic practices and community assets I hoped to help create ways for the community to imagine alternative possibilities.

I decided to use the photo essays as opening points for focus group discussions that would attempt to explore the already existing diverse economy within the community. This would involve holding discussions that might uncover other economic activities taking place in the community. As noted in Chapter two, such activities might include unpaid work such as housework, or work around the neighbourhood, or non-market transactions such as exchanging childcare services or agricultural/horticultural produce, or work in the volunteer sector such as time donated to NGOs or other organisations. The aim of this activity was to learn about the diverse economy and in exposing it, create a perspective of the community as already viable and productive.

A second approach that was used in the contextualising phase drew on an asset based community development $(A B C D)$ approach developed by John Kretzman and John McKnight (1993 in Cameron \& Gibson, 2005). In addition to highlighting the physical assets such as disused buildings and run down parks, and institutional assets such as schools and hospitals, it was important to include "the abilities and skills, dreams and passions of those groups in the community who are most readily thought of in terms of needs" (Cameron \& Gibson, 2005 , p. 324). To draw out these skills, dreams and passions, I planned to translate and adapt Cameron and Gibson's (2001) adaptation of Kretzman and McKnight's Portrait of Gifts (1997 in Cameron \& Gibson, 2005). The Portrait of Gifts is a questionnaire which collects data regarding community member's everyday skills and abilities such as cooking, child care, household repairs and animal care as well as their dreams and passions. I planned to use the questionnaires as prompts in a second focus group and welcome people to share any skills, dreams or passions they wanted to share. The idea was to bring to the surface, and to communicate among community members all the positive things people are doing, to provide proof that the community is full of effective people participating in a variety of activities within the community. This way I planned to build a picture of community members as already capable, active citizens. 


\subsubsection{Working towards change}

The third stage, working towards change, involved building on these stories and understandings to imagine and enact new economic subjectivities (Cameron \& Gibson, 2005). I planned to organise a group discussion that would reflect on the results of the Portraits of Gifts, and explore options for "collective possibilities" (2005, p. 325). I wanted to reproduce Cameron and Gibson's (2005) atmosphere of fun, trust building, creativity and exploration that they created by inviting everyone to make scones or pizza together. This is important from a post-structuralist perspective because positive transformation is theorised to involve both macro and micro politics. Searching out the positive perspectives of the community that might enable alternative futures to be imagined represents addressing the macro politics. However, the micro politics of how a person understands themselves is also considered to be important. Cameron and Gibson (2005, p. 320) seek to tap "into positive emotional registers that promote pleasure and creativity and enhance the likelihood for shifts in identification." They have sought to do this by "harnessing the creativity of more everyday events that might inspire previously unknown possibilities and increase a willingness to explore different ways of being in the world" (p. 320). I planned to discuss with my community contacts what might be the best way to emulate a relaxed, fun atmosphere in a Bolivian context. Within this context, I aimed to promote discussions around the results of activities to this point, which should have constructed a perspective of the diverse economic practices and community assets that sustain community wellbeing. I then planned to extend the discussions into an exploration or 'brainstorming session' into options for collective possibilities.

I planned to see how this initial activity went and whether any ideas for "collective possibilities" were formed that people wanted to pursue. If the community members were interested and if I could locate suitable experts, I planned to organise a 'how to' workshop (Cameron \& Gibson, 2005) on specific economic or community project ideas that might have come out of the group discussions. Further, if there was interest and I could arrange it, I planned to organise fieldtrips (Cameron \& Gibson, 2005) to successful examples of the economic ideas to come out of the group activities. Through these brainstorming sessions, 'how to' workshops and fieldtrips, I hoped that people could draw on their diverse strengths and capabilities to imagine and enact alternative economic pathways. 


\subsection{Section two: Negotiating a research project in Yachakay}

\subsubsection{Finding some new friends to work with}

Over the next couple of weeks I investigated possible alternative locations for research. While I attempted to keep several options open throughout the duration of my stay in Sucre, the community I eventually focused most attention on was Yachakay, a relatively new neighbourhood on the outskirts of Sucre. My search for a new research location had led me to a resident of this neighbourhood, Delia Beltran ${ }^{16}$. Delia is a Spanish, English and Quechua language teacher, who had been holding Spanish lessons with an Australian couple at the home-stay we were staying at. Delia and I had 'hung out' several times before I thought to ask her for help with my research. Furthermore, we had several language exchanges ${ }^{17}$ leading up to my first period of field work in San Miguel, during which I had sought her advice on conducting ethically sound research in an indigenous Bolivian context, so she was familiar with the broad theme of my research.

Through initial conversations with Delia and her husband Alberto I learnt that Yachakay is a small neighbourhood of approximately 26 households located on the outskirts of Sucre, the constitutional capital of Bolivia. The people of Yachakay are mostly of Quechua indigenous decent, although there are some Aymara indigenous residents too. People are largely employed in the informal economy, with women mainly working as domestic employees for wealthier people in the city and men as construction workers. Many of the residents have small plots of land which are used to grow flowers, herbs and vegetables to supplement their incomes. Many households also raise a number of animals such as cows, sheep, goats, pigs and chickens which are mostly kept for household consumption rather than for sale. I saw Yachakay as appropriate to collaborate with for many of the same reasons discussed in Chapter four, with one obvious difference. Yachakay's greater proximity to the city of Sucre meant greater possibilities for participation in the capitalist market economy. I thought that it would provide an opportunity to explore how the increased access to, or at least proximity to the capitalist market activity benefited the wellbeing of these people.

\footnotetext{
${ }^{16}$ Delia and Alberto's real names are used with their permission.

${ }^{17}$ A language exchange is an informal meeting where two (or more) people are each trying to learn a language the other is fluent in. In our case it often involved meeting up over lunch and chatting in Spanish for 30 minutes and then English for 30 minutes.
} 


\subsubsection{Formal permission and localisation}

I approached Delia and broached the subject of doing research with her and her community. We organised a meeting to discuss further details of the research. Attempting to uphold indigenous methodology principles, I treated this first meeting as an initiation of dialogue in which I presented a detailed plan of the research I wanted to do, but was very clear that this was a flexible plan that I hoped could be altered and moulded to suit their interests, needs and protocols (see Menzies, 2001). Delia brought her husband Alberto, who is also a community leader in Yachakay, to the initial meeting. They appeared enthusiastic and affirmed they would investigate the level of community interest in participating. If sufficient interest prevailed they agreed to seek out permission from the community to carry out the research. In the meantime, Delia and Alberto agreed to participate in a semi-structured interview in which I hoped to get to know more about them, their community and their perceptions around my research questions. Although it was not planned in advance, data collected in this interview is used in Chapter seven to document the situation.

Forming a relationship with Delia, Alberto and the community of Yachakay was one of the most rewarding experiences of the research process. At our next meeting, Delia and Alberto informed me that the community had expressed interest and given consent for me to do the research. ${ }^{18}$ However, they were concerned to inform me that a potentially insignificant number of residents would be available to participate, and further, that no community members had the time to take on a

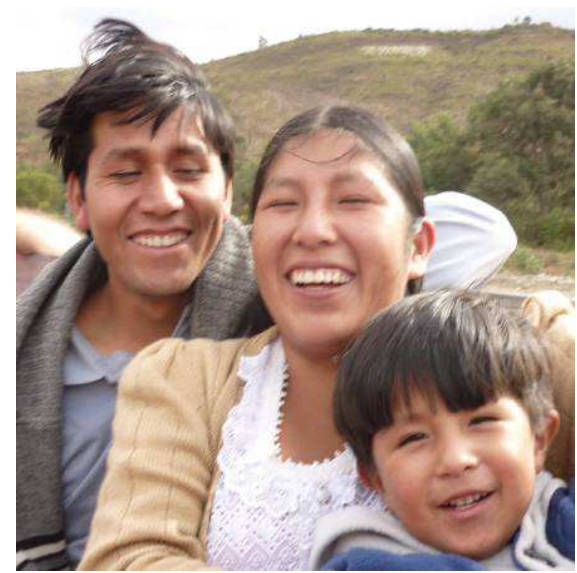

Plate 5.1: Alberto, Delia and Alaín community researcher position. In addition, community members were only available on Sunday afternoons, and the following Sunday was unavailable due to a community meeting. It was with some trepidation that I realised that at most this left the four Sunday afternoons in June 2010 before I departed Bolivia. The same nervousness that I felt in San Miguel around having the capacity to carry out collaborative research within the timeframe allowed by the university began to resurface, however I felt I had little other options at this stage other than to proceed with the research. Community members had given me permission and

\footnotetext{
${ }^{18}$ See appendix ten and eleven for a copy of the community permission form community leaders and I signed.
} 
were willing to participate, Delia and Alberto were enthusiastic in helping me, and the community seemed like a good location to explore my research questions and seek positive change.

\subsubsection{Community researchers}

Delia and Alberto played a central role in the research process and their roles can be described as incorporating aspects of research collaborators, community researchers, translators and cultural consultants. Some authors have highlighted the lack of attention given to the positionality of research assistants and translators and their influence on the research (e.g. Turner, 2010). Delia and Alberto are young (mid to late 20s) indigenous Bolivians of Quechua decent. They both grew up in modest backgrounds, and have worked hard at completing secondary and tertiary education in order to pursue their careers of choice. Delia has a Bachelor in Communication for Journalism and Languages and is currently working as a language teacher. Alberto is currently studying towards a Bachelor in Languages, works as a carpenter of fine furniture and dedicates much time to his role as a community leader. Delia and Alberto's tertiary education differentiates them from some other community members of Yachakay, who did not have the same level of education.

Delia and Alberto were partially motivated to help me out of empathy for my difficult task. Delia in particular, having recently completed research as a component of her university degree, was aware of the difficulties involved and empathised with my situation of doing research in a foreign culture. I felt that these factors, along with Delia's work teaching Spanish to tourists, and the fact that we had built a friendship, contributed to the normality of my positionality as a foreign researcher and facilitated a solid research friendship based on mutual respect and empathy. These factors contributed to the need to form a more nuanced understanding of the power dynamics in research. Feminist and indigenous perspectives often construct power as being in the hands of the researcher (but absent from the researched). I had considerable power in terms of ultimately deciding the direction of the research. Yet Delia and Alberto were conscious of my relative powerlessness in a Bolivian context and of their power in terms of their ability to facilitate access to their community.

As noted earlier my plan ideally involved community researchers, but Delia and Alberto informed me that there would be no one in the community who would have the time to take on the role of a community researcher. Unofficially, however, Delia and Alberto willingly 
(and extremely generously) took on many of the tasks of community researchers. They sought permission for me to do research with their community, provided endless advice on ways to make the research culturally appropriate, translated during research activities, and hosted the group activities at their house. I came to see their role as contributing to the fulfilment of indigenous methodology requirements that research with indigenous people resemble "... fluid and dynamic approaches that emphasise circular and cyclical perspectives. Their main aim is to ensure that research on Indigenous issues is accomplished in a more sympathetic, respectful, and ethically correct fashion from an Indigenous perspective" (Louis, 2007, p. 133).

\subsection{Re-negotiated methods}

With community members only available for four afternoons and only one afternoon of group activities, I had to downscale and reorganise my plan. The initial plan involved group activities at all stages and the sequence was important as each activity built on the previous activities. I tried to retain some elements of this sequencing, yet fit activities around the constraints of community members. I eventually carried out Portraits of Gifts questionnaires, a community mapping exercise, a brainstorming exercise and semi-structured interviews. I will discuss the reasoning behind the choice of each research activity and the sequencing in more detail in the following paragraphs.

\subsubsection{Research day one: Portrait of Gifts}

The Portrait of Gifts questionnaires were carried out on the first Sunday. According to the post-structuralist PAR model I was following, this activity should have fallen into the second, contextualising phase, following activities that documented the current situation. However community members preferred to carry out only one day of group activities as this was more disruptive than other research methods. Furthermore, I felt that carrying out the questionnaires could be a relaxed way to introduce myself to community members and to invite them to participate in other research activities. I set aside the first Sunday to carry out these questionnaires at community members' houses.

Beginning with Cameron and Gibson's (2001) Portrait of Gifts, I adapted the questions to be appropriate to Yachakay. I sought advice from Bolivian friends in Sucre, as well as Delia and Alberto regarding how best to do this (see my adaptation, appendix seven). My version 
included all the same section headings, but the specific questions that fell under some of these headings were altered. I took out questions that seemed inappropriate, for example experience videoing, or using commercial cooking equipment. I tried to make questions culturally relevant. I asked Bolivian friends to proof read the questionnaire and carried out a test run. The first questionnaires that were carried out were also treated as test runs. There were a few distracting grammatical errors, which were verbally corrected in the following questionnaires.

\section{Who, where, and how?}

Similar to the situation in San Miguel, the community members with whom we carried out the Portraits of Gifts questionnaires were selected because they were adult ${ }^{19}$ men or women who participated in some form of diverse economic activity. As this requirement covered most people, it came down to finding community members who were interested and available to collaborate with me on these questionnaires. Delia and Alberto guided me around the neighbourhood to people they thought might be interested, and took time to introduce me and my research topic and gain informed consent. Therefore, who we spoke to was restricted to those community members Delia and Alberto had connections to and were available and interested in participating.

I attempted to sway micro-geographies of power in favour of community members by carrying out the questionnaires in front their houses. I assumed this would be both convenient and more likely to be a location where the community members would feel empowered (rather than a café in the city for example). Furthermore, I preferred to complete the questionnaires in person because this promoted subsequent discussion around the skills, abilities, dreams and passions of community members (Cameron \& Gibson, 2005).

The Portrait of Gifts questionnaire successfully collected information regarding sixteen Yachakay community members' everyday skills, passions and aspirations for the community. Through the process of carrying out the questionnaires I hoped to begin to communicate an

\footnotetext{
${ }^{19}$ I carried out the questionnaire with one 13 year old at other community members' suggestion. Permission was granted for the girl to carry out the questionnaire by her mother, who was present throughout the process.
} 
understanding of Yachakay community members as multiply skilled. I aimed to build on this understanding in the remaining research activities.

\subsubsection{Research day two: Community mapping and brainstorming}

I held two group activities on the second Sunday, a community mapping exercise and a brainstorming session around the results of the portrait of gifts. I conceived the community mapping exercise as partially documenting the situation as it would allow community understandings of current situation to surface. However I also positioned it as part of the contextualising phase, as it was a process of mapping the physical assets of Yachakay and thus beginning to build a picture of the community as resourced.

Yet because I could only hold one day of group activities, and as it was also important to challenge and extend these prevailing understandings in a group setting, I also carried out a group brainstorming exercise. Ideally more time would have been spent discussing community members' assets and economic activities and trying to build on positive feelings of hope and possibility in focus groups. Unfortunately there was insufficient time and I had to decide between equally important group activities. I chose the brainstorm activity as I thought it could potentially achieve aspects of contextualising the situation and working towards change.

\section{Community mapping}

As noted above, I had planned to organise community researchers to create photo essays that told stories of their life in Yachakay. Delia and Alberto initially agreed to do this and began taking photos with the disposable cameras I provided. However, these instructions were vague and conceptual, and they had not fully understood the purpose of the activity. Eventually I abandoned the idea and carried on with other tasks. I replaced the planned photo essay themed focus groups with a community mapping exercise as it had potential to draw out community assets and diverse economic activity, while still being consistent with my epistemological and methodological objectives. The activity was adapted from McKinnon and McKinnon's (2010) model which involved inviting a group of community members to a suitable space to construct a map of the community out of sticks, stones and whatever materials were available. Physical assets such as buildings and roads could be added to the assets in the form of skills, dreams and aspirations that were documented in the Portraits of Gifts questionnaires. 
I felt this activity met the requirements of indigenous methodology as community members remained in control of creating the data. Therefore, it was essential that the activity was visual as this allowed all community members to participate regardless of their literacy ability level.

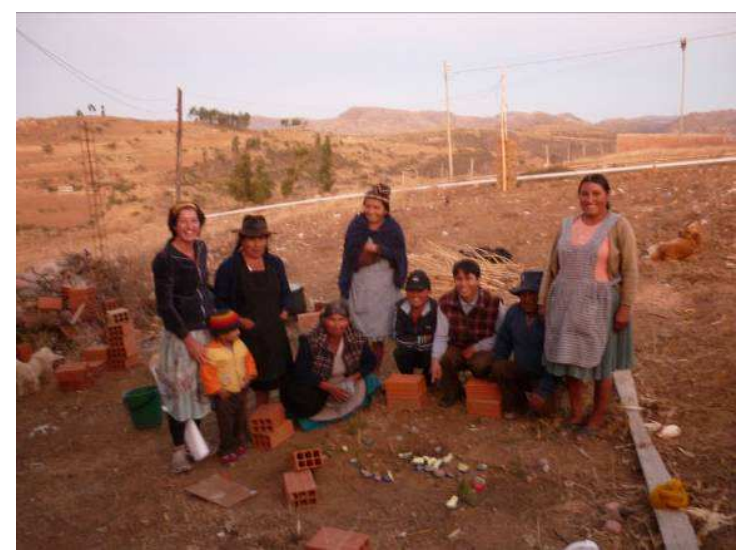

We carried out the community mapping exercise outside Delia and Alberto's house. This location was chosen because it was convenient for people to get to and we thought people would feel comfortable in the space. Delia and Alberto participated

Plate 5.2: Yachakay community members and I with the map.

and helped facilitate by clarifying my Spanish and translating from Quechua to Spanish. Nine community members participated in the community mapping exercise (see Plate 5.2), most of whom had completed a Portrait of Gifts questionnaire. I started the process by introducing myself, explaining the activity, what the information would eventually be used for and seeking verbal informed consent from everyone before beginning. Delia and Alberto preferred to participate in the activity rather than strictly facilitate or only translate. I thought this was appropriate as it would contribute to feelings of trust and comfort in community members who did not know me as well.

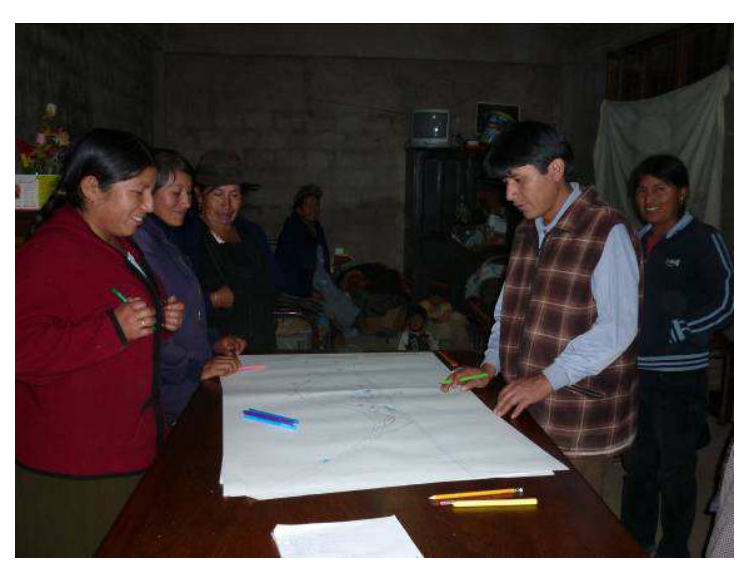

Plate 5.3: Transferring the map to paper.
Although some sources suggest that the researcher should take a "back seat" (Kesby, Kindon, \& Pain, 2005, p. 147) while participants create the diagram, I was interested in exploring the diverse economic activities that occurred in different locations on the map, in addition to the physical assets. Therefore, I attempted to draw out stories regarding the diverse economy in Yachakay by asking questions throughout the process of constructing the map. Examples of questions I asked included: Where (on the map) do you spend your time during the days? Does anyone sell anything in the community? Does anyone exchange anything in the neighbourhood? Does anyone do anything for free in the neighbourhood? I was made aware 
of the need to take a backseat because asking questions during the process seemed distracting for the map constructors and I didn't get many responses. The process of "interviewing the diagram" (Kesby, et al., 2005) in this way was more successful when community members transferred it to paper. This is a further example of control exerted by community members as they responded to my unsolicited questions only when they felt comfortable doing so.

This community mapping exercise documented a number of the physical assets of the community (such as cultivatable land). These assets will be discussed in Chapter seven. This exercise and the Portraits of Gifts exercise were used to build a picture of the community of Yachakay as skilled and resourced.

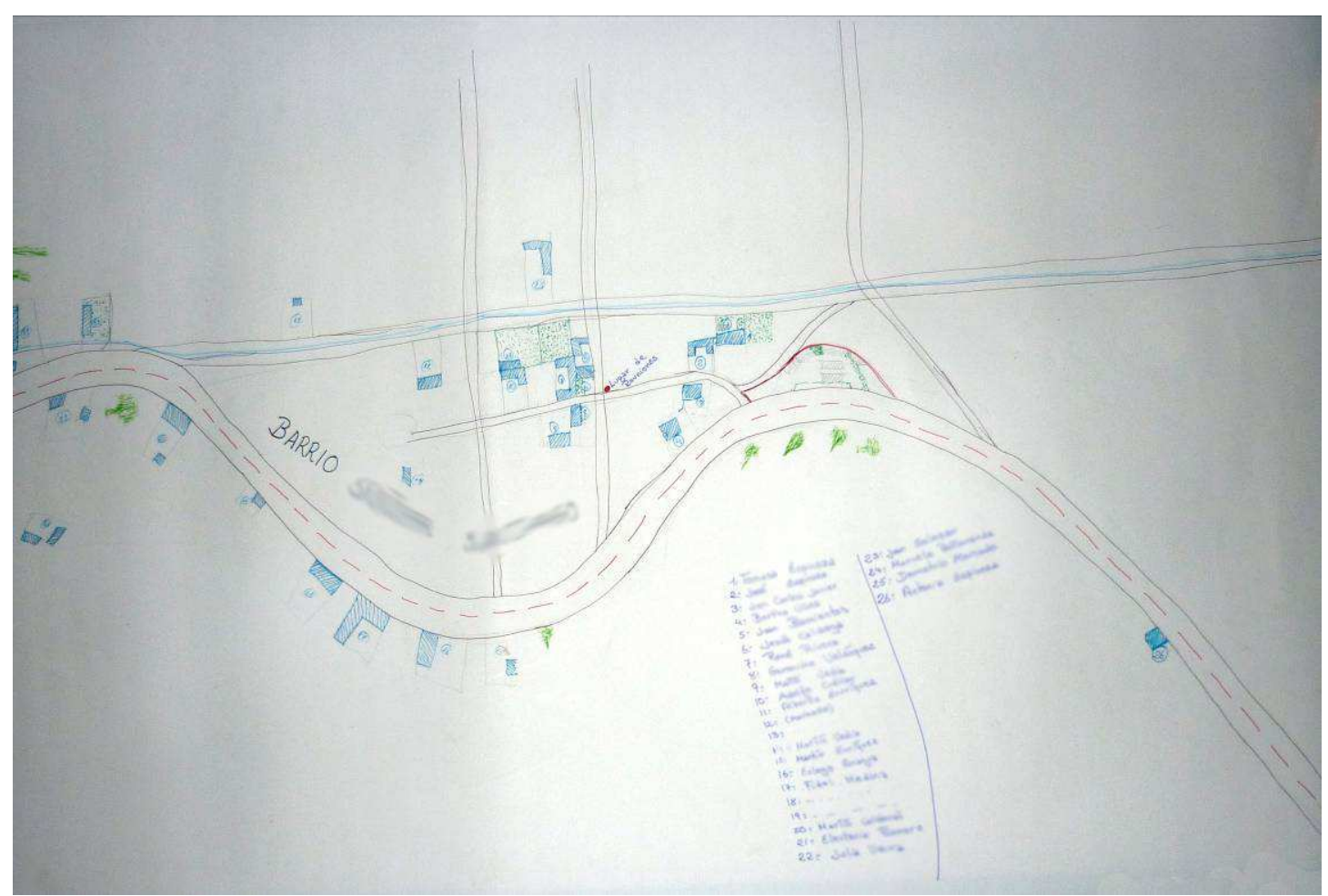

Plate 5.4: Yachakay's community map.

\section{The brainstorm activity: A community project in Yachakay}

As my second group activity I planned to hold a brainstorming activity that I hoped could achieve several objectives at once. Inspired by Cameron and Gibson's (2005) brainstorm activity, I hoped to draw on the outcomes of the mapping activity and the Portraits of Gifts questionnaire and begin to work towards opening a space for discussion around alternative economic futures. I wanted to share and build on responses to the Portraits of Gifts 
questionnaires regarding community members' ideas for community projects, passions or skills they wanted to learn. I then wanted to challenge community members to draw on their current assets, skills and abilities in brainstorming ways to bring such ideas to fruition.

Delia and I decided that researching and printing off pictures from the internet to represent these ideas would allow the activity to be both inclusive and functional. Community members who felt inadequate or unwilling to draw these images would not be asked to, and literacy was not required. There were a variety of objects and activities depicted such as potable water, street pavement, sewerage, a football field, sewing and cooking. These activities were chosen because they were highlighted in the Portraits of Gifts as activities people wanted to learn or create a project around. These images were spread out on Delia and Alberto's dining room and everyone was asked to choose the picture that represented the activity they thought best for a community project and explain why. The community members took turns at explaining their reasoning. In order to narrow the ideas down to the most popular one, Alberto suggested that we use the same voting system the community regularly uses at meetings. This involved everyone voting on each picture, with the picture with the most votes being selected to continue brainstorming.

Potable water received the most votes and everyone seemed pleased at this conclusion. I then asked people to think about possible ways the community could work towards getting potable water in their neighbourhood. Delia and Alberto responded that they could put together a proposal and take it to the local government. When I probed for other possible ways they could go about it, they suggested they could petition their national government representative. Appeals to a local business and an international NGO were also suggested. Finally they suggested that if these options were unsuccessful, they could protest based on their right to drinking water. I appealed to community members to explore other pathways to get access to potable water. All strategies proposed resembled appeals to external institutions. At the time, I considered my role to encourage the community to come up with a way that they could draw on their own assets and resources (rather than external resources) to achieve their goals. When this proposal was received with blank stares, I was taken aback. Alberto informed me in a gentle, but slightly perplexed tone, that this would be impossible. It would be far too expensive for the community to independently connect water to their neighbourhood. 


\subsubsection{Unexpected benefits and lessons}

I felt quite distressed at that point. The realisation that he was probably right hit me forcefully. In hindsight, it was incorrect of me to insist on an independent community project. Gibson-Graham (2005a)and Cameron and Gibson (2005) encourage working together with local government, local businesses and other organisations. The distinguishing factor for Cahill (2008, p. 302), was that "groups approached government agencies for technical and funding inputs only after they had ... decided what input they wanted." While I believe this outcome reflects more on my beginner stage in the learning process at the time of carrying out this activity, it is interesting to note that critics have highlighted the lack of clarity around the role intended for institutions outside the community in the community economy process. In commentaries on Gibson-Graham's (2005a) work in the Philippines, Laurie (2005), Lawson (2005) and Kelly (2005) call for more attention to scale and power. I will return to this point in Chapter seven.

Following this, I attempted to alter the activity to make it more applicable to what the community had expressed. I suggested we select a theme around which the community could create an independent project. At this point, I should have gone through the same democratic process we used to get to potable water. However, I was exhausted from the long day of shopping, cooking, communicating and observing in a foreign culture. I was flustered because I felt like the first attempt at this exercise had not worked. As a result, I forwent the democratic process of theme selection and discussion regarding what form such a project might take. Alberto suggested a sewing project, which was one of the community projects put forward, but it had not featured high on the list of democratically selected themes. Skipping ahead of a discussion on what such a project might look like in the community and how local resources could be mobilised to achieve it, I offered to find an expert that could possibly speak to the community about small sewing ventures ${ }^{20}$. The exercise felt rushed. In trying to achieve too many objectives at once, I achieved very few, very poorly.

In the context of this activity, the underlying power relations became clear. Alberto and I both initially attempted to adjudicate for power disparities (myself as the researcher in charge of the activity and him as a community leader). I wanted to hear all community

\footnotetext{
${ }^{20}$ I ran out of time to organise a speaker, but I did find an NGO that offered a one year certificate in industrial sewing to people who are less well off financially for 50 Bolivianos (Approx NZ\$10). I passed these details on to the community who agreed to discuss the possibility of supporting a community member to enrol.
} 
members preferred activities and their reasoning and Alberto suggested the democratic vote system. When the activity did not run as I had hoped, I asserted power by suggesting a new direction. Alberto asserted power by bypassing the democratic process and suggesting an activity. Our socially situated positionalities, the location of the activity (Delia and Alberto's kitchen), our emotional and mental states at the time all coalesced to form the power dynamics which enabled this particular outcome.

Although this brainstorming exercise did not achieve what I had hoped it would, it did have an unpredicted benefit. Alberto, who is one of three community leaders in Yachakay, felt the activity was beneficial because he now knew significantly more regarding community members' priorities for the neighbourhood. Furthermore, in the reflective interviews that I carried out in the following two Sundays, community members responded that they had enjoyed the activities and felt that they would contribute to positive change in the neighbourhood. In these ways I have come to view my 'failed' research activity as a valuable exercise both for myself as a learning researcher and the community who learnt more about each other through the process. This highlights that even when the researcher has not achieved the outcomes they imagined, unexpected benefits can arise which are considered important to community wellbeing.

\subsubsection{Research days three and four: Semi-structured interviews}

On the third and forth Sundays I held three semi-structured interviews with five community members (one of these was a group interview with three community members). I had hoped to carry out more interviews but no other community members were available to talk to me in the time period available. The interviews consisted of questions reflecting on the three phases of documenting the situation, contextualising the situation and working towards change (see appendix six). I drew on and extended the concepts and ideas introduced in the Portraits of Gifts, community mapping and brainstorming exercises. I endeavoured to draw on positive emotional registers - moments of joy, happiness or pride that arose throughout the group activities - to promote the enabling of other economic subjectivities. This method allowed me to gather community members' stories in a sensitive and people-oriented way. Furthermore, I planned to use the opportunity to give feedback regarding the results of the Portraits of Gifts and to receive feedback regarding community members' perceptions of the research process and the results presented. 
One interview was carried out at Delia and Alberto's house; the remaining two interviews were carried out at the participants' houses. The decisions around the locations, the role played by Delia and Alberto and the number of people per interview were made based on what were the most convenient and comfortable options for the community members and to facilitate understanding in the case of translation. At some points during the interviews I was aware that translations from Quechua to Spanish were briefer than I had expected. I would receive a one sentence translation for several minutes of conversation. In this way community members controlled what knowledge I was allowed to know. In hindsight this was quite a useful mechanism for allowing community members to discuss the question in relative privacy before providing me with an answer. A principle of indigenous methodology is that indigenous peoples should be given the opportunity to decide what information is communicated and what is not (Louis, 2007). In the context of the interviews, community members asserted control over the research process through their availability and their use of language.

This section has discussed the research activities that were carried out in Yachakay, paying specific attention to the ways in which the activities were moulded to suit the context. It has also noted the difficulties faced in negotiating a PAR project over four afternoons. The following section will analyse these findings with a view to responding to research question two.

\begin{tabular}{|l|l|l|l|l|}
\hline \multicolumn{5}{|c|}{ Figure 5.1: Research plan summary Yachakay } \\
\hline Research phase & No. & Research activity & Who will do it? & Time needed \\
\hline $\begin{array}{l}\text { Documenting } \\
\text { the situation }\end{array}$ & 1. & Photo essays & Community researchers & Two weeks \\
\hline $\begin{array}{l}\text { Contextualising } \\
\text { the situation }\end{array}$ & 2. & Portraits of Gifts questionnaires & $\begin{array}{l}\text { Community researchers, } \\
\text { other community members } \\
\text { and I }\end{array}$ & Half day \\
\cline { 2 - 6 } & 3. & $\begin{array}{l}\text { Focus group discussion on photo } \\
\text { essays }\end{array}$ & $\begin{array}{l}\text { Community researchers, } \\
\text { other community members } \\
\text { and I }\end{array}$ & Two hours \\
\cline { 2 - 6 } & 4. & $\begin{array}{l}\text { Focus group discussion on results } \\
\text { of Portraits of Gifts questionnaires }\end{array}$ & $\begin{array}{l}\text { Community researchers, } \\
\text { other community members } \\
\text { and I }\end{array}$ & Two hours \\
\hline $\begin{array}{l}\text { Working } \\
\text { towards change }\end{array}$ & 5. & $\begin{array}{l}\text { Group discussion/brainstorm on } \\
\text { community economic possibilities }\end{array}$ & $\begin{array}{l}\text { Community researchers, } \\
\text { other community members } \\
\text { and I }\end{array}$ & Two hours \\
\cline { 2 - 6 } & 6. & 'How to' workshop & $\begin{array}{l}\text { Local expert with } \\
\text { community members }\end{array}$ & Two hours \\
\hline
\end{tabular}




\begin{tabular}{|l|l|l|l|l|}
\hline & 7. & Field trip & $\begin{array}{l}\text { Community researchers, } \\
\text { other community members } \\
\text { and I }\end{array}$ & Half day \\
\hline
\end{tabular}

\begin{tabular}{|c|c|c|c|c|}
\hline \multicolumn{5}{|c|}{ Figure 5.2: Revised research summary } \\
\hline Research phase & No. & Research activity & Who was involved? & Date \\
\hline $\begin{array}{l}\text { Contextualising } \\
\text { the situation }\end{array}$ & 1. & Portraits of Gifts questionnaires & $\begin{array}{l}\text { Delia, Alberto and I with } 16 \\
\text { community members }\end{array}$ & $6 / 6 / 2010$ \\
\hline $\begin{array}{l}\text { Documenting } \\
\text { the situation/ } \\
\text { Contextualising } \\
\text { the situation }\end{array}$ & 2. & Community mapping & $\begin{array}{l}\text { Nine community members } \\
\text { and I (Delia and Alberto } \\
\text { translated as necessary) }\end{array}$ & $13 / 6 / 2010$ \\
\hline $\begin{array}{l}\text { Contextualising } \\
\text { the situation/ } \\
\text { Working } \\
\text { towards change }\end{array}$ & 3. & $\begin{array}{l}\text { Group discussion/brainstorm on } \\
\text { community economic possibilities }\end{array}$ & & \\
\hline All three phases & 4. & Semi structured interviews & $\begin{array}{l}\text { Delia, Alberto and I with } \\
\text { five community members }\end{array}$ & 20 and $27 / 6 / 2010$ \\
\hline
\end{tabular}

\subsection{How do research contexts shape the production of research and why should we care?}

That research plans are modified in the course of qualitative research seems to be relatively widely accepted; Denzin and Lincolns' (2005) work (discussed in Chapter three) certainly seems to indicate this. I have included Figures 5.1 and 5.2 above as summaries of the significant changes that occurred between my planned and actual research methods. While many factors contribute to the need for flexibility of research methods, this chapter argues for the significance of context in this process.

Louis (2007, p. 133) argues that research with indigenous peoples must involve reciprocal appropriations, "in which man (sic) invests himself in the landscape; and at the same time incorporates the landscape into his own most fundamental experience." Her key point is that both the researched and the researcher adequately benefit from research with indigenous peoples. However in highlighting the significance of context, I argue that the 'landscape' often has considerably more power in moulding the research than is allowed in critiques of exploitative research. My research indicates that a more nuanced understanding of unique power differentials in different research contexts could contribute to researchers who are better equipped to negotiate appropriately in multiple contexts. 
An examination of the process of negotiation in the context of Yachakay illustrates this point. I spent considerable energy trying to place myself in the exploitative researcher box and Delia and Alberto in the exploited subaltern category. At one point I emailed Delia asking the following questions:

I wrote: "In different parts of the project (questionnaires, group activities, and interviews), what emotions did you and Alberto feel? E.g. happy, frustrated, sad etc. When you were helping me, facilitating my project, did you feel uncomfortable, stressed or embarrassed at any point? (Maybe you felt uncomfortable trying to facilitate the project between your neighbours and I)."

Delia replied: "Well, in the course of the project I think we were all excited and happy." (Delia, Pers. Comm., 11/11/2010)

On looking back over the context specific negotiation of my research in Yachakay, I came across numerous anomalies to the understanding of researcher as powerful exploiter, researched as powerless and exploited. This can be seen in Delia and Alberto's initial motivation to help me out of sympathy for my difficult task. I was constructed as the powerless one in this situation. While community members agreed to help me, they also set the limits. I was motivated to carry out research that was respectful, suitable to the context and from an indigenous perspective. I aimed to mitigate the perceived power imbalance by opening the research to be modified in these ways. Yet, neither Delia, Alberto nor other community members had time to make this a possibility. In this instance it was more respectful to attempt to follow my own research plan. Although I retained 'power' in terms of deciding what would be researched and what would be written, the community retained power because they wanted to help but preferred not to alter the research.

Furthermore, community members controlled when they would participate and to what extent. Research activities could be carried out on Sundays, as this was when they were available. Within research activities they controlled their level of participation. Plate 5.2 shows Delia, Alberto and $\mathrm{Eva}^{21}$ in action poses with pens in hand around the community map, with other community members in varying degrees of participation. Language was also used in some instances to control what information was conveyed to me and what was not. As noted in Chapter four, other researchers have discussed how they did not always occupy

\footnotetext{
${ }^{21}$ Pseudonym.
} 
positions of power in their research (Chacko, 2004; Mandel, 2003; Sharp, 2005; ThaparBjorkert \& Henry, 2004). Indeed Thapar and Bjorkert (2004) highlight that it is disempowering to always approach the researched as powerless victims with no agency to decide who they interact with and how.

More can be learnt from this process. The above conclusion still constructs the researcher as the invasive outsider intent on exploiting locals, who exercise mechanisms to resist or mitigate this intrusion. Thinking of research as a knowledge exchange with differential negotiations of commensurability between the researched and the researcher has helped me to understand the situation. Each knowledge exchange is unique and surrounded by differential power relations and results in various benefits for each party.

Some feminist and indigenous writers would consider the research exchange as always exploitative, surrounded by uneven power dynamics and benefits which need to be adjusted for. However, I have come to think of at least some of my research transactions as gift exchanges amongst friends. Although I tried to carry out research that benefitted the community, these benefits could be considered minimal in comparison to the significant benefit of a Masters degree. Yet we do not consider all transactions with uneven benefits exploitative. Volunteering and gift giving are common practices in our society. These transactions could be conceived to result in uneven benefits yet we (normally) do not consider them exploitative. By examining the unique power dynamics and research benefits within research contexts in Yachakay, I have come to the conclusion that at least some of my research exchanges more closely resemble gift exchanges. This is not to say that research resembles or should resemble gift exchanges among friends, ${ }^{22}$ simply that not all research is exploitative. An understanding of research as an exchange allows a nuanced examination of the complex possibilities for power dynamics and negotiations of commensurability. Approaching research contexts with this understanding could contribute to fewer assumptions being made about the power and motivations of the 'researched.'

\subsection{Conclusion}

This chapter has introduced my methodology and methods for Yachakay. I have discussed the ways in which these methodologies were challenged and methods altered by the context

\footnotetext{
${ }^{22}$ Although see Tillmann-Healy (2003) for an investigation of friendship as method.
} 
specific personalities, motivations, availabilities and power dynamics. I have noted the ways in which these unique dynamics contributed to the information I received and thus the research I was able to produce. In analysing these factors I have argued that a more nuanced understanding of power dynamics in research is needed. Research is not inherently exploitative. In some contexts it could be considered a gift exchange among friends. An increased sensitivity to the complex possibilities for power dynamics, personalities and motivations within research contexts will contribute to better equipped researchers. 


\section{A diverse economy in San Miguel}

\subsection{Introduction}

This chapter draws on data collected in San Miguel to present my findings and analysis in response to research question one; what can be learnt about the community economy approach through exploring community economies in two indigenous communities? I also address research question three regarding the potentials and limitations of carrying out community economy research within a Masters framework. I have discussed some of the ways this research is situated in previous chapters. With these parameters in mind, this chapter draws on the stories I collected through semi-structured and conversational interviews with San Miguel community members to create a new story - of the economy of San Miguel as diverse. I applied a simple manual coding process to sort research material. I have then analysed the data according to an anti-essentialist Marxist understanding of class as a process. Exploring the various ways surplus is appropriated and distributed within different economic practices is one approach to analysing the contribution to wellbeing of various economic practices and the associated power dynamics. I have also drawn on narrative analysis to enrich the picture of the diverse economy and mitigate my ultimate editing power. These approaches are discussed below.

Uncovering some aspects of the diverse economy can be seen as one task in the greater community economy process. It is also an achievable approach to exploring community economies for a Masters level student. The potential significance of this approach could be seen in the logic of performative research. Performative research denotes that the process of highlighting the diverse range of economic activity renders this activity more visible and real in a context where only capitalist activity is appreciated and seen as viable. Because my research in San Miguel was cut short I did not get a chance to engage with community members regarding which activities they saw as strengths, or to encourage discussion regarding which activities could be strengthened or extended. Although I plan to send a summary of this research back to the community, with some community members not being completely literate this process will likely have limited impact. This prompts me to question whether this approach then runs the risk of becoming research for research sake. I will conclude this chapter with a discussion around for whom the diverse economic practices will 
become more real and visible for and what the significance of this is. This discussion responds to research question three, regarding the viability of researching community economies within a Masters framework.

\subsection{Analysis approach}

I have analysed and interpreted my findings continually throughout the research process; however my approach for this particular chapter draws on three key techniques, a simple manual coding process, narrative analysis and an anti-essentialist class process framework. The simple manual coding process was used initially to sort the data. Interviews were transcribed word for word then printed out along with journal entries and other field notes. The data was sifted through slowly and annotated or "open coded" (Crang, 2005) to begin building ideas from the text in response to my research questions. I then followed a basic coding system where data was sorted into relevance to my respective research questions, and sub-themes of these research questions.

Following indigenous methodology (Louis, 2007; Smith, 1999), ideally analysis would have been carried out in collaboration with community members. However this would have been very difficult without being in San Miguel for a longer period of time and particularly due to some community members being illiterate. Therefore while acknowledging that ultimate editing power lies with the researcher and interview texts are responses to unsolicited questions (England, 1994), I have drawn on the principles of narrative analysis as a way to add in community members stories. Narrative analysis is "a form of interpreting a conversation or story in which attention is paid to the embedded meanings and evaluations of the speaker and their context" (Wiles, Rosenberg, \& Kearns, 2005, p. 90). This form of analysis is a way to be more accountable to community member's stories and perspectives because "... the researcher is not accorded a monopolistic and superior status as the only person involved in the interview capable of 'interpreting' proceedings ..." (Wiles, et al., 2005, p. 92). I emphasise these analysis statements made by community members and also weave in my own interpretations to construct a story about the diverse economy in San Miguel.

Furthermore, narrative researchers also "view themselves as narrators" (Chase, 2000, p. 657) as they make their subjective, situated interpretations of the narratives they have collected, constructing their own story. The researcher inevitably "makes decisions about how to 
translate and transcribe the narrator's story, which parts of the story to include in the final product, and how to organize and edit those parts into a text ..." (Chase, 2000, p. 665). Therefore, in line with Feldman (1991, in Evans, 2010, p. 30) editing "can be part of the construction, reconstruction and simulation of contexts" and furthermore that researchers would do well to express editing decisions overtly and clearly rather than covertly or apologetically (Malkki 1995, in Evans, 2010). I have included (and excluded) specific sections of the interviews that I felt were most relevant and I have made my own translations, choosing the English words I thought fitted best. ${ }^{23}$ Narrative analysis often involves including large story sections from interviews. I have done this in chapter seven; however this chapter includes shorter excerpts of narrative. This reflects my interactions with community members in San Miguel. Our socially situated worlds meant linguistic and cultural commonalities were stretched to create bridges of understanding, often resulting in shorter (but still significant) interview responses. I have used my ultimate editing power to include narratives from certain interviews and to enrich my story about the diverse economy in San Miguel.

\subsubsection{Three practices: Transactions, labour and enterprise}

The following section draws on Gibson-Graham (2006) to explain in further detail how their diverse economy model teases out differences from the capitalist economy, both within capitalist activity and non-capitalist activity. The language of the diverse economy is developed around three main practices: transactions, labour and enterprise. Referring to Figure 6.1 below and reading vertically down the columns, transactions, labour and enterprise are then divided out into their capitalist, non-capitalist and alternative capitalist counterparts. A new way of viewing the economic landscape then becomes available as the capitalist processes are joined by the multiplicity of alternative capitalist and non-capitalist practices. The categories are not considered to be neat boxes with hard edges which encompass all economic activities. Indeed, Williams, Nadin, Rodgers and Round (2011) argue that a continuum could be a more appropriate way to categorise diverse economic activity. I have used the categories proposed below as a guide because the purpose of the model is not to understand the economy 'as it really is', but to develop new language to "disarm and dislocate the naturalized hegemony of the capitalist economy and make space for new

\footnotetext{
${ }^{23}$ Therefore interview translations which do not flow clearly are sometimes the product of my chunky translations, rather than a reflection on the language of the interviewees.
} 
becomings - ones that we will need to work at to produce" (Gibson-Graham, 2006, p. 60). In the following paragraphs I will explain each column of the table below (Figure 6.1).

Figure 6.1: The diverse economy

\begin{tabular}{|c|c|c|}
\hline Transactions & Labour & Organisational Form \\
\hline Market & Wage & Capitalist \\
\hline “Free" & Salaried & Family firm \\
\hline Naturally protected & Unionized & Private unincorporated firm \\
\hline Artificially protected & Nonunionized & Public company \\
\hline Monopolized & Part time & Multinational \\
\hline Regulated & Temporary & \\
\hline \multirow[t]{2}{*}{ Niche } & Seasonal & \\
\hline & Familial & \\
\hline Alternative Market & Alternative Paid & Alternative Capitalist \\
\hline Sale of public goods & Co-operative & Socially responsible firm \\
\hline Ethical "fair trade" markets & Self-employed & State enterprise \\
\hline Local trading systems & Indentured & Green firm \\
\hline Alternative currencies & Reciprocal labour & Nonprofit \\
\hline $\begin{array}{l}\text { Underground market } \\
\text { Co-op exchange }\end{array}$ & $\begin{array}{l}\text { Work for welfare } \\
\text { In kind }\end{array}$ & $\begin{array}{l}\text { Producer and consumer co- } \\
\text { operatives }\end{array}$ \\
\hline \multicolumn{3}{|l|}{ Alternative credit } \\
\hline \multicolumn{3}{|l|}{ Barter } \\
\hline \multicolumn{3}{|l|}{ Informal market } \\
\hline Non-market & Unpaid & Non-capitalist \\
\hline Household flows & Volunteer & Communal \\
\hline Gift giving & Housework & Independent \\
\hline Indigenous exchange & Family care & Feudal/peasant \\
\hline State allocations & Neighbourhood work & Slave \\
\hline State appropriations & Self provisioning labour & \\
\hline Gleaning & Slave labour & \\
\hline \multicolumn{3}{|l|}{ Hunting, fishing, gathering } \\
\hline \multicolumn{3}{|l|}{ Theft } \\
\hline Poaching & & \\
\hline
\end{tabular}

(Adapted from Gibson-Graham, 2006, pp. 61-65)

\subsubsection{Transactions}

Transactions are the varied ways in which goods, services and finances move between entities, and the different ways that commensurability for such transactions is negotiated among the respective parties. Formal market transactions are defined by economists as the exchange of items of equivalent value, thus freeing exchangers of any further obligations outside of the transaction (Gibson-Graham, 2006). Within this system, commensurability, the method by which an exchange is negotiated as equal, is determined by the laws of supply and demand that eventuate from a society of rational, self interested producers and 
consumers. Ideologically the formal market is presented as 'free', however this is infrequently the reality with markets being "naturally and artificially protected, monopolized, regulated, and niched and, in all these cases, transactions are governed by context-specific power relations, rather than abstract and universal logics" (2006, p. 62). I came across no capitalist transactions in San Miguel.

Often neglected in formal economic analysis are the plethora of non-market transactions (Gibson-Graham, 2006) that sustain people. Feminist literature has highlighted the vast amounts of goods and services produced and shared within households. Goods and services are gifted by people and organisations, or allocated by the state. Other examples of nonmarket transactions include goods that are taken from the natural environment, goods are stolen and ritual exchange directs the exchange of some goods and services within and among communities. To some degree cultural norms indicate how much time or product is given, taken, stolen, allocated or shared. However there are no rules for non-market transactions and no formal measurements for determining commensurability (GibsonGraham, 2006).

A third category of transaction is the alternative market transaction (Gibson-Graham, 2006). Here, commensurability is determined socially between the involved parties. Sites of alternative market transactions include worker co-operatives where products are exchanged based on a motivation to sustain the co-operative. Other examples include informal and underground markets, where prices for goods and services can be seen to be socially negotiated, rather than solely by formal market logic. A further example is barter where goods or services are exchanged for other goods or services, and no money is involved in this transaction. In alternative market transactions, the equivalence of value of the respective goods and services is determined by the exchangers (Gibson-Graham, 2006). I came across a number of non-market and alternative market transactions in the Bolivian community contexts which I will discuss below.

Distinguishing between these three types of transactions allows one to see all the different ways in which goods and services are exchanged in everyday life. While capitalist economic activities are often assumed to be the key transactions that maintain wellbeing, this disaggregation brings into focus all the other transactions that sustain us. It also contributes to an understanding of the ways these transactions are socially determined as 'fair.' 


\subsubsection{Labour}

The performance of labour and its remuneration are similarly disaggregated into three categories: wage labour, alternative paid and unpaid labour. Capitalist wage labour is usually understood to be labour which is sold by people who do not own any means of production, in exchange for a wage set at a level that allows the purchase of sufficient commodities for subsistence for themselves and their dependents (Gibson-Graham, 2006). However, within this category of wage labour clear disparities can be seen as different groups have divergent capacities to negotiate the power relations that determine employment. There are those who have very little power or protection such as non-unionised, part-time, temporary and seasonal workers. However, others such as unionised workers are able to negotiate higher wages and benefits. There are also those who are highly skilled or whose skills are in demand, who can exert considerable power in the workforce and can negotiate high salaries that allow a lifestyle well above subsistence (Gibson-Graham, 2006). I came across one instance of 'wage' labour in San Miguel, although obviously potentially more instances exist that I did not encounter.

Alternative labour (Gibson-Graham, 2006) is distinguished from capitalist wage labour, although it is still paid, this payment takes a slightly different form. This could include labour which is paid in kind or instances where efforts are reimbursed partially in kind and partially with a wage. Other forms of alternative labour include self employed people who set their own wage and co-operative workers whose wages are set by the co-operative at a living wage rate. Co-operative workers may also receive capital payouts proportional to their share of the organisation (Gibson-Graham, 2006).

However, as Gibson-Graham (2006) highlight, the most prevalent form of labour is the unpaid labour performed in households, families, communities and neighbourhoods. Although this labour is not remunerated with a wage, many argue that it does not go unremunerated. The sense of belonging, value, love, security and emotional support as well as the enjoyment of the fruits of this labour (for example, a clean house, cared for family members, food prepared and/or grown, clothes sewed etc) can all be considered remuneration. I came across a number of instances of alternative and unpaid labour in San Miguel. 
Skewing the concept of what is counted as valuable labour is important because "to include all of this work in a conception of a diverse economy is to represent many people who see themselves (or are labelled) as "unemployed" or "economically inactive" as economic subjects, that is, as contributing to the vast skein of economic relations that make up our societies" (2006, p. 63). This labour section has described the disaggregation of the hegemonic understanding of labour as only capitalist wage labour and illustrates both the diversity of labour types within the wage labour category, as well as outside this category.

\subsubsection{Enterprise}

Enterprises, or production units, in the diverse economy are viewed in terms of the different ways in which wealth is generated and distributed. I have drawn on Gibson-Graham's (2006) understanding of class as a process and their use of the Marxist concept of surplus labour to understand these different enterprise types. Surplus labour, or surplus product is defined as the labour performed that is more than the labour that is necessary for reproduction. In most societies, this surplus labour, or surplus product, is claimed by someone other than the performer of the labour (the producer). Within capitalist enterprises, the existence of a wage contract is seen to render exempt any claims by workers to surplus and to legitimise the capitalist employer's appropriation of this surplus. Diverse capitalist firms such as family-run capitalist firms, private unincorporated firms, public firms and multinational firms, generally operate by appropriating surplus from their workers and distributing this as they see fit (Gibson-Graham, 2006). I found no capitalist enterprises in San Miguel.

In the case of alternative capitalist firms such as co-operatives "producers do control their own rate of surplus production and appropriation and are the ones who decide how distributions out of surplus should be allocated" (2006, p. 67). Other alternative capitalist firms commit themselves to social or environmental objectives in addition to profit making. State enterprises appropriate surplus labour but have the capacity to redistribute this for the betterment of public good. Non-profit firms also appropriate surplus from their workers, however they are legally unable to retain or distribute surplus and are frequently dependant on grants and subsidies as they struggle to cover their costs (Gibson-Graham, 2006). Enterprise types can thus be seen to be diverse in the way they generate, appropriate and redistribute surplus. In other words, an enterprise can be understood to be alternative capitalist if it meets either or both of two objectives: either the producers influence the 
distribution of the surplus, or the surplus is used for a purpose other than, or in addition to simply making more profit for the enterprise.

Non-capitalist enterprises can also be understood by drawing on the Marxist concept of surplus labour. Gibson-Graham (2006) note how in many 'developing' countries feudal institutions dictate that tenant farmers must perform surplus labour on their landlords land, or provide a portion of their surplus product as payment for use of land for subsistence. In family units where a gendered division of labour exists, housework completed by women could be seen to be appropriated and distributed by the head of the household. Independent, self-employed producers can demarcate their own wage/surplus ratio and decide how the surplus is to be distributed. I came across a number of alternative and noncapitalist enterprises in San Miguel, which will be discussed below.

Examining the different ways in which wealth is generated and deployed in different types of enterprises shows how an economy can be seen to be made up of a much wider variety of enterprise types, rather than just capitalist enterprises (Gibson-Graham, 2006). Examining the distribution of this appropriated wealth, whether it is consumed, reinvested in the enterprise or distributed to wider society, allows one to view the social and political potential in various practices (Gibson-Graham 1997 in Carnegie, 2008).

\subsection{The diverse economy: San Miguel}

The following section introduces the diverse economy of San Miguel from the data I have collected. Figure 6.2 below summarises it and the following paragraphs describe the individual practices in more depth.

\subsubsection{Transactions}

Transactions in San Miguel are weighted heavily in the direction of alternative and nonmarket transactions. I found no instances of formal market transactions, although I came across a number of alternative and non-market transactions. Alternative market transactions largely occur in the form of informal market transactions and take place in the local neighbourhood, in neighbouring towns or further afield. 


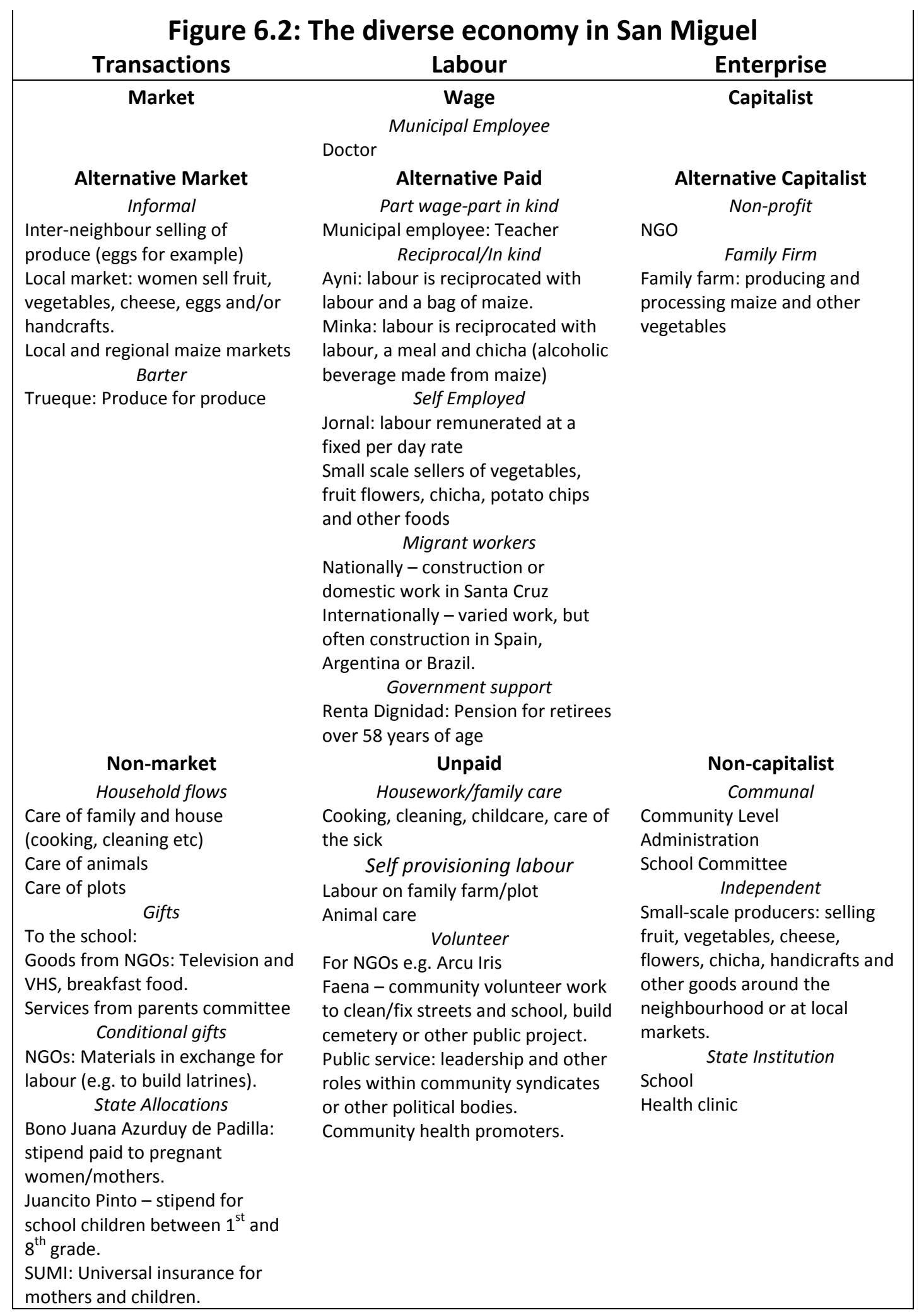


Community members sell their produce such as eggs or home-made cheese to each other. If there is a surplus of household vegetables, fruit, flowers, cheese or eggs, or if women have handcrafts to sell, I was informed that they travel to the closest market town to sell these products. Unfortunately I do not have data relating to how the commensurability of these transactions is negotiated. The markets are held weekly, although women do not necessarily go every week as there is not always a surplus to be sold and transport to the market takes time. Money gained from sales is usually spent immediately on other items needed for the household, with little or no cash left over.

A key transaction for many families in San Miguel is selling their maize at regional markets or to bulk buyers. I do not have significant detail relating to how prices are determined, however Sara ${ }^{24}$ (Pers. Comm., 21/4/2010), a young campesina, explained that there were six major regional markets per year in her area. Her family attended all of these markets because different prices could be received at different markets, but there was no way of telling in advance what price they would be able to get. Whether this was because of fluctuations in formal market value, quality of the maize (and the buyer's perception of this) or the price they could negotiate with the buyer on the day, I did not ask in the initial interview.

All of these markets are, to varying degrees, informal. In the case of the neighbourhood transactions, there are no government regulations or taxes affecting these exchanges. The larger weekly markets, regional markets and bulk buyers are much more complex. Although the sale of produce is not taxed, the local government does charge for street spaces. This reflects the broader pattern in Bolivia where the formal economy makes up "only a fraction of the nation's productive activity, most of which is 'informal': unregulated and usually untaxed" (Lopez Levy, 2001).

A further alternative transaction can be seen in the indigenous practice of trueque. Some residents of San Miguel practice trueque, indigenous barter of produce for produce, however this is infrequent.

\footnotetext{
${ }^{24}$ Pseudonym. Sara preferred not to have the interview recorded so I have paraphrased her words rather than directly quoting them.
} 


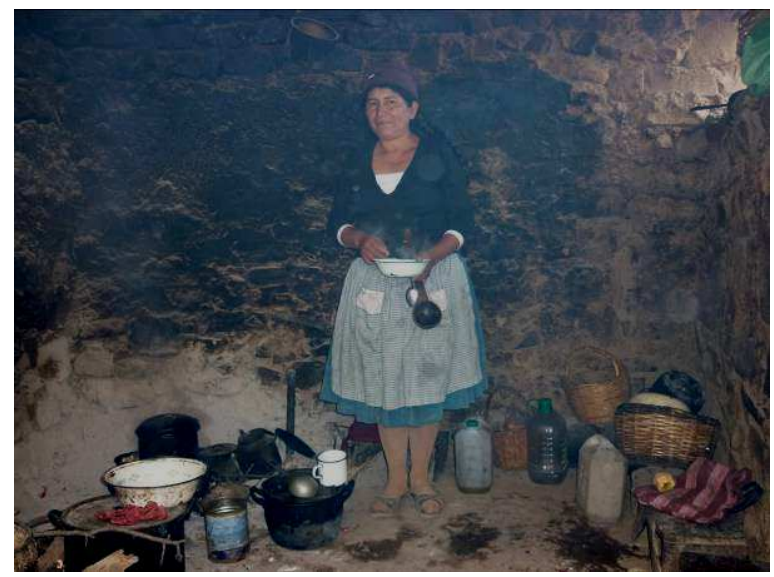

In San Miguel I came across a number of non-market transactions of goods and services. While acknowledging that my interactions were with more women than men, the data I collected indicates that household flows, an area traditionally managed by women in San Miguel, make up the bulk of these transactions.

\section{Plate 6.1: Guadalupe in her kitchen}

Practically all services performed by women, both inside and outside of the household, are gifted to the family or the community. In the household, women perform all aspects of domestic labour and are also responsible for caring for household animals. The picture above (Plate 6.1) shows Guadalupe in her kitchen where she cooks meals for the family and the animals. Animals are kept for household consumption purposes rather than commercial farming purposes. The animals are only sold occasionally. If the women are not taking the sheep and goats to pasture their labour services are gifted to the family on the family plot. As one community member stated: "The women, yes, [laughs] the women have a lot of work in the house, in the chacra ${ }^{25}$, everywhere" (Juan, Pers. Comm., 19/4/2010).

Another form of non market exchange is the conditional gift giving by NGOs in San Miguel. In San Miguel an NGO in coordination with the local government took the initiative to provide materials to families to build latrines. The materials were conditionally provided to those families who could both transport the materials from the nearest town (at significant personal cost) and provide the labour to build the toilets within a specified time. In this case, commensurability of the transaction appeared to be determined by the NGO and the local government, as they were the parties with the power to decide what the project would consist of and to provide the raw materials. The NGO did hold a community meeting to discuss the project, allowing space for community members to influence the commensurability of the transaction.

Further non-market transactions can be seen in government allocations. Juancito Pinto is a stipend of 200 Bolivianos (\$NZ40.00) per annum per child that is paid to parents of children enrolled in school between first and eighth grades. This stipend is to contribute to the

\footnotetext{
${ }^{25}$ Farm
} 
purchase of school uniforms, books, stationary, shoes and other necessities. Juana Azurduy is a stipend of cash payments totalling US\$260 paid to pregnant women/mothers in instalments on the condition they attend pre and post natal checkups and have a medical professional present at the birth. SUMI is a an insurance that ensures free health care for mothers and their children up to six months of age.

\subsubsection{Labour}

As is the case for the transactions column, the labour column is weighted heavily to the alternative and non capitalist categories.

I came across one example of wage labour, the state employed doctor, Lucia ${ }^{26}$. I determined her employment to be an example of wage labour because she held a formal contract with the state to work as a doctor at the clinic in Camiri ${ }^{27}$ neighbouring San Miguel. This work was remunerated regularly with a wage.

The teacher at the local school, Eduardo also holds a contract with the state, and is also remunerated regularly with a salary. However, I have categorised his labour in the alternative paid category because it is partially paid in kind. In addition to a regular cash wage, Eduardo is remunerated through the use of a boarding house. The situation is also considered alternative because Eduardo and his wife have an informal arrangement where they share this teaching position and remuneration. Strong Bolivian teacher unions work to mitigate the power of employers in determining wage rates and working conditions (Postero, 2005). This excerpt from the semi-structured interview with the local teachers Eduardo and Sandra highlights their feelings regarding the level of remuneration they currently receive:

Me: What do you think the government, NGOs or other institutions, should do to improve education?

Eduardo: Well, for the teachers we are always hoping that, that a fair salary will materialize for the teachers as well, for us.

Why? So that an incentive is provided for us as well, so that we work with enthusiasm and so that there are no problems with the magistrate, yeah? At this point in time there isn't a good salary, we are dissatisfied and we are striking and protesting. It's not good for the children this way either." (Eduardo, Pers. Comm., 22/4/2010)

\footnotetext{
${ }^{26}$ Pseudonym

${ }^{27}$ Pseudonym
} 
Residents of San Miguel participate in a range of alternative paid labour. The three campesina women I spoke to provided agricultural labour on their family owned plots of land. The key produce grown is maize; however various other vegetables are also grown. Labour on the family plots did not seem to be remunerated in cash, rather it was a family obligation that was remunerated through a sense of belonging, protection, food and shelter.

At the time of seed sowing and produce harvesting, extra labour is required over a short period of time. To satisfy this demand for extra labour, indigenous systems of ayni and minka continue to be utilised. Both are communal labour systems: "Everyone works, everyone helps" (Alejandra, Pers. Comm., 20/4/2010). They are also reciprocal labour systems: "Whoever comes to help, you have to go and help them as well. If you don't go, they won't come next year" (Lucia, Pers. Comm., 20/4/2010). Minka occurs during seed sowing and involves an exchange of labour for labour with the host family also providing meals and chicha ${ }^{28}$ throughout the day.

Ayni occurs at harvesting time and also involves an exchange of labour for labour, with the addition of labourers being remunerated with a bag of maize for their efforts. The labour exchange does not necessarily have to occur on equivalent jobs. A person could work on another community member's plot at harvest time and the owed day of labour could be claimed to help fix the first person's house or any other job s/he needs doing. Alejandra explained this to me:

“I'Il help you now with the harvest. But in ten days I'll go and ask to be repaid for this work. I'll say to you: I've worked for you on the harvest, can you come and help me fix my house? I am not asking you to work for me on my harvest, but to help me repair my house... Although as the greatest need at this time [March] is the harvest, I'll help you with your harvest and you'll help me with my harvest." (Alejandra, Pers. Comm., 20/4/2010)

The indigenous systems of ayni and minka can be categorised as alternative labour systems because remuneration is socially determined between the involved parties.

\footnotetext{
${ }^{28}$ Fermented maize beverage.
} 
There are instances where people are paid in cash for a day of labour. This is referred to as jornal and generally occurs at harvest time if maize is not plentiful. However, it can also occur at other times, for any work, if the individuals involved have come to that

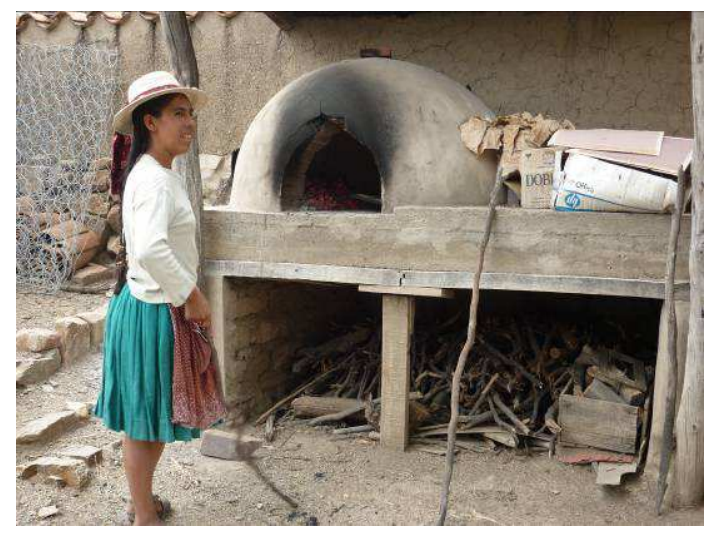

Plate 6.2: Luisa baking bread for a neighbour in exchange for a jornal. arrangement. I have included it in the alternative labour section because the instances I came across were arranged between the individuals concerned on a casual ad-hoc basis, with no formal law binding contracts or tax paying involved. Also, remuneration can be socially determined between the involved parties. One instance of a work arrangement that is remunerated with a jornal can be seen in Plate 6.2 left where Luisa is baking bread in an outdoor oven for a neighbour. To a certain extent Luisa and her employer determine how she will be paid between them: "When I want, she pays me cash, pays me only in cash, pay it to me! I say to her, or when I want potato, she gives me potato. Its up to us" (Luisa, Pers. Comm., 20/4/2011). However, the broader social rules dictate that the standard daily wage rate in San Miguel is 30 Bolivianos for men and 20 Bolivianos for women, regardless of the work. Luisa felt that this was justified because "the men do more work than the women, us women can't lift as much weight" (Luisa, Pers. Comm., 20/4/2010). In a later conversation, Alejandra disagreed with this. She felt that in many circumstances women did the same amount of work as men, but the custom was to pay them less, so social pressure made it difficult to go against this.

I have included migration for work to supplement cash incomes in the alternative labour section of the diverse economy. It is categorised as alternative labour because it often involves working in informal, unregulated sectors such as construction or domestic service. All community members I spoke to in San Miguel had directly experienced migration or had one or more family members that regularly (or permanently) migrated for work. Guadalupe spoke emotionally about the need for her husband to migrate for two to three months a year to Argentina or Santa Cruz to supplement their family income. If the family is to send their children to school, the 2500 Bolivianos (approximately NZ\$500) Guadalupe's husband can bring home in remittances for two months of migration work is essential. 
I have included the pension in the alternative transactions section because arguably it is payment for a life's work. Renta Dignidad, a universal and non-contributory pension of US\$314 per annum, is available to all elderly Bolivians (Müller, 2009).

In the unpaid labour section I have included the numerous hours of domestic labour. Another significant entry in this section is the indigenous system of faenas, or community volunteer days. Whole communities are mobilised to clean the road or lay out the power cables ready for extension of electricity to the neighbourhood.

\subsubsection{Enterprise}

I have interpreted the enterprises I came across in San Miguel as alternative capitalist and non-capitalist. In the alternative capitalist section I have noted a non-profit NGO and the family agriculture enterprises. The family agriculture businesses direct a portion of family labour to producing, processing and selling maize, which is the main cash crop. Other vegetables such as potatoes are also grown. Plate 6.3 shows three different types of maize laid out to dry as part of the process of preparing it to be sold. To meet the high labour demand in seasons of planting and harvesting, families participate in the communal indigenous practices of ayni and minka. These practices work to

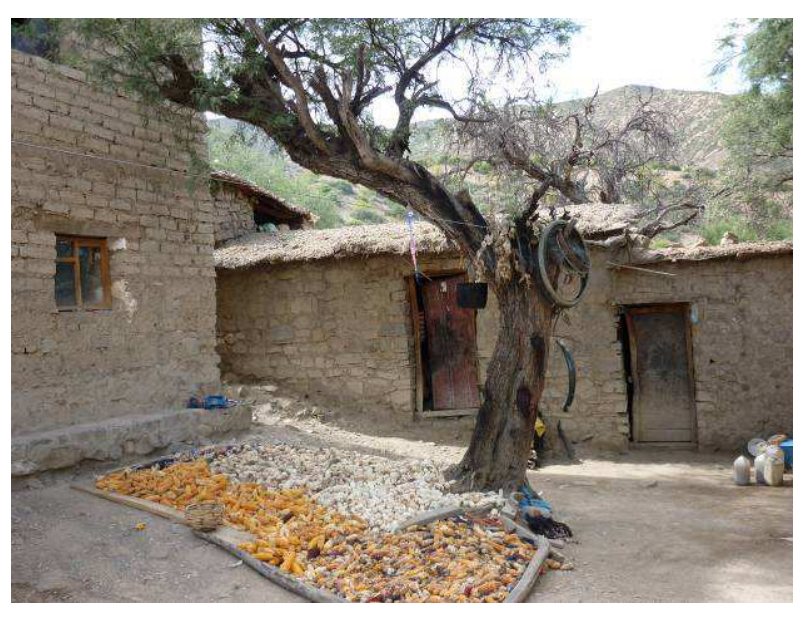

Plate 6.3: Maize drying outside Guadalupe's home. ensure the wellbeing of more people than just those involved in the family enterprise. However, in many cases surplus from producing, processing and selling maize is barely sufficient to ensure continued production above subsistence. For many rural Bolivian families migrating to find work to supplement this income is necessary for survival (Gisbert, Painter, \& Quitón, 1994). Through the semi-structured interviews with the three campesina women it became apparent that their family units drew on multiple practices to sustain family members.

In the alternative enterprise section I have also placed a local NGO which worked to supplement health care provision and contribute to water infrastructure in San Miguel. I do 
not have a significant amount of data regarding the NGO however the surplus labour of its workers could be seen to be appropriated by the organisation and redistributed for humanitarian purposes.

I have placed the state school and the health clinic in the non-capitalist enterprise section because no surplus labour or product is created, nor is it sought after. The state employees are paid a regular wage (partly in kind in the teachers' case) to provide services in education and health care. Both enterprises are run on a scarce budget, which often makes it difficult for the state employees to do their jobs. The school is supplemented in its operations by generous support from its parent committees as well as donations of food and other necessities from international NGOs to ensure its continued functioning.

The parent committees (juntas in Spanish) are located in the non-capitalist enterprise section under the communal sub-category. This institution is run by an active and well organised group of parents who meet regularly to manage the numerous hours of volunteer work necessary to keep the school running smoothly. A representative is arranged to travel to the nearest town to collect donated food, rosters are established to ensure someone is available to cook school breakfasts, a vegetable patch is maintained, faenas or community volunteer days are organised to collect firewood and clean or repair the school. Representatives are also sent to local and district ministry of education meetings. Small levies are collected from parents to cover travel costs. The parent committees redistribute surplus labour to support the local school (a humanitarian purpose).

A further group in the communal sub-section of the non-capitalist enterprises is the community level administrations. The 1994 Law of Popular Participation transferred 20\% of the national budget on a per capita basis to the municipalities and recognised rural/indigenous communities as legal entities mandated with formal oversight of municipal spending (Kohl, 2002). In San Miguel, the community level organisation has regular meetings and intense discussions to democratically select projects that will best meet the needs of the community, and to ensure that the resources allocated for such projects (calculated on a population basis) are dispensed in the most judicious, efficacious manner. These community meetings attempt to achieve consensus to carry a decision. I have included this institution as a non-capitalist enterprise because it directs community labour and government resources 
to serve community purposes. Also, decisions regarding the distribution of surplus are consensus based.

A further non-capitalist form of enterprise can be seen in the numerous independent producers of fruit, vegetables, flowers, chicha, handicrafts and other goods. I have limited data regarding independent producers, thus it is difficult to categorise them accurately. However, three campesina women I spoke to were involved in producing, consuming and selling one of the above listed products. It was not clear whether this activity should be classified as part of a household unit or independent producer. These independent producers claim their own surplus labour/product and decide how to distribute this. However, as noted above for the women of San Miguel this surplus is usually immediately spent on household necessities.

This section has drawn on stories collected in semi-structured and conversational interviews with community members of San Miguel to create a new story of the diverse economy of San Miguel. As with all research there are many gaps, however this chapter provides a glimpse of some of the ways community members ensure wellbeing as well as some of the power dynamics within these practices. The following section will address the significance of this information. It will work towards addressing whether a picture of the diverse economy might contribute to greater community wellbeing.

\subsection{Performative research: Who benefits?}

\footnotetext{
"Poststructuralist thinking offers insight into the ultimate undecidability of meaning and the constitutive power of discourse, calling into question received ideas and dominant practices, heightening an appreciation of the political effectivity of theory and research, and demonstrating how openings for alternative forms of practice and power can emerge." (Gibson-Graham 2000 in Gibson-Graham, 2006, pp. 54-55)
}

As discussed in Chapter two, post-development theorists such as Escobar (1995) and Sachs (1992) have drawn on post-structural theory to highlight the way the development industry tends to produce development norms, persuasive theories about what the ideal 'developed' state is and how to go about achieving it. The community economy approach to development attempts to put these development norms to one side to create space for local 
ideals and practices to emerge (Gibson-Graham, 2006). By searching out the diverse practices San Miguel residents engage in to maintain wellbeing, space opens up for local ideals and strategies to be considered as viable pathways for development.

This chapter draws on the concepts of performative research and weak theory. Performative research (Gibson-Graham, 2008) denotes that knowledge creation is a political act which has an effect on the world. Therefore, this research becomes a conscious attempt to bring the diverse economy into focus, rendering its components more visible and viable where they would otherwise be obscured in the shadow of more 'robust' capitalist economic activity. This approach works with 'weak theory' (Gibson-Graham, 2008), which holds that the future is contingent and as yet unwritten. So rather than assuming that there is only one pathway to economic development, this perspective suggests that multiple possible pathways could be imagined, potentially extensions of the newly focused diverse economy. Cahill (2008, p. 300) highlights that development interventions which do not consider alternative economic activities as viable avenues for promoting community wellbeing "overlook a whole range of resources, networks and activities that could stimulate local economic development." So by discussing the diverse economy of San Miguel, the aim is to highlight the many practices people engage in to ensure their wellbeing in addition to capitalist activities, and suggest that multiple strategies for economic development could be imagined from these already existing practices.

My experience has contributed to the formulation of several questions revolving around the concept of performative research. I initially considered uncovering the diverse economy as a task that could be useful in its own right, even though it represents only one aspect of building a community economy. I thought that the performative effect of highlighting the diverse practices that sustain San Miguel could contribute to these things being more visible, valuable and viable as alternative paths for development. Also, I saw it as an achievable task within a Masters framework. Although my research in San Miguel was cut short, I was able to collect sufficient data to create a picture of some of the elements of the diverse economy of San Miguel. Unfortunately I was unable to communicate this picture back to community members while I was there. However, the questions I asked while in San Miguel and the summary of this research that I will send back to the community, could, in a small way, have the political effect discussed above. 
However, even if I had managed to communicate a clear picture of the diverse economy back to the community, would this perspective be of significance to community members? What is the potential performative effect of this information? The diverse economy of San Miguel allows an understanding of a community that engages in a diverse range of activities to maintain wellbeing. Yet, for some San Miguel community members, these diverse strategies in their current forms do not sufficiently maintain wellbeing. The emotional appeal of Guadalupe regarding her husband's seasonal migration is indicative:

\footnotetext{
"With small children what can we do? Leave them to walk the streets? Today the jornales pay you less and later. There is no money. Money leaves this place. There is none here, it doesn't fall from anywhere. The money doesn't come here." (Guadalupe, Pers. Comm., 17/4/2010)
}

Is it possible that in presenting the diverse economy and not taking further action, communities are left to their difficult situations, with this development approach not contributing in a significant way towards positive change?

Furthermore, does merely presenting the diverse economy run the risk of endorsing the status quo? Through the process of highlighting economic practices to indicate their latent potential, inequalities also become more visible. In San Miguel, I came across gender disparities in the daily wage rate for jornales. Juan discussed how he disagreed with inequitable pay for men and women, although felt he could not challenge this social norm for fear of being reproached by his peers. Referring to Gibson-Grahams' (2005a) work in the Philippines, Kelly notes that, "many of these transactions and arrangements incorporate gendered and generational power relations that are not always welcome" (Kelly, 2005, p. 42). I was unable to carry through the feed-back loops, so I have no data as to what the impact might have been. However, one risk is that without critically engaging with the components of the diverse economy, the status quo - inequities included - could be endorsed.

It seems that the latter phases of building a community economy, moving "beyond the representational moment" (Gibson-Graham, 2005a, p. 17), are of key importance to avoid these risks. This aligns with Gibson-Grahams' (2005b, p. 123) perspective as they view power disparities not as structural issues which limit possibilities, but "as challenges, problems, barriers, difficulties - in other words, things to be struggled with, things that present themselves as more or less tractable obstacles in any political project." Uncovering the 
diverse economy is clearly valuable in that it opens space for locally inspired development pathways to be imagined. However I think the critical engagement with components of the diverse economy is a key stage. Therefore, in order to gain the most value for the communities involved, future forays into community economy research at Masters level ought to incorporate steps beyond the moment of representation.

\subsection{Conclusion}

This chapter has presented a picture of the diverse economy of San Miguel. I have drawn on an anti-essentialist class process framework and narrative analysis to order and interpret stories collected through semi-structured and conversational interviews. Despite a short research period, my picture of the diverse economy of San Miguel is populated with a number of alternative and non-capitalist practices. I was unable to feedback the results of the diverse economy, nor encourage the community to critically discuss the economic practices within their diverse economy. Therefore, the potential benefits of this research to the community of San Miguel are minimal. While in some cases circumstances make it difficult, I propose that moving past the 'moment of representation' is of key importance to community economy research. My recommendation is that future community economy research (or future development initiatives) would do well to work with communities to strengthen or extend those economic activities which community members consider beneficial to maintaining community wellbeing. 


\section{A community economy in Yachakay?}

This chapter has two objectives. The first objective is to present my findings and analysis relating to data collected from Yachakay. In Yachakay, I drew on Cameron and Gibson's (2005) post-structural model of PAR to explore the community economy. This involved a three stage process of documenting the situation, contextualising the situation and working towards change. I have drawn on the same techniques of analysis (manual sorting and narrative analysis) as described in the Chapter six. The second objective is to draw on these findings in response to research question one: what can be learnt about the community economy approach through exploring community economies with two indigenous communities? Finally, I will address research question three pertaining to the potentialities and limitations of this approach within a Masters level framework.

\subsection{Documenting the situation}

Documenting the situation involved exploring how community members currently see their life situations in Yachakay and tapping into their feelings about these current situations. In order to draw out the "prevailing local representations and knowledges" (Cameron \& Gibson, 2005, p. 322), I have employed narrative analysis as a story telling mechanism. Drawing on narrative analysis was appropriate because of its parallels with the aims of the photo essay approach (as discussed in Chapter five). This method allowed an understanding of some of the local knowledges and prevailing local representations of life in Yachakay, "from the perspective of someone's life and in the context of someone's emotions" (McEwan \& Egan, 1995, p. viii).

A post-structuralist perspective holds that multiple discourses and practices affect the formation of economic subjectivities (Cameron \& Gibson, 2005). One prevailing local understanding that emerged from the narrative was a prejudiced perspective of campesinos as unintelligent and incapable of carrying out more than unskilled jobs. This is one discourse that affects the formation of particular economic subjectivities. The aim was to document such perspectives, then introduce a view of "the diverse, but hidden economic practices already existing" in Yachakay and to draw on a "set of emotions in which hope and 
possibility became associated with these diverse economic practices" (Cameron \& Gibson, 2005, p. 321).

In this chapter I include larger stories from an open ended interview with Delia and Alberto. This is because they help bridge the gap between the socially situated worlds of the Yachakay community members and me. As discussed in Chapter five, Delia and Alberto could be considered more privileged community members of Yachakay because of their tertiary educations, Delia's job and Alberto's position of leadership in the community. Some of these characteristics, such as a tertiary education, in addition to other social indicators such as age, were social commonalities between Delia, Alberto and I. These commonalities allowed an ease of communication which facilitated such narratives to occur. This was not as present in interviews with other community members. It was apparent that Delia and Alberto needed less help in having their voices heard than other community members with less social power. Nevertheless, I have drawn on their narratives because our social commonalities and friendships allowed the formation of a rich picture which contributed to bridging the gap between other community members and me.

As discussed in Chapter six, narrative analysis works to add-in the 'voice' and analysis of the researched. I acknowledge that I carried out the transcriptions, translations, selections of interview text and construction of this thesis. Although these were emailed to Delia to allow space for her to edit (she suggested no changes), the final construction is essentially mine.

The following passages will document the situation by drawing on the narratives of Delia and Alberto to illuminate some 'local understandings' of life. This narrative is taken from the open ended interview with Delia and Alberto carried out on $16^{\text {th }}$ April 2010 (See Delia \& Alberto, Pers. Comm., 16/4/2010). The conversation was started with a request to hear a story about their lives. Taking a 'back seat' here, I allowed space for these stories to flow through a variety of topics as directed by Delia and Alberto.

\subsubsection{Delia and Alberto: Some stories about life in Yachakay and Bolivia.}

Delia: We can't be like our parents, because my Mum, at least when she was small, she didn't go to school and she doesn't know how to read very well. Later she has learnt in literacy classes, but this was when she was already older, and she has just 
learnt some words, more or less her name and how to sign it. But she didn't go to school when she was a child. In the past the women didn't go to school, because the mothers said why should the girls go to school? What reason have they got to learn? The boys yes, because they have to go to the army. And so the girls couldn't go to school. But my Mum helped me to study, not with my homework because she didn't know, but she gave me moral support and this meant a lot to me, and it has helped me a lot and I think she is very proud to see her daughter.

Alberto: For example, my father doesn't know how to read, he's illiterate, nothing, zero. Well, the same is true of my friends with whom I went to school, those who have stayed in the same place. I knew that the place wasn't going to develop, it wasn't going to give, there was no economic movement. There is no improvement of life, everything is always the same, the same. And so the people that stay, that were my companions, sometimes it's a shame, when I go home and I see the humble people, it's always the same, nothing changes. What I like is that the people at home are very humble, they are so much more respectful. But to improve as a person, to be something in life, I think that those who have stayed there, static, they haven't advanced at all, absolutely not at all. This is what worries me, but I think that at least we can be an example. For example Delia wears a pollera ${ }^{29}$. People say that those who wear the pollera don't know anything. Generally the people in the country wear them. Those in the city wear trousers.

Delia: They think that, at least, I've felt this many times at school, like when I was studying in the city. The first years I did, kindergarten and primary, I did in the country and after, I went to study in La Recoleta which was a prestigious college, well it was a prestigious college, I'm not sure if it's as good now, but it was a good college that taught students well, but sometimes I felt discrimination, and at university too.

Well, in college not that much because nearly everyone was at the same economic level. But when I entered university the discrimination was immense, from the professors and the students, because there are different social statuses.

They call us women who wear the pollera, cholas ${ }^{30}$ or cholitas, and often fellow students called me "cholita, cholita," and sometimes it was a type of discrimination in the way they expressed it.

Alberto: The people, some people, not everyone, say that the people from the country aren't educated, that they can't [do anything], that they are stupid. But I think that often, we demonstrate that yeah, we can [achieve things], and then what happens is that we aren't given the opportunity. Yeah, well, we have succeeded, but from our own efforts. Our parents can't help because they don't have any money. This is the worst grievance for us. At least to have a table where we can do our

\footnotetext{
${ }^{29}$ A pollera is a pleated skirt worn with petty coats that was introduced by the Spanish colonists and still worn by many indigenous and mestizo women. Nowadays many indigenous and meztiso women living in rural and urban areas prefer Western dress to the pollera. Although others like Delia, are reclaiming it as an empowering act of solidarity with their indigenous identity and as an act of protest against discrimination against indigenous people. ${ }^{30}$ The online Spanish translator SpanishDict gives 3 definitions of Chola: 1. Halfbreed of European and Indian parentage. (America). 2. Familiar diminutive in kindly tone, equivalent to son, deary. 3. (Cono Sur) coward ("SpanishDict," 1999). These definitions hint at how the term Chola could be used in a range of ways from friendly to patronising to malicious discrimination.
} 
homework, a room where we can feel relaxed, but if they don't have it they can't. And so they think that we can't achieve anything. But despite that, yeah, people can do it. The people from the country are talented and they can do many things.

Delia: We can get ahead, but often, here in the city the people think that women who wear polleras, above all the young people, can only ever be street vendors or domestic employees in a house. Two or three weeks ago, when Tom ${ }^{31}$ was still here, I had a bad experience in the market. The thing is, every time they see me with a foreigner they say insults, well, I'm sorry because they speak amongst themselves and they speak in this way. Sometimes I feel bad, but sometimes I just say well good for them.

One time I was in the market with Tom and he said I want a sandwich with avocado and I said, no, in the market they won't make that for you, you can buy avocado and bread, but in the market they won't make it for you. And he said no, I'm going to pay for them to make it for me. And we went to the market where they sell fruit and the woman said we don't do that here, and he said but I'm going to pay, [and the vender replied] no, no, no, why doesn't she make it for you? She's your employee isn't she? And I said you know what madam, I am not his [domestic] employee, I am his teacher, and I have no reason to make it for him, so make it for him because he's going to pay you, it's not going to be free. I felt rage.

Alberto: These things happen, but I think the best thing to do is demonstrate that it's not like they think it is, we're so much more. Like, l'd like it if the people thought in this way, that they could succeed, that they could be men capable of anything. But when one doesn't sacrifice, one can't do this. For us, at least for me, it has cost me too much, I had to study, study, work, every day. But now I feel a little more relaxed, because I know that I can stand up for myself against anyone, no one can humiliate me easily, because at least I have a higher education now.

\footnotetext{
${ }^{31}$ Pseudonym for Australian language student.
} 


\subsubsection{Intertwining my researcher's narrative}

I have included this particular section of narrative because it communicates one discourse that contributes to the formation of certain types of economic subject identities. Delia and Alberto discussed how there is a commonly held perception that people from the country (campesinos) "aren't educated, that they can't [do anything], that they are stupid" (Alberto, Pers. Comm., 16/4/2010), and that they "can only ever be street vendors or domestic employees in a house" (Delia, Pers. Comm., 16/4/2010). Likewise, in reference to the socioracial stratification between the white and campesino population, Ströbele-Gregor (2011, p. 84) states that "[t]he indios-mestizos are socially defined as "under classes" in urban space: as service workers, traders and the poor." I saw this perspective as a discourse that has a negative effect on what is considered 'possible' in terms of economic identities for some Bolivians.

Delia's story highlights how she was socially constructed in this way by another pollera wearing women, despite her education and employment status. Even though Delia consciously chooses to wear a pollera to disrupt stereotypes of the economic capabilities of campesinas, continually being constructed this way results in feelings of frustration. Here, I drew on Cameron and Gibson's (2005, p. 323) post-structural understanding of the importance of a micro-politics of self transformation. As such, I tried not to dwell on feelings of frustration, hopelessness and anger, "rather these feelings were acknowledged and recognised in order to move on to other kinds of enabling and creative emotions." I saw enabling emotions of hope and determination in Alberto's comments that "these things happen, but I think the best thing to do is demonstrate that it's not like they think it is, we're so much more" and "we can be an example" (Alberto, Pers. Comm., 16/4/2010) to other Bolivians of campesinos who have succeeded.

Delia and Alberto's strategy of being 'an example' to show how racial discrimination is unfounded has parallels with my post-structural approach to this research. I also aimed to put forward a specific understanding of Yachakay and the economic capacities of its residents. I hoped this perspective could be 'an example' with the potential to have positive effects on the formation of economic subjectivities of Yachakay residents. 


\subsubsection{Connecting with other Yachakay community members}

Eleven out of sixteen Yachakay community members that participated in the Portrait of Gifts questionnaire identified their main occupation as being a housewife or a domestic employee. At a glance, these eleven women could be socially defined as part of Sucre's "under classes" of service workers, traders and the poor (Ströbele-Gregor, 2011). While the discriminatory perspective discussed above is one discourse that contributes to the formation of certain types of economic subjects, I was curious as to what this 'local understanding' was obscuring. Ströbele-Gregor (2011, p. 71) argues that:

\footnotetext{
"In the socio-racial stratification between whites and Indians (Postero 2008: 27) that characterizes society in Sucre, unwritten and historically developed lines of demarcation and norms give its urban space its structure. They mark where "indios belong" - and where they do not. Paradoxically, the everyday reality of Sucre, in which the lifestyles of the middle and upper classes would be unthinkable without the services provided by and the diverse economic activities of the indigenous and mestizo population, is not perceived as a contradiction within the exclusive self-awareness of criollos as such. Regarding the construct of the city, however, the indigenous population is made invisible."
}

I have introduced this 'local knowledge' because it appeared to be a key discourse influencing the economic subjectivities of campesinos. However, I did not focus significantly on discourses and practices that detrimentally affect the potential economic subjectivities of Yachakay community members. This was partly because of the context specific factors that affected the length and depth of the research as discussed in Chapter five. It was also because of the post-structuralist approach to PAR which emphasises the political nature of language and knowledge creation. By focusing closely on the problems and their causes, the risk is that this perspective comes to dominate the local imaginary. Representing Yachakay community members as only capable of certain economic positions could have been used to appeal to outside institutions for assistance packages. Yet as noted by Cameron and Gibson $(2005$, p. 319) in reference to their research in the Latrobe Valley, this strategy could be argued to fuel "the despair and hopelessness felt by many. It robs residents of any sense of economic possibility other than to be dependent on special assistance packages from government or the benevolence of a yet-to-be-secured major employer." Furthermore, this representation makes it difficult to see the diverse economic activities within Yachakay that 
could be drawn on to fuel economic development (Cahill, 2008; Cameron \& Gibson, 2005; Carnegie, 2008; Gibson-Graham, 2005a, 2006).

From the early stages of this research I had begun to get a sense of the fullness of Yachakay community members' lives, especially seeing as I was only permitted to carry out research activities on Sundays. I was also increasingly aware of the wide variety of activities with which they filled their days. With confidence that alternative economic activities were taking place, I sought to highlight such activity, with the intention of having a positive effect on what was considered possible in terms of economic subjectivities.

\subsection{Contextualising the situation: Assets and economies}

As noted in Chapter five, the purpose of contextualising the situation was to offer "another understanding of the situation" (Cameron \& Gibson, 2005, p. 324), an understanding which might create space for alternative economic futures to be imagined. To achieve this, I sought to uncover and emphasise two key perspectives of Yachakay. The first drew on the results of the Portraits of Gifts to highlight the many assets of Yachakay. I drew on Kretzmann and McKnight's (1993) asset-based community development approach which seeks to highlight the physical and institutional assets, but "most importantly they include the abilities and skills, dreams and passions of those groups in the community who are most readily thought of in terms of needs ..." (Cameron \& Gibson, 2005, p. 324). The second understanding I sought to introduce was the diverse economy of Yachakay. I drew on the community mapping exercise, in addition to formal and informal interviews to discuss the diverse economic practices not normally considered valuable. Activities such as housework or volunteer work were drawn out and counted as contributing to community wellbeing. This way, a picture of community members as capable active citizens was put forward, with the intention of planting seeds of hope for ways that current economic practices and community assets could be drawn on to improve community wellbeing.

\subsubsection{Portraits of Gifts}

I have summarised the results of the Portraits of Gifts which were carried out with 16 community members, in Figures 7.1 and 7.2 below. Figure 7.1 shows a number of different skills and abilities held by community members. Following Cameron and Gibson's (2005) model, I have loosely divided the skills into three categories, abilities of the hand, abilities of 
the heart and abilities of the head. Figure 7.2 lists some hobbies and passions, skills people want to learn, volunteer work and community projects people want to participate in. Not surprisingly the results of the Portraits of Gifts show that the residents of Yachakay have many skills, talents, interests, dreams and passions. This data highlights a plethora of skills and abilities, networks and social assets that sustain these community members and could form a strong basis that community members could draw upon to improve wellbeing. It also shows that community members have a number of ideas for ways in which they would like to see their community improved, and are already active in bringing some of these ideas to fruition.

Figure 7.1: Skills and abilities of community members in Yachakay

\begin{tabular}{|c|c|c|c|c|c|}
\hline $\begin{array}{c}\text { Abilities of the } \\
\text { hand }\end{array}$ & $\begin{array}{c}\text { Proportion } \\
\text { of people }\end{array}$ & $\begin{array}{c}\text { Abilities of the } \\
\text { heart }\end{array}$ & $\begin{array}{c}\text { Proportion } \\
\text { of people }\end{array}$ & $\begin{array}{c}\text { Abilities of the } \\
\text { head }\end{array}$ & $\begin{array}{l}\text { Proportion } \\
\text { of people }\end{array}$ \\
\hline $\begin{array}{l}\text { Horticulture and } \\
\text { agriculture }\end{array}$ & Everyone & $\begin{array}{l}\text { Childcare and } \\
\text { parenting }\end{array}$ & Everyone & Organisation skills & Nearly $3 / 4$ \\
\hline $\begin{array}{l}\text { Pet care/animal } \\
\text { husbandry }\end{array}$ & Everyone & $\begin{array}{l}\text { Education and } \\
\text { youth activities }\end{array}$ & Everyone & Computer skills & $1 / 5$ \\
\hline Transportation & $1 / 4$ & $\begin{array}{l}\text { Healthcare and } \\
\text { welfare }\end{array}$ & Everyone & $\begin{array}{l}\text { Administration or } \\
\text { office skills }\end{array}$ & $1 / 2$ \\
\hline $\begin{array}{l}\text { Mechanical and } \\
\text { electrical }\end{array}$ & Nearly $1 / 2$ & & & & \\
\hline $\begin{array}{l}\text { Food, catering and } \\
\text { hospitality }\end{array}$ & Everyone & & & $\begin{array}{l}\text { Literacy and } \\
\text { language skills }\end{array}$ & Everyone \\
\hline Arts and crafts & Everyone & & & & \\
\hline $\begin{array}{l}\text { Music, theatre and } \\
\text { film }\end{array}$ & $\begin{array}{l}\text { Nearly } \\
\text { everyone }\end{array}$ & & & & \\
\hline $\begin{array}{l}\text { Construction and } \\
\text { maintenance }\end{array}$ & Nearly $3 / 4$ & & & & \\
\hline $\begin{array}{l}\text { Cleaning and other } \\
\text { household chores }\end{array}$ & Everyone & & & & \\
\hline Safety and security & $\begin{array}{l}\text { Nearly } \\
\text { everyone }\end{array}$ & & & & \\
\hline
\end{tabular}




\begin{tabular}{|c|c|}
\hline \multicolumn{2}{|c|}{$\begin{array}{l}\text { Figure 7.2: Some passions, dreams and aspirations of community members in } \\
\qquad \text { Yachakay }\end{array}$} \\
\hline $\begin{array}{l}\text { Some interests, } \\
\text { hobbies and things } \\
\text { people are passionate } \\
\text { about: }\end{array}$ & $\begin{array}{l}\text { Care: Helping people; giving counsel; family; communication; cooking; washing } \\
\text { clothes. } \\
\text { Creative: dressmaking; knitting; weaving; spinning wool. } \\
\text { Outdoors: Animal wellbeing; horticulture; selling things; bricklaying. } \\
\text { Sport: Football; basketball; volleyball. }\end{array}$ \\
\hline $\begin{array}{l}\text { Some things people } \\
\text { want to learn how to } \\
\text { do: }\end{array}$ & $\begin{array}{l}\text { Kitchen based skills: Pastries; cakes and confectionary; cooking skills. } \\
\text { Art/craft: Dressmaking; embroidery; weaving; traditional weaving; macramé; } \\
\text { artisan skills. } \\
\text { Trades: Agriculture (e.g. how to make insecticides); beauty salon. } \\
\text { Technical/transport: Computer skills; ride a bike or drive a car. }\end{array}$ \\
\hline $\begin{array}{l}\text { Volunteer work and } \\
\text { contributions to the } \\
\text { community: }\end{array}$ & $\begin{array}{l}\text { Community leadership; maintaining the school, the cemetery the streets and } \\
\text { the community generally; mother's club; sports secretary and Church } \\
\text { catechist. }\end{array}$ \\
\hline $\begin{array}{l}\text { Community projects } \\
\text { that people want to } \\
\text { participate in: }\end{array}$ & $\begin{array}{l}\text { Infrastructure: Potable water; roads; street lighting. } \\
\text { Craft: macramé and weaving in the Mother's Club. } \\
\text { Physical: sports activities; dances. } \\
\text { Cooking: confectionary making. }\end{array}$ \\
\hline $\begin{array}{l}\text { Ideas for community } \\
\text { based projects: }\end{array}$ & $\begin{array}{l}\text { Infrastructure: Potable water; public street lighting; hospital; health clinic; } \\
\text { sewage system; paving of streets. } \\
\text { Community/entertainment: Community meeting hall; crèche; football field. }\end{array}$ \\
\hline
\end{tabular}

I communicated the perspective of Yachakay with an asset base of skills, abilities, dreams and passions in three key ways. The first was during the process of carrying out the Portrait of Gifts questionnaires. Delia, Alberto and I carried out the questionnaires with three community members simultaneously, hoping to provoke subsequent conversation regarding existing capacities. The second involved three follow up interviews within which the above perspective was presented and discussed. Community members agreed with the findings and thought they could potentially have a transformative effect in the community. The third involved a group brainstorming exercise, which communicated ideas put forward through the Portraits of Gifts questionnaires for community projects. Space was then created for 
discussion around community priorities. In the context of the limitations discussed in Chapter five, I emphasised a perspective of Yachakay as a community with multiple skills, abilities, dreams and aspirations.

\subsubsection{Mapping the diverse economy}

The community mapping group exercise was carried out by ten community members as a way to document their community space. It was also used to explore some of the diverse economic practices that occurred within this community space. I have drawn on GibsonGraham's (2006) model of the diverse economy as introduced in Chapter six. This model differentiates between economic practices by focusing on the various types of transactions, labour and enterprises. However, I will discuss the various transactions and labour practices through the nexus of the two key interconnected institutions that are apparent in the community map (Plate 7.1), the family and the community.

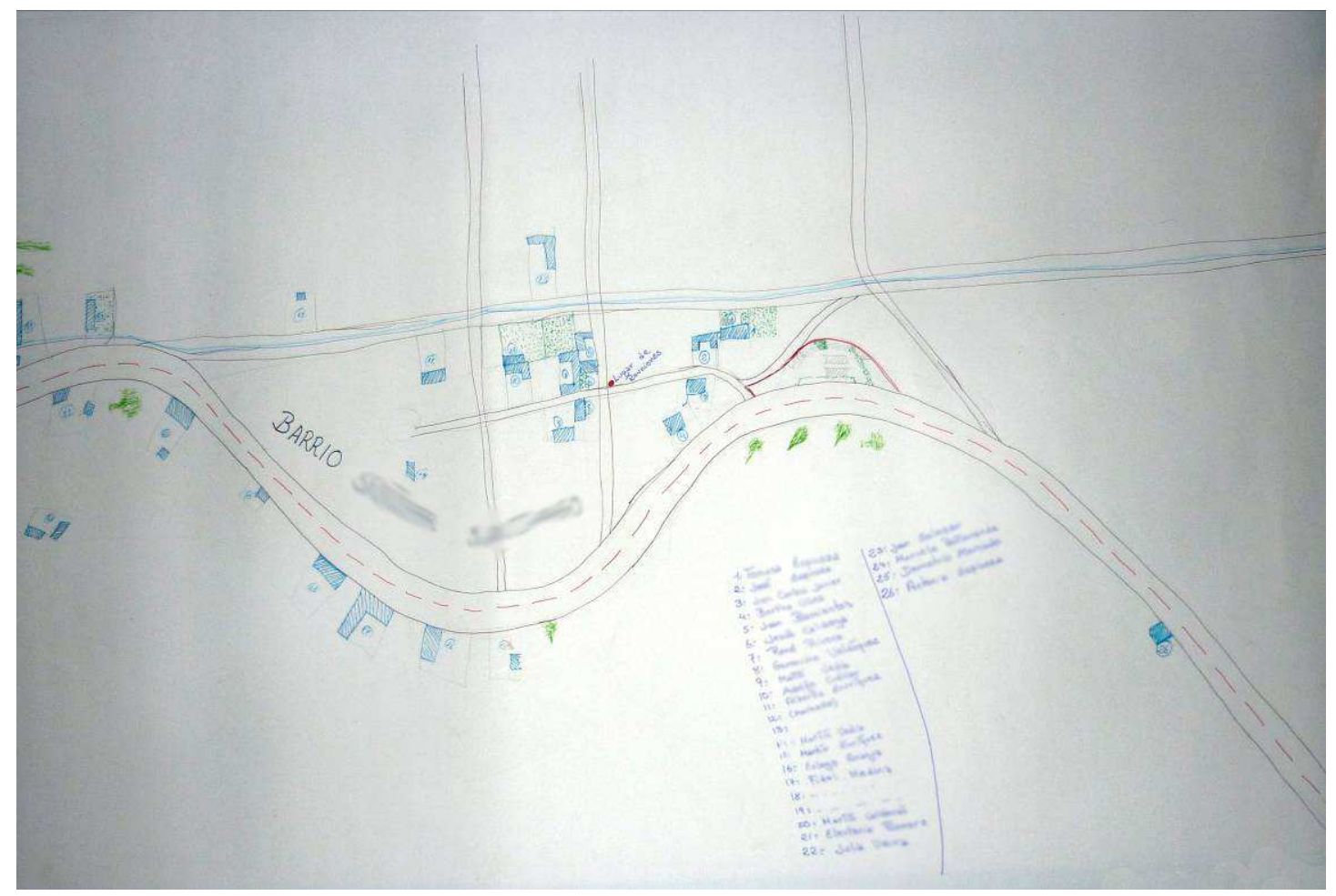

Plate 7.1: Community map of Yachakay.

The family unit appeared to be a key non-capitalist economic institution in Yachakay. On the map, twenty six blue coloured boxes represent the houses in which Yachakay families live. Within these households family members share the benefits of their labour. Electricity is connected, but there is no water or plumbing infrastructure. This means the unpaid 
domestic labour of washing clothes, dishes and cooking for family members takes extra time as water needs to be collected first. In the alternative paid section, some individuals contribute to family income by working as self-employed domestic employees, or construction workers. I also came across several waged positions in Yachakay; a language teacher (Delia) and municipal employees. Just off the edge of the map, community members catch "micros" or buses to their jobs in the city. Others attempt to save a portion of their earnings by walking to their jobs.

Family incomes are further supplemented through subsistence agriculture. Pencilled in (and sometimes coloured green) rectangles surrounding the houses represent the plots where community members grow maize, potatoes and other vegetables to supplement their incomes. Produce is mostly grown for consumption purposes and thus labour on family plots can be considered self-provisioning labour. However some families sell a portion of this produce in markets in the city to supplement monetary incomes. One family runs a commercial chicken farm, the one formal capitalist enterprise that I came across. Through this community mapping activity, I found that family units in Yachakay appealed to a number of economic practices to maintain their wellbeing.

The community level administration is also a significant non-capitalist institution. Yachakay, like other indigenous/rural community administrations, is recognised as a legal entity with formal oversight over a percentage of municipal spending under the 1994 Law of Popular Participation (Kohl, 2002). This institution is administrated through the unpaid volunteer labour of community members. Some of their duties include organising and running community meetings. A significant point on the map is the community meeting place, marked with a red dot at the intersection of two gravel roads and labelled "Lugar de Reuniones" or meeting place. This is an outdoor space where the community gathers every month to discuss matters of importance to Yachakay. For example community faenas or community volunteer days are discussed. Unpaid community labour is subsequently directed to projects that benefit the whole community, such as tidying the streets or maintaining the cemetery. Discussions also revolve around choosing which three community projects will be submitted to the Municipality in petition for their allocation of taxpayer money to carry out one of these projects. In these ways the Yachakay community administration mobilises community labour and draws on national processes of redistribution to benefit the community. 
I was beginning to find that alternative and non-capitalist practices were much more prevalent than capitalist practices. Alternative economic practices are often rendered invisible to community members, NGOs and government institutions because of capitalocentric thinking (Cahill, 2008; Carnegie, 2008; Gibson-Graham, 2005a). Such institutions often only envision capitalist paths to community development, such as how to make community members more employable or how to create more jobs in the formal market economy. Yet through highlighting these diverse economic practices, paths for community development open up in multiple directions. Through the process of carrying out this exercise and the subsequent formal and informal interviews, I began to emphasise a picture of the diverse economy of Yachakay and hint at the underlying potential for community development within it.

In contextualising the situation I have emphasised two key 'understandings' of the community of Yachakay. The first understanding was of the multiple assets in terms of skills, abilities, dreams and aspirations of Yachakay community members. The second is of the diverse economic practices that maintain community wellbeing in Yachakay. Through my role as the post-structural researcher, I have sought out these particular perspectives of Yachakay because of their potential performative effects (Gibson-Graham, 2008). I hoped that these perspectives might provide the basis from which alternative pathways to economic development might be imagined.

\subsection{Working towards change: Sharing dreams and priorities}

The working towards change phase aimed to open space for discussion regarding alternative economic futures. The community economy framework introduced in Chapter two, is a process whereby a community deliberately discusses its level of economic interdependence. It involves a conscious and critical examination of which activities sustain wellbeing, and which activities the community could strengthen or extend (Gibson-Graham, 2006). The research activities up to this point (the Portraits of Gifts and the mapping exercise) attempted to bring to the surface community assets and diverse economic practices of Yachakay residents. To build on this positive perspective of Yachakay, and to begin to open space for public community discussion of economic interdependence, a brainstorming 
exercise was carried out. Follow up interviews reflected on the process and continued to build space for discussion around community interdependence.

\begin{tabular}{|l|l|}
\hline \multicolumn{2}{|c|}{$\begin{array}{c}\text { Figure 7.3: Community priorities for a } \\
\text { community project }\end{array}$} \\
\hline Project theme & Votes \\
\hline Potable water & 9 \\
\hline Sewing venture & 4 \\
\hline Pastry shop & 3 \\
\hline Kitchen/cooking project & 6 \\
\hline Insecticides & 6 \\
\hline Road paving & 8 \\
\hline Animal wellbeing & 6 \\
\hline Hospital post & 9 \\
\hline Football field & 8 \\
\hline
\end{tabular}

The brainstorming activity aimed to provide a space for community members to share their passions and dreams for the community at the same time as allowing a relaxed space for people to interact, express their opinions and explore ideas for "collective possibilities" (Cameron \& Gibson, 2005, p. 325). I drew on ideas that were put forward by community members in the Portrait of Gifts for community projects, things they were passionate about or things they wanted to learn how to do (as listed in Figure 7.2). From this point a space was opened where the group was invited to think about what their priorities were and why. These ideas were discussed and voted on to get a sense of the group's priorities. I have summarised the results of this vote in Figure 7.3 above. As discussed in Chapter five, a solid resolution for a community project was not arrived at, yet the activity provided a space where everyone's dreams and aspirations for the community could be shared. It was also an opportunity for these community members to begin to think about what their priorities were as a group and if and how these priorities might translate into action. An unexpected benefit transpired in that Alberto, one of the community leaders, admitted that he felt that he had learned significantly more regarding the priorities of these community members.

This concludes my second attempt to explore community economies as an alternative approach to practicing development. I have drawn on the Cameron and Gibson's (2005) paper Participatory action research in a post-structuralist vein, to explore community 
economies with the community of Yachakay. While this section has presented my findings relating to this process, the following section will draw on these findings to respond to research questions one and three. From this experience, what can be said about community economies as an alternative way to practice development? What restrictions (or openings) did I face as a result of doing this research as part of a Masters degree?

\subsection{Reflections on the process}

\subsubsection{Community economies: An alternative way to practice development?}

One difficulty I struggled to reconcile relates to the documenting the situation phase. I felt uncomfortable searching out 'dominant understandings' that were supposedly preventing alternative economic subjectivities from being enacted. Although the discriminatory perspective of campesinos was one I came across often during my time in Bolivia, I was concerned that in writing about it I would performatively perpetuate it. Given my aim to carry out research that was beneficial rather than detrimental to the community, I began to question the need for this stage in the research at all.

Engaging with a community to get a sense of their existing understandings and feelings around their current life situations should be a key stage of any development intervention as sparse development resources should not be directed to communities that are content the way they are. However rather than directly exploring community member's happiness levels with the status quo, this approach to documenting the situation seems to seek out personal barriers to exploring the diverse economy. If all knowledge creation is political, this too is a political selection of certain understanding of reality. Once these 'barriers' are located, they seem to form justifications for further research highlighting the diverse economy and building a community economy. One key critique that Gibson-Graham (2005a) make of mainstream development practitioners is that they assess communities according to foreign understandings of their needs and then justify foreign solutions. Does documenting the situation resemble identifying community needs as specified by the diverse economy model?

This query seems to point to the fact that Gibson-Graham do "valorise certain options" (Aguilar, 2005 in Gibson-Graham, 2005b, p. 121). I take no issue with valorising certain options. In this thesis I too valorise similar options. However, perhaps care could be taken 
when documenting the situation to be clear about the political motivations behind this documentation, especially when communicating this perspective to community members.

These next points join the ranks of Laurie (2005), Lawson (2005)and Kelly (2005) who call for greater attention to scale and power in community economy research. The approaches I undertook in San Miguel and Yachakay involved directed attention to local assets and economies as resources for alternative economic development. Yet it was difficult to ignore national and international connections. In San Miguel current and past negotiations with international NGOs were the source of benefits for some and frustrations for others. In any case, their presence and interactions with San Miguel community members made it difficult to acknowledge only local assets and diverse economic practices.

In Chapter five, I discussed the difficulty Yachakay community members and I faced in brainstorming a way to get potable water connected to their neighbourhood. Community members suggested appealing to local and regional government, a local business and an international NGO for help getting water connected (an exercise beyond the means of local funds). Concerned to draw on the local assets and local diverse economy, I suggested community members explore a community project they could work on more or less independently. As noted in Chapter five, Gibson-Graham (2005a, 2006) do encourage working with external institutions, such as state bodies, businesses and NGOs. However the 'understandings' of the diverse economy and local assets they suggest to introduce do not seem to include (or encourage) these national and international level institutions as resources to be drawn on. It seems to be a key part of the empowerment process to uncover local resources. However, perhaps in future ventures into community economies, one improvement might be to more explicitly include national and international scale assets as resources that communities could draw on.

A further power related problem I faced was "a quandary of any form of participatory / grassroots / community development praxis - without the cooperation of key individuals such programmes are unlikely to flourish, but with their cooperation they may simply reinforce existing structures of power" (Kelly, 2005, p. 41). As discussed throughout this work, in both San Miguel and Yachakay I perceived power disparities between certain community members and was dependent on community contacts in order to engage with each community. However, like Gibson-Graham (2005b), I perceive internal community 
power relationships as issues to be proposed for community discussion rather than reasons not to engage with communities.

On a related note, this community economy approach does not seem to directly address power inequalities at national and international scales (Kelly, 2005; Laurie, 2005; Lawson, 2005). In Yachakay I found a common local perception to be that campesino's are thought to have limited economic capacity. The contextualising phase aims to disprove this by drawing out the multiple capacities of campesinos, empowering them in the process. Yet this does not address external (to the community) institutions and societal norms which continue to enact negative stereotypes by withholding opportunities. This is a valid concern, but again like Gibson-Graham (Gibson-Graham, 2005b) I view these issues as problems to be tackled head on, rather than structural limits to positive change. The community economy approach is founded on the principle of "starting here and now to create other worlds" (GibsonGraham, 2005b, p. 119).

\subsubsection{Community economies: A Masters level pursuit?}

A key issue I have grappled with regarding the limitations of carrying out research into community economies at Masters level is the reality of being a novice researcher.

Community economy research involves engaging closely with communities' ideal ways of life and strategies for achieving these. In Yachakay I diverted community members away from engaging with external institutions to connect water to their community. While this is not an objective of the community economy approach, my inexperience in research led me to make this suggestion. Making mistakes is part of the process of learning, but when others are affected by our mistakes, the question needs to be asked as to whether our research is still ethical. However two points suggest that Masters level researchers should not take the potential for making mistakes as a reason not to engage in this sort of research. Firstly, integrity in research relationships is not based on always being 'right,' rather it is more important to share the learning process in a humble and respectful way. I have attempted to do this with Delia and Alberto and am confident of the continued integrity our relationship. Secondly, as discussed in Chapter five, the researched do have agency and are able to negotiate research relationships and the knowledge produced through these relationships (Thapar-Bjorkert \& Henry, 2004). Care needs to be taken not to overstate the ability of the researcher to (unintentionally) deceive the researched. 


\subsection{Conclusion}

This chapter has portrayed my exploration with the community of Yachakay of their diverse economies and community assets. I have put forward a view of Yachakay as a community whose needs are met with a wide variety of economic activities, of which very few are capitalist. As Carnegie (2008, p. 366) argued for Oelua, I have indicated that this variety of alternative and non-capitalist economic activity should not be seen "as deficient within a global capitalist economy, as disappearing and as inconsequential to development outcomes." I have highlighted the multiple talents, abilities and physical assets which could be drawn on as openings for positive change. Moving past the moment of representation (Cameron \& Gibson, 2005) I carried out research activities through which space was opened for discussion of collective economic possibilities. While no clear outcomes eventuated in terms of a community project, community members' aspirations and priorities were discussed.

Drawing on these findings I have made some preliminary comments on community economies as an approach to practicing community development. Documenting the situation can be seen as a political representation which works to justify further community economy research - a key critique of mainstream development practices. A more explicit inclusion of potential national and international resources could open further possibilities for communities to draw on. Within this, I conclude that local level power disparities are issues to be worked through rather than reasons for not carrying out research.

Further, this chapter has focused on carrying out community economy research at Masters level. The key issue raised questioned the ethics of early career researchers like myself working closely with communities' dreams and aspirations. While mistakes are inevitable in learning processes, this does not necessarily render this sort of research unethical. Acknowledgement of community agency and sharing the learning process can contribute to more ethical research. 


\section{Conclusion}

This Masters thesis is the product of my exploration into finding a way to practice development differently to approaches considered the norm in the mainstream development industry. In Chapter one I portrayed challenging conversations with three friends as a way of introducing my reasoning regarding the need to search for a different way to practice development. The first occurred with one of my Spanish language teachers, where an explanation of wanting to work for a development NGO resulted in a realisation that NGOs were commonly perceived as corrupt. The second conversation was with a friend who lamented the arrogance of foreign NGOs who introduced inappropriate, expensive and complicated technology. The third conversation was with another Spanish teacher who challenged me to consider why I wanted to change the community I was carrying out research with. What was wrong with the way they were? These conversations were poignant reminders of why I wanted to find a way to practice development differently, and of my positionality as a foreigner associated with the development industry.

Further, these conversations connected closely to post-development sentiments, which also challenge the practice of development. A key critique raised by post-development theorists is that mainstream development practices can be seen as discourses that perpetuate certain understandings of development. These discourses do not allow for place based understandings of wellbeing or positive change. Post-development theorists have highlighted the implicit and actual violence of some development practices that have compelled 'underdeveloped' people to shed their place based understandings of wellbeing in order to become 'developed' (e.g. Escobar, 1995; Sachs, 1992). In response, postdevelopment theorists have been chastised for portraying a homogenous understanding of a diverse development industry; of uncritically romanticising indigenous cultures and most significantly, of not offering viable solutions for moving forward (Peet, 1997; Pieterse, 1998; Storey, 2000).

The community economy work of J. K. Gibson-Graham inspired me in light of these perspectives. This approach appeared to address concerns raised by post-development theorists and their critics. It also seemed to address the concerns raised in conversations mentioned above. The community economy approach involves encouraging public discussion around economic interdependence and strategies for achieving this ideal (Gibson- 
Graham, 2006). Their 'place-based globalism' prioritises neither local nor external discourses, but seeks to draw on what exists in the here and now and engage with communities in a process of becoming (Gibson-Graham, 2006). Thus, with this in mind, there is an understanding that engagement with foreign knowledge, technology and funds are not a necessary part of the development process.

The challenge as to why I wanted to change the communities (as this implied imperfections in current ways of being) has also been reconciled to a certain extent with the contribution of the community economy approach. The approach seeks to increasingly value a wider range of economic practices, rather than devaluing them as is the pattern in capitalocentric development practice. Furthermore, the approach does not necessarily involve change. The cornerstone is encouraging communities to critically discuss economic interconnectedness (Gibson-Graham, 2006). If communities are content with the status quo, then this is a viable and positive outcome in itself.

With these preliminary justifications in mind, I explored the potential contribution that can be made at Masters level to strengthen community economies in distant places. Throughout the process of carrying out this Masters thesis, this central research aim has been fleshed out into three key research questions:

1. What can be learnt about the community economy approach through exploring community economies with two indigenous communities in Bolivia?

2. How do research contexts shape the production of research?

3. What are the limitations and potentials of applying a community economy approach within a Master of Development framework?

The remainder of this conclusion will address how this research has responded to each of these research questions.

\subsection{How have I explored the research questions?}

My approach to exploring community economies has evolved throughout the process of carrying out this research. Inspired by indigenous methodologies (e.g. Louis, 2007; Smith, 1999), I initially set out to form a relationship with a community and offer my services as a 
novice researcher. I hoped to find a community that was interested in working collaboratively on a research project of their choice. Alejandra, the community contact I formed an initial relationship with, preferred not to participate directly in the formulation of my research aims. She felt that I should make the decisions regarding my research and preferred not to influence this directly. However, she seemed genuinely interested in the community economy framework and keen to facilitate me carrying out research on this topic in her community.

While Alejandra preferred not to engage in a fully collaborative approach, I continued to draw on indigenous methodological aims to carry out research that is sensitive to placebased priorities. In San Miguel, I explored community economies by carrying out informal and semi-structured interviews, as well as recording observations in a daily research journal. I had planned to carry out focus groups, as a mechanism of giving and receiving feedback regarding the initial findings of the diverse economy. However, this method was considered inappropriate due to the difficulty for community members of travelling to a single location. Thinking on my feet, I aimed to replace focus groups with individual follow up interviews. I left San Miguel prematurely after a community contact propositioned me and I no longer felt comfortable. These experiences of negotiating the research in a context sensitive way lead me to take note of the significance of this complex process. Through these experiences I formulated research question two, exploring the ways research contexts impact on research outcomes.

My second research context was in Yachakay. In forming a research relationship with Delia and Alberto, my community contacts in Yachakay, I was also open to altering my research aims to suit their preferences. After consulting other Yachakay community members, Delia and Alberto informed me that I was welcome to carry out research in the community. However, community members preferred not to be involved in collaboratively formulating a research focus.

In the time and space that resulted from changing research locations, I reconsidered my methodological approach to exploring community economies. I discovered Cameron and Gibson's PAR from a post-structuralist perspective. The approach involved a process of documenting the situation, contextualising the situation and working towards change by carrying out a number of group research activities. I felt it was more appropriate 
epistemologically because of the increased level of collaborative and inclusive knowledge creation. Also, given the approach was preferred by Cameron and Gibson to explore community economies, I reasoned that it would provide a pre-trialled method that would likely be more successful than my own methodological design.

I formulated a research plan which involved a simplified version of Cameron and Gibson's PAR approach. The context negotiated research activities included 16 Portraits of Gifts, a community mapping exercise, a community project brainstorming exercise and four semistructured interviews with seven community members (including the initial interview with Delia and Alberto). The process of negotiating this plan in a context sensitive manner involved manoeuvring a complex web of community, personal and university requirements.

\subsection{How has this research responded to the research questions?}

\subsubsection{Research question one: What can be learnt about the community economy} approach through exploring community economies with two indigenous communities in Bolivia?

Aiming to destabilise linear understandings of development, the community economies approach is grounded in local understandings of wellbeing and ways of going about achieving it. Drawing on weak theory (Carnegie, 2008; Gibson-Graham, 2008) the future is viewed as undetermined by structural logic and open to alternative possibilities. While the mainstream development industry commonly prioritises capitalist mechanisms of development as the only viable option, Gibson-Graham aim to open up a number of different paths to economic development. By mapping out the many economic practices that currently sustain communities, a number of alternative potential pathways for economic development are exposed. Mapping out community assets, physical and institutional as well as personal skills, dreams and aspirations, provides an indication that the "glass is half full." People most readily thought of in terms of their needs, are shown to have a set of resources that can be drawn on.

The concept of performative research (Gibson-Graham, 2008) is also drawn on here. The particular realities of communities with diverse assets and economic practices are sought out and communicated to community members because of their perceived potential to create positive change. The political motivation underlying this form of knowledge creation 
is thus consciously acknowledged. Moving past the moment of representation (GibsonGraham, 2005a), communities are then encouraged to critically engage with their diverse economic practices. They are encouraged to question their satisfaction with the current level of economic interdependence and to publicly discuss this. By rejecting the idea that there is only one viable pathway to development, space is opened for alternative economic pathways to be imagined. Through the presentation of the diverse economy and community assets, multiple options are opened up as potential development directions.

A key realisation that arose from leaving San Miguel prematurely is the importance of communicating the research with the community. I aimed to contribute to the wellbeing of San Miguel by presenting a perspective of their diverse economy and multiple assets. The hope was that through highlighting these activities, new pathways for increasing wellbeing could be imagined because of their increased visibility. Yet, because my research was cut short in this community I was unable to communicate this perspective to community members. Through the questions I asked in interviews and the summary of the research that I will send to the community, a performative effect may be enabled. However, without clear communication, there is little chance of promoting positive change within the community. The question then reverts to, for whom will this research have a performative effect? Such effects may be seen in other locations, such as my academic community. Yet my concern to contribute to positive change for the communities I worked with has led to a reiteration of the importance of clear communication of the research with the community. This has led me to conclude the importance of moving past the moment of representation (Gibson-Graham, 2005a) in community economy research.

In Yachakay, the brainstorming activity that did not go to plan has prompted me to consider its implications for the community economy framework. While my beginner researcher status contributed to an incorrect understanding of the community economy process, my misunderstanding possibly reflects on the community economy approach. I had understood the focus on local economic practices and local assets as resources to be drawn on to mean that drawing on external resources was not to be encouraged. When Yachakay community members suggested seeking aid from the state, a local business or an NGO in order to connect water to their community, I suggested they try to come up with local methods for gaining access. On reflection, I realised that Gibson-Graham (2006) do encourage working in collaboration with external institutions to create positive change in the community. 
Although this situation clearly reflects my beginner stage in the learning process, it has prompted me to consider whether the role of national and international scale institutions could be more explicitly expressed in the process of building a community economy. Exposing the local level resources has clear empowerment potential as it allows a view of development pathways that are not dependent on external solutions. However, external institutions could still be viewed as potential resources to be drawn on to contribute to locally determined development pathways.

The community economy approach has been criticised for romanticising diverse economic practices and failing to take into consideration the embedded "gendered and generational power relations" (Kelly, 2005, p. 42). Kelly also challenges the capacity for community economies to liberate people given their position within national and international scale structures. It was hard to ignore local and external power disparities in both San Miguel and Yachakay. Yet like Gibson-Graham (2005b), rather than considering these factors as limits to the possible, I consider them difficulties to be addressed in the process of enacting positive change starting here and now.

\subsubsection{Research question two: How do research contexts shape the production of research?}

This research is framed by indigenous, feminist and post-structural methodologies which call for increased sensitivity to place. In both San Miguel and Yachakay I initially proposed a fully collaborative research relationship and in both communities the preference was that I remained in control of the process. Consequently, I aimed to explore community economies using research methods I considered appropriate. In both communities I discovered that context-based parameters still had a strong impact on the way the research was carried out, and thus on research outcomes. I have found this to be significant for ethical and epistemological reasons.

In social research, knowledge is co-created between the socially situated worlds of the researched and the researcher (Denzin \& Lincoln, 2005). Given this post-structural framing, I aimed to be attentive to the ways the research was situated between my social world and community members' social worlds. Yet through the process of carrying out this research, I have come to see that this nexus point between our socially situated worlds is framed by a negotiation of the multiple parameters of my epistemological and methodological lenses, 
community possibilities, and university requirements. In Chapter four I noted how some researchers are paying increasing attention to the political process of negotiating research (England, 1994; Underhill-Sem \& Lewis, 2008), yet others highlight the lack of attention to this process (Mollinga, 2008; Wilkinson, 2008). My experience of carrying out research in the contexts of San Miguel and Yachakay has impelled me to consider the process of negotiation to be of key importance in shaping research outcomes.

For this reason, I have paid significant attention to the ways my research was negotiated in the contexts of San Miguel and Yachakay. In San Miguel I did not carry out focus groups due to their inconvenience for community members. In Yachakay, the PAR plan was reduced in scope and reordered to accommodate community availability and preferences, in addition to my availability within the timeframe of a Masters degree. The re-negotiated plans in both communities aimed to carry out research that satisfied my methodological and epistemological approaches, that was achievable within a Masters framework, and that was suitable according to community preferences. The research that I carried out in both communities is a product of these context-specific negotiations.

In considering the significance of this I have come to focus on some of the power relations surrounding this process of negotiation. Ethical motivations to minimise the power of the researcher and share the benefits of research often stem from a response to legacy of exploitative research. The inherently political nature of research is recognised, leading to some researchers to calling for responsibility to be taken for this political effect (Bentz \& Shapiro, 1998). In response to this, I have sought to carry out research with a key focus on benefitting those with whom I carried out research. Indigenous methodologies state that ethical research with indigenous communities must work from the indigenous perspective and benefit indigenous communities (Louis, 2007). Research relationships are recommended where indigenous communities collaborate in all stages of the research (Hodge \& Lester, 2006; Louis, 2007).

These approaches aim to minimise the power of the researcher in determining the direction of the research and to ensure that the research adequately benefits the communities and the researcher. In focusing on the context specific negotiations of the research, I have illustrated how power was negotiated in multiple ways and that I, the researcher was often the powerless one. Delia and Alberto acknowledged my powerlessness in their motivation to 
help me out of sympathy for my difficult task. Their relative level of power was also noted in their ability to introduce me to their community. Community member power was often exercised through availability to participate in research activities. It was also exercised through language; community members sometimes spoke in Quechua during interviews and the length of translations indicated that not all information was being communicated to me. These mechanisms could be considered "weapons of the weak" (Scott, 1985) and have lead me to reconsider the understanding of the researcher as always powerful and the researched as disempowered. Furthermore, Thapar-Bjorkert and Henry (2004) highlight that by assuming the researched have no access to power, the ways they do assert power are ignored. Increased sensitivity to the multiple ways power is enacted in research relationships, would contribute to a more balanced, respectful approach to carrying out research.

As a result, I see research as a knowledge exchange. Drawing on diverse economy theory, I noticed how commensurability of divergent knowledge exchanges is socially negotiated between those involved. Each knowledge exchange can be assessed for its unique power relations. Some feminist and indigenous researchers espouse a hegemony of negativity whereby research is held as always exploitative (England, 1994). Yet, by recognising research as knowledge exchanges I have come to see at least some of my research relationships as gift exchanges among friends. Exchanges such as gift giving and volunteering involve uneven benefits, yet are not commonly considered exploitative. While I perceive some benefits to have been gained by the communities, some might consider the benefits I will receive (a Masters degree) as potentially outweighing community gains. Yet the continued integrity of my relationship with Delia and Alberto has prompted me to consider that not all research relationships are exploitative, even if the power relations and benefits are uneven.

\subsubsection{Research question three: What are the limitations and potentials of applying a} community economy approach within a Master of Development framework?

Attempting to carry out community economy research in a distant location, within a Masters framework was an ambitious task to undertake. Community economy projects such as Cameron and Gibsons' (2005) work in the Latrobe Valley spanned more than a year of engagement with the community. Funding allowed teams of academics, council employees and community researchers to be trained and to work on the project. The parameters that framed my exploration into community economies were smaller in timeframe, funding, 
number of people involved and expertise. Based on my experiences, research question three seeks to interrogate whether exploring community economies within a Masters framework is a viable exercise.

In San Miguel I aimed to uncover the diverse economy by discussing community members' diverse economic practices in semi-structured interviews. After leaving San Miguel, I reflected on this approach and decided it would not uncover the diverse economy in sufficient depth or breadth, so I sought out a different approach. However, on reflection, I have considered the possibility that a more focused interview guide could have the potential to uncover more of the diverse economy than my initial guide allowed. Individual interviews as a method required minimal input from community members and were relatively easy to facilitate as a beginner researcher. In exploring community economies within a Masters framework, I would consider using individual interviews again.

However, a key stage in the process is communicating the diverse economy and community assets back to the community to show the plethora of ways in which they meet the community's needs. I aimed to communicate this picture of the diverse economy by holding focus groups. As focus groups were inconvenient I reasoned individual follow up interviews could be held. One issue with relying on individual interviews is that it does not allow space for public discussion regarding community member's favoured level of economic interdependence.

In Yachakay, I drew on a PAR approach because I felt it would be more effective in exploring the existing community economy and building on this. I adapted this approach, creating a methodology plan I thought was achievable in the remaining six weeks I had in Bolivia. In negotiating this plan with the community, I realised that I had much less time within which to carry out my adaptation. Community members were only available on Sundays, and only one group activity was possible. In Chapter five I discussed the ways in which my plan was altered to suit community preferences and availability. Therefore a key factor affecting the viability of both approaches was the essential process of negotiating the research into the field within a limited timeframe.

As a student enrolled at Victoria University of Wellington, I was required to comply with a number of regulations in completing this research. The key restriction being that the thesis is 
completed within a one year timeframe. Victoria University policy allows Masters students to take up to 18 months with a 28 day grace period (Research Policy Group, 2011). Yet, the Development Studies Programme expects students to complete within one year (Victoria University of Wellington, 2011). Furthermore, the encouraged time period for fieldwork within a Masters in Development Studies at Victoria University of Wellington is up to three months. The change in research location meant that I was unable to spend the entirety of this three month period with a single community. It is possible that either of these community economy approaches would have been more successful, given a full three months.

Despite these restrictions, the university has also been a key enabling force for me in carrying out this research. The support provided by my supervisor and my academic peers would not exist without the university framework. I received a Victoria University of Wellington Scholarship which allowed me carry out this research. In many ways, the university has provided an enabling space for me to carry out this research.

Despite the messy process of negotiating the research in the field (Mollinga, 2008), there are notable outcomes from this research. In San Miguel and especially in Yachakay, the activities I did carry out allowed community members to discuss some of their skills, abilities, dreams and aspirations. In Yachakay, the community project brainstorming activity allowed these attributes to be shared and discussed. Individual and group priorities were explored. Alberto, a community leader in Yachakay, noted that he had learnt significantly more about the priorities of community members through the process of carrying out the Portraits of Gifts and the brainstorming activity. These successes are important to acknowledge as 'potentialities' for carrying out research into community economies within a Masters framework in the future.

Through the process I have learnt a significant amount about carrying out social research and building community economies. My personal gains have been immense. However, a misunderstanding of the role of national and international institutions in the community economy process lead me to reflect on whether it is ethical to engage with communities as a inexperienced researcher. During the brainstorming activity in Yachakay, community members were discussing potential ways of going about connecting potable water to the neighbourhood. Reflecting my level of understanding, I suggested they think of local ways of 
going about connecting the water. I have concluded that while these kinds of errors are not ideal, they are an inevitable part of research. Furthermore ethical relationships are not dependent on being 'right.' Rather it is important to be humble and share the learning process.

A further challenge was completing this research in a distant place. Although I set out prepared to learn as I went (Veeck, 2001), my lack of linguistic and cultural fluency presented difficulties in carrying out this research. I was not prepared for the embodied experience of emotional and physical exhaustion. Nor had I fully considered the time it would take to translate interview guides into Spanish and interview transcripts into English. Transcribing in a second language was a slow process because my lack of fluency meant words could not be instinctually guessed at when they were not clearly audible on the tape. I eventually appealed to a Peruvian friend to help me transcribe interviews. If I attempted to explore community economies in a second language again, I would not hesitate for so long to get outside help transcribing. Despite these difficulties, the moments of understanding increased throughout the process. Therefore, in addition to the embodied emotional difficulties, an increasing number of embodied emotional joys coincided with moments of mutual understanding between community members and me.

However, perhaps the biggest limitation for me personally has been in not consistently following my own advice, "to treat the glass as half-full while not denying that it is also halfempty" (Gibson-Graham, 2005b, p. 119). It has continued to be difficult to view various anomalies that occurred as resources to be learnt from. In hindsight, the emotional burden of these difficulties would have been a lot lighter if I had carried this wisdom closer to my heart. Nonetheless, I believe I have achieved this in the end.

There are certainly benefits to carrying out community economies within a Masters framework. These benefits are relevant to both the communities involved and the researcher. However, great consideration needs to be taken in preparation for this research in the amount of time allowed to build relationships in the community and carry out the lengthy research process in a timeframe that suits the community as well as the university. While Masters level research is a learning process, to truly engage with critical theories and methodologies, a certain amount of preparedness needs to be combined with flexibility in the field and an openness on behalf of the researcher to learn. 


\subsection{Conclusion}

In this chapter I have reflected on my initial motivations for carrying out research into community economies. I have summarised the two approaches I have undertaken to explore community economies. I have returned to my research questions, detailing how this thesis has responded to each of them. In contribution to the community economy approach, I have reiterated the importance of moving past the 'moment of representation.' This is important in ensuring the potential performative benefits of this new representation are shared with the communities involved. I have explored the ways that research contexts impact on research outcomes, suggesting that a more nuanced understanding of power dynamics surrounding 'knowledge exchanges' could lead to a more ethical approach to carrying out research. I consider there to be both potentialities and limitations in carrying out research into community economies within a Masters Framework. However, this research represents my attempt to start here and now, building on my current skills and abilities to explore alternative economic futures in distant places. I hope that my findings will contribute to the growing literature on community economies and ethical methodologies, albeit in a small way. 


\section{References}

Aguilar, F. V. (2005). Excess possibilities? Ethics, populism and community economy: A commentary on J. K. Gibson-Graham's "Surplus possibilities: Postdevelopment and community economies". Singapore Journal of Tropical Geography, 26(1), 27-31.

Alberto (2010). Personal Communication. Sucre.

Alejandra (2010). Personal Communication. San Miguel.

Andolina, R., Radcliffe, S., \& Laurie, N. (2005). Development and culture: Transnational identity making in Bolivia. Political Geography, 24, 678-702.

Bebbington, A. (1993). Modernization from below: An alternative indigenous development? Environment and Development, 69(3), 274-292.

Bebbington, A. (2000). Reencountering development: Livelihood transitions and place transformations in the Andes. Annals of the Association of American Geographers, 90(3), 495-520.

Bentz, V. M., \& Shapiro, J. J. (1998). Mindful inquiry in social research. Thousand Oaks: Sage Publications.

Bishop, R. (1997). Maori people's concerns about research into their lives. History of Education Review, 26, 25-41.

Bomberry, V. (2008). Refounding the nation: A generation of activism in Bolivia. American Behavioral Scientist, 51(12), 1790-1800.

Brigg, M. (2002). Post-development, Foucault and the colonisation metaphor. Third World Quarterly, 23(3), 421-436.

Cahill, A. (2008). Power over, power to, power with: Shifting perceptions of power for local economic development in the Philippines. Asia Pacific Viewpoint, 49(3), 294-304.

Cameron, J., \& Gibson, K. (2001). Shifting focus: Alternative pathways for communities and economies: A Resource Kit Available from http://www.communityeconomies.org/site/assets/media/old\%20website\%20pdfs/a ction\%20research/Shifting\%20Focus.pdf

Cameron, J., \& Gibson, K. (2005). Participatory action research in a poststructuralist vein. Geoforum, 36(3), 315-331.

Cammack, P. (2002). Neoliberalism, the World Bank and the new politics of development. In U. Kothari \& M. Minogue (Eds.), Development theory and practice: Critical perspectives. Houndsmill: Palgrave.

Carnegie, M. (2008). Development prospects in Eastern Indonesia: Learning from Oelua's diverse economy. Asia Pacific Viewpoint, 49(3), 354-369. 
Chacko, E. (2004). Positionality and praxis: fieldwork experiences in rural India. Singapore Journal of Tropical Geography, 25(1), 51-63.

Chase, S. E. (2000). Narrative Inquiry: Multiple lenses, approaches, voices. In N. Denzin, K. \& Y. Lincoln, S. (Eds.), The sage handbook of qualitative research (3rd ed.). Thousand Oaks: Sage Publications.

Corbridge, S. (1998). "Beneath the pavement only soil": The poverty of post-development. Journal of Development Studies, 34(6), 138-148.

Cornwall, A. (2007). Buzzwords and fuzzwords: deconstructing development discourse. Development in Practice, 17(4-5), 471-484.

Cowan, M., \& Shenton, R. (1996). Doctrines of development. London: Routledge.

Crang, M. (2005). Analysing qualitative materials. In R. Flowerdew \& D. Martin (Eds.), Methods in human geography (2nd ed., pp. 218-232). Essex: Pearson Education Limited.

Crazy Bull, C. (1997). Advice for the non-Native researcher. Tribal College: Journal of American Indian Higher Education, 9(1), 24-24.

Crush, J. (1995). Power of development. London: Routledge.

Cupples, J. (2002). The field as a landscape of desire: sex and sexuality in geographical fieldwork. Area, 34(4), 382-390.

Curry, G. (2003). Moving beyond postdevelopment: Facilitating indigenous alternatives for "development". Economic Geography, 79(4), 405-423.

Curry, G. (2005). Reluctant subjects or passive resistance? A commentary on J. K. GibsonGraham's "Surplus possibilities: Postdevelopment and community economies.". Singapore Journal of Tropical Geography, 26(2), 127-131.

de Ishtar, Z. (2005). Striving for a common language: A white feminist parellel to indigenous ways of knowing and researching. Women's Studies International Forum, 28, 357368.

Delia (2010). Personal Communication. Sucre.

Delia, \& Alberto (2010). Personal Communication. Sucre.

Denzin, N., K., \& Lincoln, Y., S. (2005). Introduction: The discipline and practice of qualitative research. In N. Denzin, K. \& Y. Lincoln, S. (Eds.), The sage handbook of qualitative research (3rd ed.). Thousand Oaks: Sage Publications.

Dunn, K. (2005). Interviewing. In I. Hay (Ed.), Qualitative research methods in human geography (2nd ed.). Melbourne: Oxford University Press.

Eade, D. (2007). Editorial. Development in Practice, 17(4), 467-470.

Eduardo (2010). Personal Communication. San Miguel. 
Elwood, S. A., \& Martin, D. G. (2000). "Placing" interviews: Location and scales of power in qualitative research. The Professional Geographer, 52(4), 649-657.

England, K. V. L. (1994). Getting personal: reflexivity, positionality, and feminist research. The Professional Geographer, 46(1), 80-89.

Escobar, A. (1995). Encountering development: The making and unmaking of the Third World. New Jersey: Princeton University Press.

Esteva, G. (1992). Development. In W. Sachs (Ed.), The Development Dictionary (pp. 6-25). London: Zed Books.

Esteva, G., \& Prakesh, M. S. (1997). From global thinking to local thinking. In M. Rahnema \& V. Bawtree (Eds.), The post-development reader. London: Zed Books Ltd.

Evans, M. (2010). Feeling their way: Four men talk about fatherhood in Valparaíso, Chile. Victoria University of Wellington, Wellington.

Evans, M., Hole, R., Berg, L. D., Hutchinson, P., \& Sookraj, D. (2009). Common insights, differing methodologies: Toward a fusion of indigenous methodologies, participatory action research, and white studies in an urban aboriginal research agenda. Qualitative Inquiry, 15(5), 893-910.

Ferguson, J. (1990). The anti-politics machine: "development," depoliticization, and bureaucratic power in Lesotho: University of Minnesota Press.

Fontana, A., \& Frey, J. (2000). The interview: from structured questions to negotiated text. In N. Denzin, K. \& Y. Lincoln, S. (Eds.), The sage handbook of qualitative research (2nd ed.). Thousand Oaks: Sage Publications Inc.

Foucault, M. (1972). The archaeology of knowledge. New York: Harper and Row.

Foucault, M. (1973). The order of things. New York: Vintage Press.

Gegeo, D. (1998). Indigenous knowledge and empowerment: Rural development examined from within. The Contemporary Pacific, 10(2), 289-315.

Gibson-Graham, J. K. (2005a). Surplus possibilities: Postdevelopment and community economies. Singapore Journal of Tropical Geography, 26(1), 4-26.

Gibson-Graham, J. K. (2005b). Traversing the fantasy of sufficiency: A response to Aguilar, Kelly, Laurie and Lawson. Singapore Journal of Tropical Geography, 26(2), 119-126.

Gibson-Graham, J. K. (2006). A postcapitalist politics. Minneapolis: University of Minnesota Press.

Gibson-Graham, J. K. (2008). Diverse economies: Performative practices for 'other worlds'. Progress in Human Geography, 32(5), 613-632.

Gibson-Graham, J. K., \& Cameron, J. (2003). Feminising the economy: metaphors, strategies, politics. Gender, Place and Culture, 10(2), 145-157. 
Gisbert, M. E., Painter, M., \& Quitón, M. (1994). Gender issues associated with labour migration and dependence on off-farm income in rural Bolivia. Human Organisation, $53(2), 110-122$.

Greenwood, D., J. , \& Levin, M. (2005). Reform of the social sciences and of universities through action research. In N. Denzin, K. \& Y. Lincoln, S. (Eds.), The sage handbook of qualitative research (3rd ed.). Thousand Oaks: Sage Publications.

Guadalupe (2010). Personal Communication. San Miguel.

Harvey, D. (2005). A brief history of neoliberalism. New York: Oxford University Press Inc.

Hennink, M. M. (2007). International focus group research: $A$ handbook for the health and social sciences. Cambridge: Cambridge University Press.

Hodge, P., \& Lester, J. (2006). Indigenous research: Whose priority? Journeys and possibilities of cross-cultural research in geography. Geographical Research, 44(1), 41-51.

Jagger, A. M. (1989). Love and knowledge: Emotion in feminist epistemology. In A. M. Jagger \& S. Bordo (Eds.), Gender/body/knowledge/feminist reconstructions of being and knowing. New Brunswick: Rutgers University Press.

Juan (2010). Personal Communication. San Miguel.

Kelly, P. (2005). Scale, power and the limits to possibilities: A commentary on J. K. GibsonGraham's "Surplus possibilities: Postdevelopment and community economies". Singapore Journal of Tropical Geography, 26(1), 39-43.

Kesby, M., Kindon, S., \& Pain, R. (2005). 'Participatory' approaches and diagramming techniques. In R. Flowerdew \& D. Martin (Eds.), Methods in Human Geography (2nd ed.). Harlow: Pearson Education Limited.

Kiely, R. (1999). The last refuge of the noble savage? A critical assessment of postdevelopment theory. The European Journal of Development Research, 11(1), 30-55.

Kincheloe, J., \& McLaren, P. (2005). Rethinking critical theory and qualitative research. In N. Denzin, K. \& Y. Lincoln, S. (Eds.), The sage handbook of qualitative research (pp. 303342). London: Sage.

Kitchin, R., \& Tate, N. J. (2000). Conducting research into Human Geography. Essex: Pearson Education Limited.

Kohl, B. (2002). Stabilizing neoliberalism in Bolivia: popular participation and privatization. Political Geography, 21(4), 449-472.

Kohl, B., \& Farthing, L. (2006). Impasse in Bolivia: Neoliberal hegemony \& popular resistance. London: Zed Books.

Kothari, U. (2002). Feminist and postcolonial challenges to development. In U. Kothari \& M. Minogue (Eds.), Development theory and practice: critical perspectives (pp. 35-51). Houndsmills: Palgrave. 
Kretzmann, J., \& McKnight, J. (1993). Building communities from the inside out: a path toward finding and mobilizing a community's assets. . Evanston, IL: Institute for Policy Research.

Latouche, S. (1997). Paradoxical growth. In M. Rahnema \& V. Bawtree (Eds.), The postdevelopment reader. London: Zed Books Ltd.

Laurie, N. D. (2005). Putting the messiness back in: Towards a geography of development as creativity. Singapore Journal of Tropical Geography, 26(1), 32-35.

Lawson, V. (2005). Hopeful geographies: Imagining ethical alternatives. A commentary on J. K. Gibson-Graham's "Surplus possibilities: Postdevelopment and community economies". Singapore Journal of Tropical Geography, 26(1), 36-38.

Lopez Levy, M. (2001). Bolivia: An Oxfam Country Profile. Oxford: Oxfam GB.

Louis, R. P. (2007). Can you hear us now? Voices from the margin: Using indigenous methodologies in geographic research. Geographical Research, 45(2), 130-139.

Lucia (2010). Personal Communication. San Miguel.

Luisa (2010). Personal Communication. San Miguel.

Mandel, J. L. (2003). Negotiating expectations in the field: Gatekeepers, research fatigue and cultural biases. Singapore Journal of Tropical Geography, 24(2), 198-210.

McDaniel, J. M. (2003). Community-based forestry and timber certification in Southeast Bolivia. Small-scale Forestry, 2(3), 327-341.

McEwan, H., \& Egan, K. (Eds.). (1995). Narrative in teaching, learning and research. New York: Teachers College Press.

McGregor, A. (2007). Development, foreign aid and post-developmetn in Timor-Leste. Third World Quarterly, 28(1), 155-170.

McGregor, A. (2009). New possibilities? Shifts in post-development theory and practice. Geography Compass, 3(5), 1688-1702.

McKinnon, J., \& McKinnon, J. (2010). Participatory learning \& action: Guide for NGO facilitators \& graduate researchers. Wellington: Kinsa Associates.

McKinnon, K. (2007). Postdevelopment, professionalism, and the politics of participation. Annals of the Association of American Geographers, 97(4), 772-785.

Menzies, C. R. (2001). Reflections on research with, for, and among indigenous peoples. Canadian Journal of Native Education, 25(1), 19-36.

Mollinga, P. (2008). Field research methodology as boundary work: An introduction. In C. Wall \& P. Mollinga (Eds.), Fieldwork in difficult environments: Methodology as boundary work in development research. Zurich: Lit Verlag GmbH \& Co, KG Wien.

Müller, K. (2009). Contested universalism: from Bonosol to Renta Dignidad in Bolivia. International Journal of Social Welfare, 18(2), 163-172. 
Nandy, A. (1997). Colonization of the mind. In M. Rahmena \& V. Bawtree (Eds.), The postdevelopment reader. Bangladesh: The Universtiy Press.

Nustad, K. (2001). Development: the devil we know? Third World Quarterly, 22(4), 479-489.

Peck, J., \& Tickell, A. (2002). Neoliberalizing Space. Antipode, 34(3), 380-404.

Peet, R. (1997). Social theory, postmodernism, and the critique of development. In G. Benko \& U. Strohmayer (Eds.), Space \& social theory: Interpreting modernity \& postmodernity. Oxford: Blackwell Publishers Ltd.

Peet, R. (1999). Theories of development. New York: The Guilford Press.

Pieterse, J. N. (1998). My paradigm or yours? Alternative development, post-development, reflexive development. Development and Change, 29, 343-373.

Pieterse, J. N. (2000). After Post-Development. Third World Quarterly, 21(2), 175-191.

Postero, N. (2005). Indigenous responses to neoliberalism: A look at the Bolivian uprising of 2003. Political and Legal Anthropology Review, 28(1), 73-92.

Price, M. D. (2001). The kindness of strangers. Geographical Review, 91(1/2), 143-150.

Rahnema, M., \& Bawtree, V. (1997). The post-development reader. London: Zed Books Ltd.

Ramonet, I. (1997). The one and only way of thinking. In M. Rahmena \& V. Bawtree (Eds.), The postdevelopment reader. London: Zed Books.

Rapley, J. (2008). End of development or age of development? Progress in Development Studies, 8(2), 177-182.

Reason, P., \& Bradbury, H. (2001). Introduction: inquiry and participation in search of a world worth of human aspiration. In P. Reason \& H. Bradbury (Eds.), Handbook of action research: Participative inquiry and practice (pp. 1-14). London: Sage.

Human Ethics Policy (2007).

Master's Thesis Policy (2011).

Rist, G. (2007). Development as a buzzword. Development in Practice, 17(4-5), 485-491.

Rojas, C. (2007). International political economy/Development Otherwise. Globalizations, $4(4)$, 573-587.

Rose, G. (1997). Situating knowledges: positionality, reflexivities and other tactics. Progress in Human Geography, 21(3), 305-320.

Rushton, R. (2010). 2010 reflective journal. Unpublished Reflective journal. Victoria University of Wellington.

Sachs, W. (1992). The development dictionary: a guide to knowledge as power. London: Zed Books Ltd. 
Sachs, W. (1997). The need for a home perspective. In M. Rahnema \& V. Bawtree (Eds.), The post-development reader. London: Zed Books Ltd.

Santos, B. d. S. (2004). The WSF: Toward a counter-hegemonic globalization. In A. Sen, A. Escobar \& P. Waterman (Eds.), World Social Forum: Challenging empires (pp. 235245). New Delhi: The Viveka Foundation.

Sara (2010). Personal Communication. San Miguel.

Schneider, F. (2005). Shadow economies around the world: what do we really know? European Journal of Political Economy, 21(3), 598-642.

Schuurman, F. (2000). Paradigms lost, paradigms regained? Development studies in the twenty-first century. Third World Quarterly, 21(1), 7-20.

Scott, J. C. (1985). Weapons of the weak: everyday forms of peasant resistance: Yale University Press.

Sharp, J. (2005). Geography and gender: feminist methodologies in collaboration and in the field. Progress in Human Geography, 29(3), 304-309.

Shiva, V. (1997). Western science and its destruction of local knowledge. In M. Rahmena \& V. Bawtree (Eds.), The post-development reader. Bangladesh: The University Press Ltd.

Smith, L. T. (1999). Decolonizing methodologies: Research and indigenous peoples. London: Zed Books.

SpanishDict (1999). Retrieved 23/3/2011, from http://www.spanishdict.com/translate/chola

Storey, A. (2000). Post-development theory: Romanticism and Pontius Pilate politics. Development, 43(4), 40-46.

Ströbele-Gregor, J. (2011). Chapter 4: Black day in the white city: Racism and violence in Sucre. In O. Kaltmeier (Ed.), Selling ethnicity: Urban cultural politics in the Americas (pp. 71-90). Farnham: Ashgate Publishing Ltd.

Thapar-Bjorkert, S., \& Henry, M. (2004). Reassessing the research relationship: location, position and power in fieldwork accounts. International Journal of Social Research Methodology, 7(5), 363-381.

Tillmann-Healy, L. M. (2003). Friendship as Method. Qualitative Inquiry, 9(5), 729-749.

Tucker, V. (1999). The myth of development: A critique of a Eurocentric discourse. In M. Munck \& D. O'Hearn (Eds.), Critical development theory: Contributions to a new paradigm (pp. 1-26). London: Zed Books.

Turner, S. (2010). Research Note: The silenced assistant. Reflections of invisible interpreters and research assistants. Asia Pacific Viewpoint, 51(2), 206-219.

Underhill-Sem, Y., \& Lewis, N. (2008). Asset mapping and Whanau action research: 'New' subjects negotiating the politics of knowledge in Te Rarawa. Asia Pacific Viewpoint, 49(3), 305-317. 
United Nations Development Programme (2010). Regional and national trends in human development index1970-2010 Retrieved 21/8/2011, 2011, from http://hdr.undp.org/en/data/trends/

Valentine, G. (2005). Tell me about ...: using interviews as a research methodology. In R. Flowerdew \& D. Martin (Eds.), Methods in human geography: A guide for students doing a research project (2nd ed., pp. 110-127). Essex: Pearson Education Limited.

Veeck, G. (2001). Talk is Cheap: Cultural and Linguistic Fluency during Field Research. Geographical Review, 91(1/2), 34-40.

Victoria University of Wellington (2011). Postgraduate Prospectus 2011: Development Studies. Wellington: Victoria University of Wellington.

Walsh, C. (2005). TERS: The essential research skills. Suva: Amokura Publications.

Wiles, J. L., Rosenberg, M. W., \& Kearns, R. A. (2005). Narrative analysis as a strategy for understanding interview talk in geographic research. Area, 37(1), 89-99.

Wilkinson, C. (2008). Positioning "security" and securing one's position: The researcher's role in investigating "security in Kyrgyzstan. In C. Wall \& P. Mollinga (Eds.), Fieldwork in difficult environments: Methodology as boundary work in development research. Zurich: Lit Verlag GmbH \& Co, KG Wien.

Williams, C., Nadin, S., Rodgers, P., \& Round, J. (2011). Rethinking the nature of community economies: some lessons from post-Soviet Ukraine. Community Development Journal, 1-16.

Ziai, A. (2007). Exploring post-development: theory and practice, problems and perspectives. Oxon: Routledge. 


\section{Glossery}

Ayni: Reciprocal system of labour carried out during the harvest season.

Bolivianos: Bolivian national currency.

Campesino/a: Person from the country, peasant, - became popular after 1952 land reform when indigenous uprisings were 'captured' by the class movement. The o/a word ending represents the masculine and feminine forms of the word.

Chacra: Farm or farmed plot of land.

Chola/Cholita: Woman of mixed race. Often used in a derogatory sense.

Faena: Community volunteer day.

Indio: Term used to refer to indigenous people; today this term is often understood as derogatory.

Jornal: Day's wage.

Mestizo: Person of mixed race.

Minka: Reciprocal system of labour carried out during the planting season.

Pollera: Typical style of skirt worn by campesina women.

Trueque: Indigenous system of barter.

\section{Acronyms}

GDP: Gross Domestic Product

GNP: Gross National Product

IMF: International Monetary Fund

LPP: Law of Popular Participation

MNR: Revolutionary Nationalist Movement (Movimiento Nationalista Revolucionario)

NGO: Non Government Organisation

PAR: Participatory Action Research

SAP: Structural Adjustment Program

WTO: World Trade Organisation 


\title{
Appendices
}

\section{Appendix One: Participant Information Sheet (English)}

\author{
VICTORIA UNIVERSITY OF WELLINGTON \\ Te Whare Wananga o te Upoko o te Ika a Maui
}

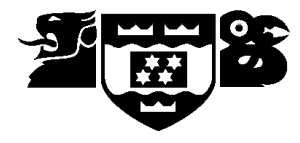

\section{Participant Information Sheet for a Study of NGO Development Projects and Community Economies}

Researcher: Renee Rushton: School of Geography, Environment and Earth Sciences, Victoria University of Wellington

I am a Masters student in Development Studies at Victoria University of Wellington. As part of this degree I am undertaking a research project leading to a thesis. The project I am undertaking is examining community economies and activities within and outside of development projects in Sucre.

I am inviting people living in your community or working in your organisation to take part in this study. If you are willing to participate, I will ask you to sit down with myself (and probably a translator) for an interview of about 30 minutes length, but no longer than an hour. I will have some basic questions prepared, but I am interested in what you have to say so it will be flexible and discussion based. I will ask your permission to record the interview.

Participation is completely voluntary and you can withdraw from the project without question at any time before the data is analysed, which will be Monday June $28^{\text {th }} 2010$. During the interview you are welcome to skip any question you do not feel comfortable answering. Just let me know at the time.

Your responses will form the basis of my research project and will be used as evidence for my thesis. My thesis will be written in a confidential way, it will not be possible for you to be identified personally. I will change your names and take out any other identifying information from any report I publish. All material collected from this interview or focus group will be locked away so as to ensure your confidentiality. No other person besides me, my supervisor, Andrew McGregor, will see or hear the interview transcripts. The thesis will be submitted for marking to the School of Geography, Environment and Earth Sciences and deposited in the University Library. It is intended that one or more articles will be submitted for publication in scholarly journals. There is a possibility that information may be disseminated at academic or professional conferences. Diaries and questionnaires will be destroyed two years after the end of the project.

If you have any questions or would like to receive further information about the project, please contact me by email: renee.rushton@gmail.com; or by mobile telephone: +64 272455049. While in Sucre, Bolivia you can contact me at the Natanial Aguire 209, mobile telephone: 77123486. My supervisor, Andrew McGregor can be contacted at the School of Geography, Environment and Earth Sciences, by email: andrew.mcgregor@vuw.ac.nz; or by telephone: +64 44636452.

Renee Rushton

Signed: 


\title{
Appendix Two: Participant Information Sheet (Spanish)
}

\author{
VICTORIA UNIVERSITY OF WELLINGTON \\ Te Whare Wananga o te Upoko o te Ika a Maui
}

\section{Hoja de información del participante para un estudio de los proyectos de desarrollo del ONG y de las economías de comunidad}

Investigadora: Renee Rushton: Escuela de la geografía, del medio ambiente y de las geologías, Universidad de Victoria de Wellington

Soy estudiante de maestria en estudios del desarrollo en la Universidad de Victoria de Wellington. Como parte de este curso estoy emprendiendo un proyecto de investigación que lleva a una tesis. La investigación que estoy haciendo está examinando las economías y actividades dentro de la comunidad de Señor Santiago, Azari, Sucre, Bolivia.

Estoy invitando a la gente que vive en su comunidad para participar en este estudio. Si usted está dispuesto a participar, pediré que usted se siente con migo (y probablemente un traductor) para una entrevista de la longitud de cerca de 30 minutos, pero no más que una hora. Tendré algunas preguntas básicas preparadas, pero estoy interesado en lo que usted tiene que decir, así que será flexible el dialogo. Pediré su permiso para registrar la entrevista.

La participación en todas las actividades es completamente voluntaria y todos los participantes pueden renunciar en cualquier momento sin preguntar, antes de que los datos sean analizados, lo cual sera el lunes 28 de Junio. Durante la entrevista usted es agradable omitir cualquier pregunta que no sienta la contestación cómoda. Apenas déjeme en ese momento.

Las respuestas formarán la base de mi proyecto de investigación y serán utilizadas como evidencia para mi tesis. La cual será escrita de manera confidencial, no será posible que sean identificados personalmente. Cambiaré sus nombres y sacaré cualquier otra información de identificación de cualquier informe que publique. Todo el material recogido de esta entrevista o grupo principal se mantendra en secreto para asegurar su anonimato. Ninguna otra persona aparte de mí, mi supervisor, Andrew McGregor y mis traductores Delia Beltran y Alberto Enrriquez verá u oirá las datos de la investigación. La tesis será sometida a consideracion de la escuela de geografía, del medio ambiente y de las geologías y depositada en la biblioteca de la universidad. Se piensa que uno o más artículos serán publicados en revistas academicas. Hay una posibilidad de que la información se puede diseminar en las conferencias académicas o profesionales. Los diarios y los cuestionarios serán destruidos dos años después del final del proyecto.

Si usted tiene cualesquiera preguntas o las quisiera recibir la información adicional sobre el proyecto, éntreme en contacto con por favor por el email: renee.rushton@gmail.com; o por el teléfono móvil: +64 272455049. Mientras estoy en Sucre, Bolivia puedes contactarme a Nataniel Aguire 209, teléfono móvil: 77123486. Mi supervisor, Andrew McGregor puede ser entrado en contacto con en la escuela de la geografía, del ambiente y de las geologías, por el email: andrew.mcgregor@ vuw.ac.nz; o por el teléfono: +6444636452.

Renee Rushton

Firma: 


\title{
Appendix Three: Consent form (English)
}

\author{
VICTORIA UNIVERSITY OF WELLINGTON \\ Te Whare Wananga o te Upoko o te Ika a Maui
}

\section{Consent Form}

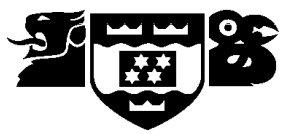

Title of project: Building on community strengths: An exploration into community economies as an alternative to development.

I have been given and have understood an explanation of this research project. I have had an opportunity to ask questions and have them answered to my satisfaction. I understand that I may withdraw myself (or any information I have provided) from this project at anytime (so long as it is before Renee Rushton (the researcher) starts the analysis on Monday June $28^{\text {th }}$ 2010).

I understand that any information I provide will be kept confidential to the researcher and the supervisor, the published results will not use my name, and that no opinions will be attributed to me in any way that will identify me.

I understand that I will have an opportunity to check the transcripts of the interview before publication.

I understand that the data I provide will not be used for any other purpose or released to others without my written consent.

I agree to take part in this research.

Signed:

Name of participant (Please print clearly):

Date:

\section{Tape recordings and results summaries}

I would like the tape recordings of my interview returned to me at the conclusion of the project.

I would like to receive a summary of the results of this research when it is completed.

\section{Address}

If you would like the tape recordings of your interview returned and/or a summary of the research, please print your postal address below: 


\title{
Appendix Four: Consent form (Spanish)
}

\author{
VICTORIA UNIVERSITY OF WELLINGTON \\ Te Whare Wananga o te Upoko o te Ika a Maui
}

\section{Forma del consentimiento}

Título del proyecto: Elaborando/Construyendo en fuerzas de la comunidad: Una exploración en economías de comunidad como alternativa al desarrollo.

Me han dado y he entendido una explicación de este proyecto de investigación. He tenido una oportunidad de hacer preguntas y de hacerlas contestar a mi satisfacción. Entiendo que puedo retirarme (o cualquier información que haya proporcionado) de este proyecto en cualquier momento (si es antes de que Renee Rushton (la investigadora) comience el análisis el lunes 28 de junio de 2010).

Entiendo que cualquier información que proporcione será mantenida confidencial a la investigadora y al supervisor, los resultados publicados no utilizará mi nombre, y que no se atribuirá ningunas opiniones a mí de ninguna manera que me identifique.

Entiendo que tendré una oportunidad de comprobar las transcripciones de la entrevista antes de la publicación.

Entiendo que los datos que proporciono no serán utilizados para ningun otro propósito ni serán lanzados a otros sin mi consentimiento escrito.

Acuerdo participar en esta investigación.

Firmado:

Nombre del participante (imprima claramente por favor):

Fecha:

Grabaciones y resúmenes de los resultados

Quisiera las grabaciones de mi entrevista vuelta a mí en la conclusión del proyecto.

Quisiera recibir un resumen de los resultados de esta investigación cuando se termina.

\section{Dirección}

Si usted quisiera las grabaciones de su entrevista vuelta y/o de un resumen de la investigación, imprima por favor su dirección postal abajo: 


\section{Appendix Five: Interview guide San Miguel}

\section{English}

1. Can you tell me a bit about yourself?

2. What's a normal day like for you in this season?

3. What sort of work do you do to earn a living? Can you tell me a bit about this?

4. What else do you do to supplement your income and/or your food? Can you tell me a bit about this?

5. If you had the opportunity, how would improve your income?

6. Do you participate in communal work such as Minka, Ayni, Jornal and a la partida? Could you tell me a bit about these systems? How do they work? Do they work well for you?

7. Does the government or the municipality provide any services here? If so, what services?

8. Are there any NGOs working here? What are they called? What do they do? Could you tell me a bit about this? What do you think of their work?

9. Do the people from the NGOs talk to you before, after and during their projects? What do they talk to you about?

10. Do you think that the projects could be improved? How?

11. What do you propose (or what would you like) NGOs to do in the community?

12. What good things does your community have?

13. What could be improved?

\section{Spanish}

1. Puedes dicirme un poco sobre tu, una corta historia de tu vida?

2. Como es un dia normal para ti en este epoca/estacion?

3. Como participas en el trabajo para tener con que viver?

4. Que otros trabajos haces para aumentar/suplir tu plata y/o tus alimentos?

5. Si tendrias una opportunidad, que quisieras para que mejore tus ingresos?

6. Ustedes participan en algunas trabajos comunales? (como minka, ayni, faina, o a la partida). Puedes decirme como funcionan estas systemas, y son buenos para ustedes?

7. Hay servicios municipales o del gobierno? Cuales?

8. Hay ONGs o instituciones cooperando aquí? Como se llaman? Que hacen? Puedes decirme sobre esto? Que piensas sobre los trabajos de los ONGs?

9. La gente de los ONGs les hablan a ustedes antes, durante y despues de sus trabajos? De que hablan?

10. Piensas que pueden mejorah estos proyectos? Como?

11. Que propones (o que quisieras) que hagan las ONGs en la communidad?

12. Que cosas buenas tiene la comunidad?

13. Que se puede mejorar? 


\section{Appendix Six: Interview guide - Yachakay}

\section{English}

1. Can you tell me a bit about yourself? A short story about yourself?

2. What do you do for work?

3. What's a normal week like for you at this time of year?

4. What other things do you do to augment your income/food?

5. Do you participate in any communal work? (Like minka, ayni or faina)

6. How would you define poverty?

7. Did you enjoy the group activities the other day?

8. Would you agree with these results? (No? what do you think needs to change?)

9. How do you feel about the results?

10. Do you think these result will contribute to changes in the community? What kind of changes for example?

11. What does wellbeing mean to you?

12. What do you think could be done to improve wellbeing?

13. When you think about a project in ... (sewing/cooking) how do you see it working? What form do you see it taking?

14. What things/abilities do you have now that could help to begin this idea?

15. Do you have any ideas for how you could realise this idea? It could be anything.

\section{Spanish}

1. Puedes dicirme un poco sobre tu, una corta historia de tu vida?

2. Que haces para trabajar?

3. Como es una semana normal para ti en este epoca/estacion?

4. Que otros cosas haces para aumentar/suplir tu plata y/o tus alimentos?

5. Ustedes participan en algunas trabajos comunales? (como minka, ayni, faina, o a la partida)

6. Y como definas la pobresa? Sabes alguien o algunas personas que puede ser son pobresas?

7. Desfrutaste estos actividades? Cuales cosas te gustaron?

8. Piensas que estos resultados son corectos? (No - Que necesitamos cambiar?)

9. Como te sientes sobre estos resultados?

10. Piensas que estos resultados van a contribuir a cambios en la comunidad? Cuales cambios por ejemplo?

11. Para ti, que significa bienestar?

12. Crees que puedas hacer algo para lograr este mejor nivel de bienestar? Cuales cosas?)

13. Cuando piensas en un proyecto de ...... (costura/posteleria etc) como lo percibes? En que forma lo percibes?

14. Cuales cosas/habilidades tienes ahora que puede ayudar en empesando este idea?

15. Tienes algunas ideas por como puedas actualizar este idea? Puede ser cualquier cosa. 


\section{Appendix Seven: Portrait of gifts questionnaire (Spanish)}

This questionnaire was adapted and translated from Cameron and Gibson's (2001) Appendix 2: Sample Portrait of Gifts and Brochure Reporting Results. Because it is quite large I have just included the Spanish version.

\section{Retrato de Regalos}

Cada individuo tiene regalos. Regalos de la cabeza, la mano y el corazón. Puede ser que tenga un talento o un conocimiento de como funcionan las cosas (cabeza), habilidad para arreglar cosas (mano) o aún tenga un interés entusiasta en el medio ambiente (corazón). La investigación es sobre la identificación de los regalos de la gente, y mejorar las percepciones de la gente de la comunidad. También crear un ambiente de posibilidades para nuevos proyectos económicos que estén basados en la comunidad.

La información que nos da puede ser presentada en talleres comunales para demonstrar la gama de habilidades que tiene la gente en la comunidad. La información recolectada será usada de manera confidencial. Los talleres son para construir conecciones con otra gente en la comunidad y para desarollar las ideas para proyectos tangibles e iniciativos. Quizas tu quisieras venir y compartir tus ideas y participar en la crear/formentar/ampliar de ideas nuevos para proyectos economicos dentro de tu comunidad.

Tu Ayuda en rellenando este inventario de habilidades estara inestimable para el éxito del proyecto.

Estoy de acuerdo de la presentacion de la informacion proporcionara en las talleres comunales (Entiendo que informacion identificada personal mio no estara presentada).

Nombre:

Firma:

Fecha:

\section{Capacidad para cuidar de los niños}

Cuidado de los niños

Niños bajo de 1 año

Niños 1 año hasta 6 años

Niños 7 años hasta 13 años

Cuidado de los niños con necesidades educativas especiales

Cuidado de otros niños (no tuyos) para la noche

Cuidado para niños infermos

Has estado tenido una relacion especial con un niño que no es miembro de tu familia Otro (especifica por favor):

\section{Transportacion}

Manejar un coche

Manejar un bus

Manejar un camion comercial

Manejar un tractor

Marcha atras un trailer

Mudanzar los muebles 
Otro (especifica por favor):

\section{Habilidades mecánicas y eléctricas}

Reparación de electrodomésticos pequeños (por ejemplo: televisor)

Reparación de electrodomésticos mas grandes (por ejemplo: refrigerador)

Reparación de motores pequeños

Reparación de vehículos con motores

Marcha atras un trailer

Otras habilidades mecánicas (especifica por favor):

Habilidades eléctricas (especifica por favor):

\section{La Seguridad}

Habilidades de bombero

Habilidades de Primeros auxilios

Otro (especifica por favor):

\section{Atención Sanitaria y Bienestar}

Hacerle los recados a alguien, hacer las compras o acompañar alguien a algo lugar que necesite ir.

Escuchar o apoyar a alguien que necesite hablar sobre su problemas

Ayudar una persona o familia que tiene problemas medicales

Proporcianar respiro o ser interno cuidar de alguien para mas que 24 horas

Ayudar para una persona o familia con delincuencia juvenil, libertad condicional, cárcel o problemas legales

Visitar o llamar a alguien que esta confín en casa o que esta solitario

Dar comida, ropa, dinero, o muebles a una familia que este necesitada

Cuidarles los ancianos

Cuidarles gente con enfermedad mental

Cuidarles los infermos

Cuidarle gente con discapacidad fisicas o intelectuales

Otro (especifica por favor):

\section{Horticultura y agricultura}

Crear alimentacion para la casa

Crear alimentacion para vender

Usar systemas orgánicos en mi jardin

Hacer la sembra

Hacer la cosecha

Crear papas

Crear maiz

Cuidar a la tiera

Manejar el riego u otro systema de agua

Otros habilidades horticulturas (especifica por favor):

Cuidar pollos

Cuidar chanchos

Cuidar ovejas

Cuidar cabras

Cuidar vacas

Cuidar buros

Otros habilidades agriculturas (especifica por favor): 


\section{Educacion y actividades jóvenes}

Organización de juegos/actividades para niños o adolescentes

Compromiso con equipos de deportes para niños o adolescentes

Leer o narrar cuentos a niños o adolescentes

Escuchar a un niño leyendo en voz alta

Ayudar en una aula

Ayudar la escuala en alguna manera (por exemplo cocinar almuezos, arreglar edificios o otras cosas, limpiar algo) (especifica por favor):

Compartir habilidades con un grupo o individual (especifica por favor):

Otro (especifica por favor):

\section{Habilidades de organización}

Dirigir actividades recreacionales (especifica por favor):

Organización de una fiesta o evento especial

Contactar con una lista de gente para invitarles a participar en algo

Otra habilidad de organización (especifica por favor):

\section{Conocimientos de informática}

Usar una computadora. Por favor especifica con cuales programos estas lo mas familiar:

Procesor de textos

Introducir datos dentro una computadora

Programación de computadores

Conocimientos de internet

Otra habilidades de computadores (especifica por favor):

\section{Comida/hostelería/hospitalidad}

Hornear tortas, pan etc

Habilidades de mesero

Decoracion de tortas

Preparacion de comida para menos que 10 personas

Lavar los platos para mas que 10 personas

Planificacion del menú para mas que 10 personas

Poner/recoger las mesas para mas que 10 personas

Preparacion de comidas para mas 10 personas

Servir comida para mas que 10 personas

Otro (especifica por favor):

\section{Administracion/habilidades de la oficina}

Escribir cartas

Archivacion o introduccion de datos en computadora

Hacer el presupuesto

Rellenar los impresos

Contestar telefonos y recordar mensajes

Escribir informes de negocios

Inventarios de existencias

Habilidades de contabilidad

Otro (especifica por favor):

\section{Artisania}

Dibujar o pintar

Ceramica y alfararia 
Artisania con cuero

Habilidades de costura

Tejer o crochet

Labor de retazo, cajera

Trabajar en telar

Otro (especifica por favor):

Habilidades de Construcción y mantenimiento

Pintar casas (por favor circular - interna / externa)

Tejar, embaldosar o poner azulejos en los paredas

Enlucir

Usar concreto

Usar ladrillos

Hacer trabajo de plomeria

Hacer aislamiento

Revestimiento para suelos

Construccion de casas

Conosimientos ebanistas

Otros abilidades de construccion o mantenamiento (especifica por favor):

Limpiar la casa y otras tareas domesticos

Limpiar canalón

Limpiar las ventanas

Limpiar alfombra

Tareas de casa en general

Reordenar muebles o equipo

Arreglar grifos con gotea

Cortar leña

Decoración interior

Lavar coches/caros

Otros (especifica por favor):

Musica, teatro, pelicula

Direccion/produccion/guardarropía de teatro

Interpretacion

Bailar

Cantar

Tocar instrumento

Ensenar un instrumento

Otros (especifica por favor):

\author{
Alfabetización e idioma \\ Escribir \\ Leer \\ Familiaridad con mas que un idioma \\ Habilidad hablar otro idioma \\ Habilidad leer otro idioma \\ Habilidad escribir otra idioma \\ Habilidad ser traductor \\ Otros (especifica por favor):
}




\section{Cuidar las mascotas/cría de animales}

Cría de animales

Ordeño las vacas o cabras

Esquilar las ovejas u otros animales

Almohazar las mascotas

Hacer ejercicio de las mascotas

Hacer el entranamiento de las mascotas

Hacer quiso

Habilidades de carnicero

Desollar y curtir el cuero

Otros (especifica por favor):

\section{Otro}

Habilidades de peluquero

Otros (especifica por favor):

Tienes otras habilidades o aficiones has mencionado?

Tienes algunas habilidades que quieres mencionar?

Hay algunas abilidades que quisieras aprender?

Hay algo sobre que te lo sientas apasionado? El medio ambiente, coches, herencia cultural, bienestar de animales etc

Alguna vez has manejado un negocio pequeño o has pensado de empezar uno? Por favor dime los detalles.

Alguna vez has participado en o has pensado participar en alternativas formas de negocios? (como cooperativos, grupos de truque, systemas de credito comunal)? Por favor dime los detailes

Alguna vez has sido voluntario/a en una organización basada en la comunidad? (Como vigilancia vecinal, grupos de deportes, organizaciones benéfico(a), de caridad, grupos de la iglesia etc). Por favor dime los detailes.

Alguna vez has contribuido a tu comunidad o bario en una manera informal (como limpiar la calle, arreglar algo en la escuela)? Por favor dime los detailes.

Hay algunas proyectos de la comundad en cuales te gustaria participar?

Tienes algunas ideas para proyetos basados en tu comundad? Por favor dime los detailes.

Tus ideas son inestimable. Por favor promocionar tus comentarios:

Muchos gracias para ayudarme completar tu retrato de regalos. Me gustaria ponerte al dia con el proyecto, especificamente en manera de invitarte a una taller comunal donde puedes compartir tus ideas con otra gente.

Completaria esa seccion si querias estar en contacto contigo. (Este informacion solo va estar usado para $\mathrm{xxxxxx)}$

Nombre:

Direccion:

Telefono: 
Appendix Eight: List of community members involved in the research

\begin{tabular}{|l|l|l|l|l|}
\hline \multicolumn{5}{|c|}{ San Miguel } \\
\hline Pseudonyms & Occupation & Age range & $\begin{array}{l}\text { Semi-structured } \\
\text { interview }\end{array}$ & $\begin{array}{l}\text { Informal } \\
\text { conversation/s }\end{array}$ \\
\hline Alejandra & & $60-70$ & & Yes \\
\hline Juan & & $60-70$ & $20 / 4 / 2010$ & Yes \\
\hline Luisa & Campesina & $20-30$ & $20 / 4 / 2010$ & Yes \\
\hline Guadalupe & Campesina & $50-60$ & $17 / 4 / 2010$ & Yes \\
\hline Sara & Campesina & $20-30$ & $21 / 4 / 2010$ & Yes \\
\hline Lucia & Doctor & $30-40$ & $17 / 4 / 2010$ & Yes \\
\hline Eduardo & Teacher & $30-40$ & $22 / 4 / 2010$ & Yes \\
\hline Sofia & Teacher & $30-40$ & $22 / 4 / 2010$ & Yes \\
\hline
\end{tabular}

\begin{tabular}{|c|c|c|c|c|c|c|c|}
\hline \multicolumn{8}{|c|}{ Yachakay } \\
\hline $\begin{array}{l}\text { Name and } \\
\text { Gender }\end{array}$ & Occupation & Age & $\begin{array}{l}\text { Portrait } \\
\text { of Gifts }\end{array}$ & $\begin{array}{l}\text { Community } \\
\text { Mapping }\end{array}$ & Brainstorming & $\begin{array}{l}\text { Semi- } \\
\text { structured } \\
\text { interview }\end{array}$ & $\begin{array}{l}\text { Informal } \\
\text { conversation }\end{array}$ \\
\hline Delia (w) & $\begin{array}{l}\text { Language } \\
\text { teacher }\end{array}$ & $20-30$ & Yes & Yes & Yes & $16 / 5 / 2010$ & Yes \\
\hline Alberto (m) & Carpenter & $20-30$ & Yes & Yes & Yes & $16 / 5 / 2010$ & Yes \\
\hline \multicolumn{8}{|l|}{ Pseudonym } \\
\hline Eva (w) & $\begin{array}{l}\text { Domestic } \\
\text { employee }\end{array}$ & $20-30$ & Yes & Yes & Yes & $27 / 6 / 2010$ & Yes \\
\hline Alegría (w) & Housewife & $50-60$ & Yes & Yes & Yes & $27 / 6 / 2010$ & Yes \\
\hline Teresa (w) & Housewife & $40-50$ & Yes & Yes & Yes & $27 / 6 / 2010$ & Yes \\
\hline Manuela (w) & Housewife & $20-30$ & Yes & Yes & Yes & $20 / 6 / 2010$ & Yes \\
\hline Andrea (w) & Housewife & $50-60$ & Yes & Yes & Yes & $20 / 6 / 2010$ & Yes \\
\hline Adriano (m) & & $50-60$ & & Yes & Yes & & \\
\hline Malvina (w) & Seamstress & $20-30$ & Yes & & & & Yes \\
\hline $\begin{array}{l}\text { Valentina } \\
(\mathrm{w})^{*}\end{array}$ & Student & $10-20$ & Yes & & & & \\
\hline Valentina (w) & Housewife & $40-50$ & Yes & & & & \\
\hline Mafalda (w) & Housewife & $50-60$ & Yes & Yes & Yes & & Yes \\
\hline Elena $(w)$ & Housewife & $50-60$ & Yes & & & & Yes \\
\hline Evita (w) & $\begin{array}{l}\text { Domestic } \\
\text { employee }\end{array}$ & $20-30$ & Yes & & & & Yes \\
\hline Carla (w) & Housewife & $30-40$ & Yes & & & & \\
\hline Susana (w) & Housewife & $40-50$ & Yes & & & & Yes \\
\hline
\end{tabular}

*Valentina participated in the portrait of gifts with the permission of her mother, who was present. 


\section{Appendix Nine: Community permission (English)}

Please note: these permission forms are copies which use the pseudonym Yachakay to maintain confidentiality.

\section{Yachakay}

Sucre, $21^{\text {st }}$ June 2010

To the respected leaders of the Community of Yachakay:

\section{Ref.- Request for formal permission for Renee Rushton to do research with people in the community of Yachakay, Sucre, Bolivia.}

I am a Masters student in Development Studies at Victoria University of Wellington. As part of this degree I am undertaking a research project leading to a thesis. The project I am undertaking will examine community economies and activities within the community of Yachakay, Bolivia. I would like request formal permission to do this research with the community of Yachakay, Sucre, Bolivia.

With the permission and informed consent of the community and its residents, I would like to conduct interviews, questionnaires and two group activities, including a community mapping exercise and a community brainstorming exercise. Participation in all activities is completely voluntary and all participants can withdraw from the project without question at any time before the data is analysed, which will be Monday June $28^{\text {th }} 2010$.

The responses will form the basis of my research project and will be used as evidence for my thesis. My thesis will be written in a confidential way, it will not be possible for anybody to be identified personally. I will change your names and take out any other identifying information from any report I publish. All material collected from this interview or focus group will be locked away so as to ensure your confidentiality. No other person besides me, my supervisor, Andrew McGregor, and my translators Delia Beltran and Alberto Enrriquez will see or hear the research data. The thesis will be submitted for marking to the School of Geography, Environment and Earth Sciences and deposited in the University Library. It is intended that one or more articles will be submitted for publication in scholarly journals. There is a possibility that information may be disseminated at academic or professional conferences. Diaries and questionnaires will be destroyed two years after the end of the project.

I am very grateful for the information provided so far and I would like to contribute to the community in some way. For this reason I am committed to sending a copy of the results of my investigation and I would like to make a small donation to help the community.

I hope that you will accept my request for formal permission,

Yours sincerely,

Renee Rushton

We, the leaders of the community of Yachakay, Sucre, Bolivia, agree to Renee Rushton conducting this research in our community. 


\section{Appendix Ten: Community permission (Spanish)}

Sucre, 21 de Junio de 2010

Senores:

Barrio Yachakay

Presente.-

\section{Ref.- Solicitud de permiso formal para Renee Rushton para hacer una investigación con la gente de la comunidad de Yachakay, Sucre, Bolivia.}

Soy estudiante de maestria en estudios del desarrollo en la Universidad de Victoria de Wellington. Como parte de este curso estoy emprendiendo un proyecto de investigación que lleva a una tesis. La investigación que estoy haciendo está examinando las economías y actividades dentro de la comunidad de Yachakay, Sucre, Bolivia. Me gustaria solicitar permiso formal para hacer esta investigación dentro de la comunidad de Yachakay, Sucre, Bolivia.

Con el permiso y consentimiento brindado de la comunidad y sus habitantes, me gustaria hacer entrevistas, cuestionarios, y dos actividades grupales, incluyendo una actividad de realizar un mapa de la comunidad y una actividad de lluvia de ideas. La participación en todas las actividades es completamente voluntaria y todos los participantes pueden renunciar en cualquier momento sin preguntar, antes de que los datos sean analizados, lo cual sera el lunes 28 de Junio.

Las respuestas formarán la base de mi proyecto de investigación y serán utilizadas como evidencia para mi tesis. La cual será escrita de manera confidencial, no será posible que sean identificados personalmente. Cambiaré sus nombres y sacaré cualquier otra información de identificación de cualquier informe que publique. Todo el material recogido de esta entrevista o grupo principal se mantendra en secreto para asegurar su anonimato. Ninguna otra persona aparte de mí, mi supervisor, Andrew McGregor y mis traductores Delia Beltran y Alberto Enrriquez verá u oirá las datos de la investigación. La tesis será sometida a consideracion de la escuela de geografía, del medio ambiente y de las geologías y depositada en la biblioteca de la universidad. Se piensa que uno o más artículos serán publicados en revistas academicas. Hay una posibilidad de que la información se puede diseminar en las conferencias académicas o profesionales. Los diarios y los cuestionarios serán destruidos dos años después del final del proyecto.

Estoy muy agredecida de la información brindada y de alguna forma me gustaria contribuir a su comunidad. Por ello me comprometo a enviar los resultados de mi investigación y hacer una pequeña donación para ayudar a la comunidad.

Esperando que mi solicitud sea aceptada, me despido muy cordialmente.

Attentamente:

\section{Renee Rushton}

Nosotros, los dirigentes de la comunidad de Yachakay, Sucre, Bolivia, estamos de acuerdo con Renee Rushton haciendo esta investigación en nuestra comunidad.

Presidente

Secretario de Actas

Secretaria de Hacienda 